\title{
A revision of the Neotropical caddisfly genus Rhyacopsyche, with the description of 13 new species (Trichoptera: Hydroptilidae)
}

\author{
ANNE M. WASMUND ${ }^{1} \&$ RALPH W. HOLZENTHAL ${ }^{2}$ \\ Department of Entomology, University of Minnesota, 1980 Folwell Ave., Room 219, St. Paul, Minnesota, 55108, U.S.A. \\ E-mail: ${ }^{1}$ chri0819@umn.edu; ${ }^{2}$ holze001@umn.edu
}

\section{Table of contents}

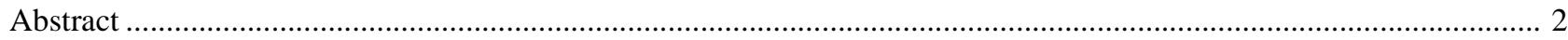

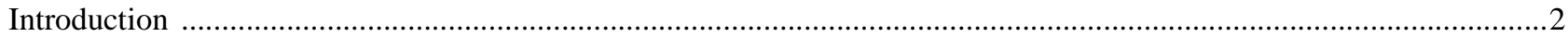

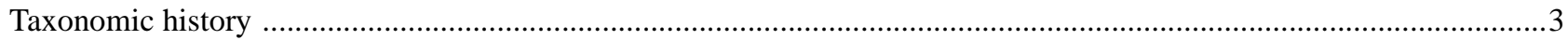

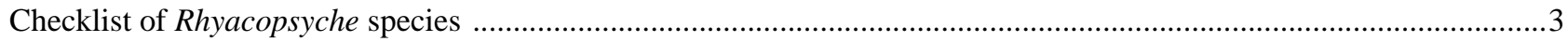

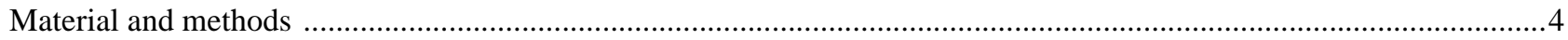

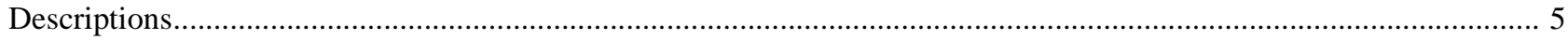

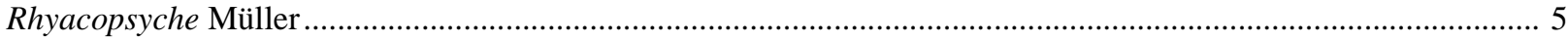

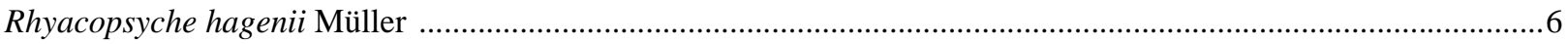

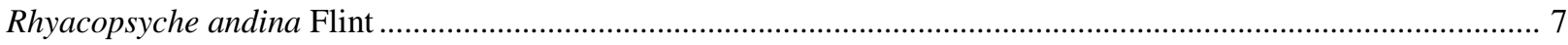

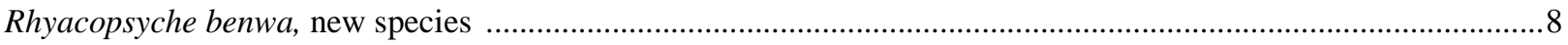

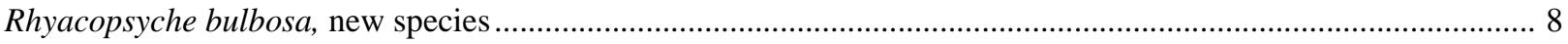

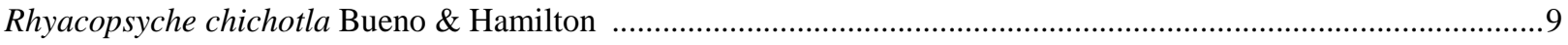

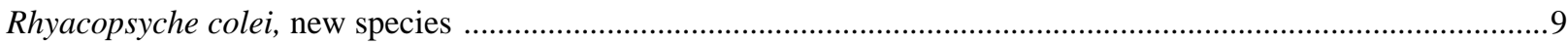

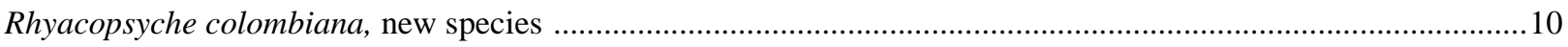

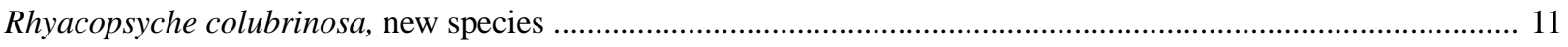

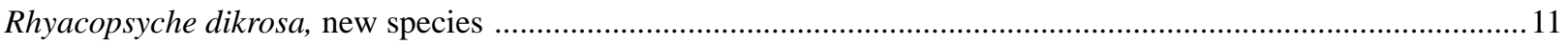

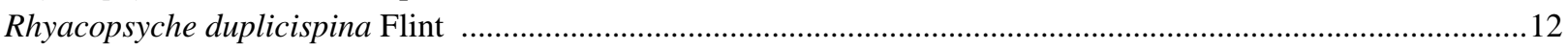

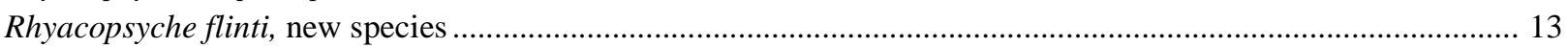

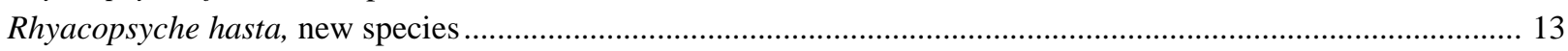

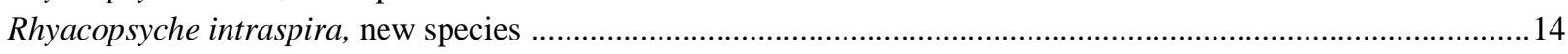

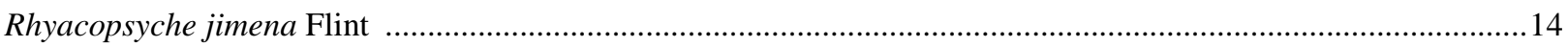

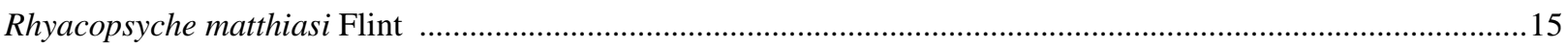

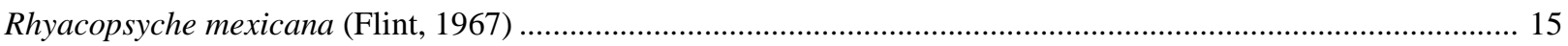

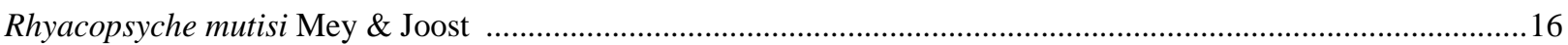

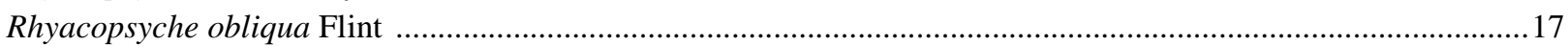

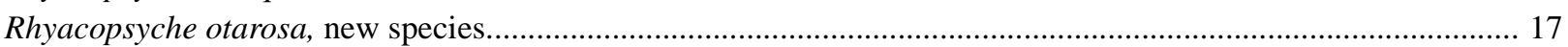

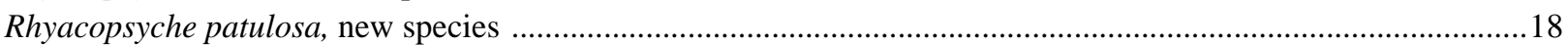

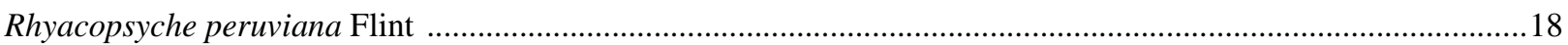

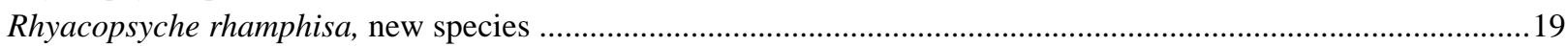

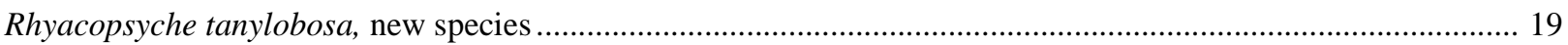

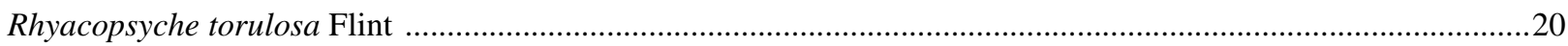

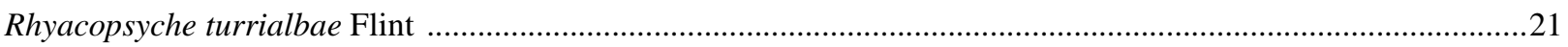

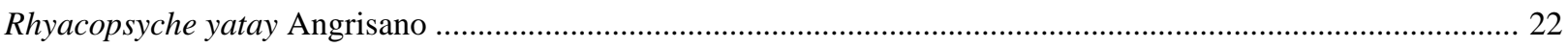

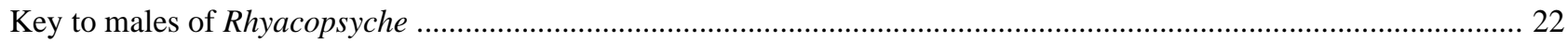

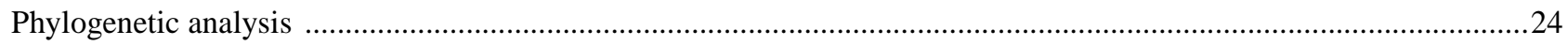

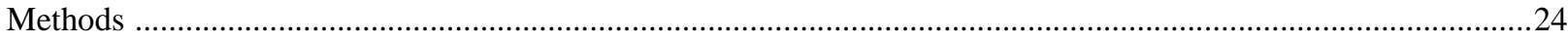

Character analysis 


\begin{abstract}
The Neotropical genus Rhyacopsyche Müller, 1879, was last reviewed in 1971 when 5 species were known. Since that time, the genus has gradually grown to 13 species: $R$. andina Flint, 1991 (Colombia, Peru, Venezuela), $R$. chichotla Bueno \& Hamilton, 1986 (Mexico), R. duplicispina Flint, 1996 (Tobago), R. hagenii Müller, 1879b (Argentina, Brazil, Uruguay), R. jimena Flint, 1991 (Colombia), R. matthiasi Flint, 1991 (Colombia), R. mexicana (Flint, 1967) (Costa Rica, Guatemala, Mexico, Nicaragua), R. mutisi Mey \& Joost, 1990 (Colombia), R. obliqua Flint, 1971 (Mexico), R. peruviana Flint, 1975 (Ecuador, Peru), R. torulosa Flint, 1971 (Costa Rica, Guatemala), R. turrialbae Flint, 1971 (Costa Rica), and R. yatay Angrisano, 1989 (Argentina). Thirteen new species are described and illustrated: R. benwa (Bolivia, Ecuador, Peru), R. bulbosa (Brazil), R. colei (Venezuela), R. colombiana (Colombia), $R$. colubrinosa (Ecuador, Peru), $R$. dikrosa (Brazil), R. flinti (Venezuela), R. hasta (Peru), R. intraspira (Peru), R. otarosa (Venezuela), R. patulosa (Brazil), R. rhamphisa (Colombia, Costa Rica), and R. tanylobosa. (Ecuador, Peru, Venezuela). The distribution of Rhyacopsyche is widened to include Bolivia and Nicaragua. Detailed illustrations are presented for all species as well as diagnoses, descriptions, and a taxonomic key.

A species level phylogenetic analysis using PAUP* 4.0b 10 was performed. A heuristic search was conducted based on 20 morphological characters of the male genitalia, with species of Ochrotrichia and Metrichia used as outgroups. A strict consensus of 23 equally parsimonious trees is presented. The analysis revealed 3 characters supporting the monophyly of Rhyacopsyche. The monophyly of 1 of the 2 previously established species groups, the turrialbae group, is supported.
\end{abstract}

Key words: Trichoptera, Hydroptilidae, Ochrotrichiini, Rhyacopsyche, new species, Neotropical, taxonomy, revision, key, phylogeny

\title{
Introduction
}

The caddisflies known as the Hydroptilidae comprise a cosmopolitan family of 68 genera and at least 1700 described species (Morse 2006). Virtually all hydroptilid larvae exhibit a type of hypermetamorphosis in that the 1st-4th larval instars are free-living and morphologically distinct from the case-constructing 5th instar (Marshall 1979). The family consists of 2 subfamilies, the more ancestral Ptilocolepinae and the more derived Hydroptilinae, the latter containing the vast majority of species. The Hydroptilinae is further divided into 6 tribes; the genus Rhyacopsyche is placed in the tribe Ochrotrichiini along with Metrichia, Ochrotrichia (Marshall 1979), and Paratrichia (Angrisano 2002). Angrisano (1995) created the subgenus Paratrichia to include Ochrotrichia (P.) cebollati. After Ochrotrichia and Metrichia were raised to generic level (Wiggins 1996, Flint \& Bueno 1998) Angrisano (2002) also raised Paratrichia to generic status. These 4 genera possess a mesoscutellum with a transverse suture, a metascutellum that is pentagonal or convexly subtriangular, 3 ocelli, and male genitalia with an inferior appendage that is generally well developed and elongate (Marshall 1979, Angrisano 1995). Harris \& Armitage (1997) also include Nothotrichia, Maydenoptila, and Caledonotrichia in Ochrotrichiini but provided no data to support this classification.

Rhyacopsyche larvae construct a purse case often partially covered with sand grains, with or without a long silken attachment stalk (Flint 1991). The pupal cases are rigidly attached to substrate by a short stalk or held to the substrate along the ventral border (Angrisano 2002). A few species, R. hagenii, R. mutisi and $R$. mexicana construct a long thread to anchor their case to the substrate; however, $R$. yatay lacks this attachment stalk and also differs in possessing 2 dorsal openings (Angrisano 2002). A few cases with long attachment stalks from Brazil examined during this study revealed larvae of an undetermined genus most likely belonging 
to the tribe Leucotrichiini. Whether these larvae actually constructed the case, or simply inhabited abandoned Rhyacopsyche cases is not known.

Rhyacopsyche larvae typically inhabit cool, fast-flowing streams. The cases have been found in the splash zones of rivers (Flint 1971) and floating in the current (Mey \& Joost 1990) attached to substrate by the stalk. The fusiform shape allows water to pass easily over the case. Cases may occur in a small cluster attached to stones, other larval cases or other stalks (Mey \& Joost 1990). Larvae use their scraping mandibles and platelike setae of the foretarsi to feed on the periphyton; $R$. mutisi using an attachment thread as a security cord (Mey \& Joost 1990). The adults are very small (forewing length $2.0-4.9 \mathrm{~mm}$ ), quite hairy in general appearance, and have narrow, acuminate wings with long costal fringes and greatly reduced wing venation. They have a simple head with unmodified antennae (the males of some hydroptilids have secondary sexual modifications on the head and antennae), 3 ocelli, and a tibial spur formula of 1-3-4.

\section{Taxonomic history}

Throughout several papers, Fritz Müller described the species Rhyacopsyche hagenii based only on the unique larval cases (Müller 1879a, b, 1880a, b). In the initial 2 publications, he described a tubular case with a long, thin attachment stalk that the larvae use to anchor themselves to the substrate. The figures of the larval and pupal cases were published in 2 subsequent papers (Müller1880a, b). Twenty-five years later, August Thienemann (1905) obtained some of Müller's material containing larvae, pupae, and pharate adults and described the larval and adult morphology, including the male genitalia. In 1921, following the death of Fritz Müller, Alfred Möller, his nephew, published a figure of the larva drawn years earlier by Müller (Möller 1921). The female was not described until 1971 when Flint (1971) published a review of Rhyacopsyche.

The genus remained monobasic until Flint's review, where he determined Metrichia mexicana Flint to be congeneric with Rhyacopsyche hagenii. In addition, he described 3 new species. Additional species have been described subsequently by Bueno-Soria \& Hamilton (1986), Angrisano (1989), and Mey \& Joost (1990), with Flint $(1975,1991,1996 a, b)$ describing the majority of the other species. Here we provide an updated checklist including the new species.

\section{Checklist of Rhyacopsyche species}

Rhyacopsyche andina Flint, 1991

Rhyacopsyche benwa, new species

Rhyacopsyche bulbosa, new species

Rhyacopsyche chichotla Bueno \& Hamilton, 1986

Rhyacopsyche colei, new species

Rhyacopsyche colombiana, new species

Rhyacopsyche colubrinosa, new species

Rhyacopsyche dikrosa, new species

Rhyacopsyche duplicispina Flint, 1996

Rhyacopsyche flinti, new species

Rhyacopsyche hagenii Müller, 1879

Rhyacopsyche hasta, new species

Rhyacopsyche intraspira, new species

Rhyacopsyche jimena Flint, 1991

Rhyacopsyche matthiasi Flint, 1991 
Rhyacopsyche mexicana (Flint, 1967)

Rhyacopsyche mutisi Mey \& Joost, 1990

Rhyacopsyche obliqua Flint, 1971

Rhyacopsyche otarosa, new species

Rhyacopsyche patulosa, new species

Rhyacopsyche peruviana Flint, 1975

Rhyacopsyche rhamphisa, new species

Rhyacopsyche tanylobosa, new species

Rhyacopsyche torulosa Flint, 1971

Rhyacopsyche turrialbae Flint, 1971

Rhyacopsyche yatay Angrisano, 1989

\section{Material and methods}

Material examined

Specimens housed at the University of Minnesota Insect Collection were collected on several trips to localities in Central and South America over the last 15 years. In addition, approximately half of the 585 specimens examined were on loan from the National Museum of Natural History. Material is deposited, as indicated, in the following institutions:

IZAM Instituto de Zoologia, Agricola, Maracay, Venezuela

MHNJP Museo de Historia Natural, "Javier Prado", Lima, Peru

MZUSP Museu de Zoologia, Universidade de São Paulo, São Paulo, Brazil

NMNH National Museum of Natural History, Smithsonian Institution, Washington, DC, USA

UMSP University of Minnesota Insect Collection, Saint Paul, MN, USA

ZMHU Museum für Naturkunde der Humboldt-Universität, Berlin, Germany

Specimen preparation

The specimens in the University of Minnesota Insect Collection were databased using Biota®: The Biodiversity Database Manager (v. 2.0, Sinauer Associates, Inc.) (Colwell 1996). A unique alphanumeric barcode was attached to each pin, or placed in each vial of specimens stored in alcohol. Each barcode label begins with the prefix "UMSP," not to imply ownership by the University of Minnesota Insect Collection, but simply to indicate that specimen is databased at that location. A detailed list of all material examined is available from http://www.entomology.umn.edu/museum/databases/BIOTAdatabase.html or is available upon request from the junior author.

To clearly expose sclerotized structures of the male and female genitalia, the abdomens were removed with an iridectomy scissors and immediately placed in a Pyrex rimless $10 \times 75 \mathrm{~mm}$ culture tube of $85 \%$ lactic acid. The tube, filled to about $1 / 3$ the volume, was placed in a Fisher Scientific dry bath incubator set at lowmedium heat $\left(110-125^{\circ} \mathrm{C}\right)$ for approximately 30 minutes. To halt the clearing process, the abdomen was rinsed in a small dish of distilled water and then transferred to $80 \%$ alcohol. Any tissue remaining in the abdominal cavity was removed with a hooked probe. The specimen was stored in a clear glass genitalia vial filled to about $1 / 4$ the volume with glycerin, or if stored in alcohol, returned to the original vial and stopped with cotton.

To view wing venation, the right wings were removed and placed in a small dish of water. Using a dissecting microscope and a pair of fine artist's brushes, the hairs were gently removed from the wings. The denuded wings were transferred to a dish of clean water prior to mounting. The wings were placed on a round glass coverslip along with a few drops of distilled water. After maneuvering the wings into place, a second cover- 
slip was laid over the first. Next, the coverslips were surrounded with tissue paper to absorb the water and weighted down with several coins before allowing the wings to dry. After several hours, the slides were bonded together with 3 drops of the adhesive Gelva along the margins. Using Gelva once again, the edge of the wing mount was affixed between a small, folded, thick piece of paper. Finally, the specimen pin was inserted through the paper with the wing mount displayed on the right side of the body.

\section{Illustrations}

Pencil sketches were created using a standard drawing tube, or camera lucida, attached to an Olympus BH-2 compound microscope. Specimens were drawn at 200-400 X magnification depending on their size. The pencil sketches were scanned into Adobe Photoshop ${ }^{\circledR}$ (v. 6.0, Adobe Systems Inc.) and later placed as a template into Adobe Illustrator ${ }^{\circledR}$ CS2 (v. 12.0, Adobe Systems Inc.) where a digital, vector based illustration was created.

Lettering of the figures has been standardized in views of the male and female genitalia as follows: Alateral view, abdominal segments IX, and X, and associated appendages; $\mathrm{B}$-dorsal view, segment IX and appendages (also segment $\mathrm{X}$ if not retracted entirely within IX); $\mathrm{C}$ - ventral view, segments IX and X; Ddorsal view of the phallus; E-details of modified setae as needed. For female genitalia: A—ventral view of abdominal segments VII-X; B-dorsal view of segments VII-X; C—lateral view of segments VII-X.

Species descriptions and key

After illustrations were completed, the species descriptions were written using the program DELTA (DEscriptive Language for TAxonomy) (Dallwitz et al. 1999 onwards). Using the DELTA Editor v. 1.04, a character database was created in which character states for each species were scored. The resulting matrix was translated into consistent, natural language descriptions using 2 of DELTA's directives: "layout for natural language descriptions" and "translate into natural language - RTF." Using the directive "layout for natural language descriptions," options for punctuation, linking characters into sentences, and defining paragraphs were edited. The next directive, "translate into natural language - RTF" was run and the file of descriptions was saved as a Microsoft Word RTF (Rich Text Format) document.

A copy of the DELTA file was created and several characters and/or character states were modified to be useful in the construction of a dichotomous key. Utilizing the directive "translate into KEY format," DELTA's "character reliabilities" were manipulated to achieve a fully dichotomous key. Under the "KEY" tab, the directive "confirmatory characters - RTF" was run; the resulting key was saved as an RTF file. The character reliabilities were adjusted several times before producing a key with a suitable layout.

Measurements (in $\mathrm{mm}$ ) of wing lengths for both sexes are given as a range followed by the mean if more than 2 specimens were measured. Females were not described or illustrated (with the exception of the type species, $R$. hagenii) because positive associations could not be established, nor could species level characters be identified.

Morphological terminology

The terminology used generally follows that of Marshall (1979), with additional terminology for features of the phallus used by Flint (1971). The wing veins are named according to the Comstock-Needham system (1898, 1899).

\section{Descriptions}

\section{Rhyacopsyche Müller}

Rhyacopsyche Müller, 1879a:40 [nomen nudum]; 1879b:143 [Type species: Rhyacopsyche hagenii Müller 1879b, monobasic]; 1880a:121; 1880b:72. —Flint,1971:516 [definition, review]. 
Generic description. Adult. Forewing length $2.0-4.9 \mathrm{~mm}$; wings narrow, acuminate, mottled with light, medium, and/or dark brown hairs; forewing veins $\mathrm{R}_{1}-\mathrm{R}_{3}, \mathrm{M}_{1}$ and $\mathrm{M}_{2}$ thickened at apex, not reaching wing margin (Fig. 3); hind wing with long fringe of hairs along ventral margin. Unmodified head and antennae; 3 ocelli. Mesoscutellum with transverse suture; metascutellum usually pentagonal in shape (Fig. 2). Tibial spurs 1-3-4.

Male genitalia. Segment IX produced into dorsolateral lobes, often bearing 1 or more dark, peglike setae (Fig. 4A). Tergum $\mathrm{X}$ weakly developed and often retracted partially (Fig. 9A) or completely within segment IX (Fig. 4A). Inferior appendage large and distinct, elongate (Fig. 7A) or tall (Fig. 12A), usually bearing 1 or more large modified setae. Intermediate appendage present, often reduced (Figs. 9A, 9C). Phallus with tubular, frequently inflated basal half, apical half with central tubule and lateral process; often surrounded with a thin membranous sheath covered with spicules (Fig. 4D).

Female genitalia. Simple oviscapt. Tergum VIII bearing a setate lobe (or lobes) from posterior margin (Fig. 5B). Segments VII, VIII and IX with long internal rod-like apodemes (Fig. 5A).

Larva. All 3 thoracic nota divided mesally (Fig. 1C); legs stout and similar in structure, apex of tibia expanded bearing several enlarged setae; tarsus broad with 1 or 2 enlarged, platelike setae; claw basally inflated (Fig. 1D). Abdominal segments IV-VII slightly swollen (Fig. 1A); tergites absent; anal prolegs compressed to sides of segment $X$.

Larval case. Bivalve case elongate, tubular and fusiform; constructed of silk only or covered in sand grains; anterior end often with long, silken stalk used in attachment to the substrate (Fig. 1E). Pupal case with oval anterior and posterior openings sealed with silk; when stalk is present, it is shortened and thickened for more rigid attachment to the substrate.

\section{Rhyacopsyche hagenii Müller}

Fig. 4, 5

Rhyacopsyche hagenii Müller, 1879b:143 [Type locality: Brazil; type depository unknown; larval and pupal cases]. Thienemann, 1905:287 [larva, male]. - Möller, 1921:525 [larva]. Ulmer, 1957:172, 187 [literature, key to larval genus]. - Angrisano, 1995:509 [distribution].

This species resembles $R$. dikrosa, new species, in that they share bifid dorsolateral lobes of segment IX and an inferior appendage with 1 or more strong apical setae. The features of the phallus are also similar, the central tubule with a hooked apex and a membranous sheath densely covered with spicules. It shares the presence of plumose setae with $R$. colei, new species. The large, truncate, midlateral lobe of segment IX is unique to $R$. hagenii.

Adult (male: $\mathrm{n}=62$, female: $\mathrm{n}=39$ ). Forewing length 2.6-3.7, $3.1 \mathrm{~mm}$ (male), 2.7-3.7, $3.3 \mathrm{~mm}$ (female). Color of head dark brown, antennae cream, legs medium brown, wings mottled medium and dark brown. Sternum VII with apicomesal point.

Male genitalia. Abdominal segment IX heavily setose, bearing several plumose setae, anterior margin slightly rounded; sternum IX, in lateral view, with posterior margin slightly undulate; posterior margin produced into large truncate lobe, apex with several peglike seta; dorsolateral lobe of segment IX elongate, in dorsal view narrowed, deeply divided, widely separated, with small medially directed lobe bearing several long peglike setae, apex bearing 2, 3, or 4 dark peglike setae. Tergum X completely retracted inside segment IX. Intermediate appendage large, undulate. Inferior appendage elongate, heavily setose, apex clavate, bearing large pointed seta. Phallus linear, thin membranous sheath surrounding virtually the entire phallus, covered with spicules; central tubule with large apical hook, apex of lateral process truncate. 
Female genitalia. Simple oviscapt. Tergum VIII bearing a setate lobe from posterior margin. Segments VII-IX with long internal rod-like apodemes.

Material examined. ARGENTINA: Misiones: Ao. Saura, 9 km No., L.N. Alem, 20.xi.1973, O S Flint, Jr. - 1 male, 1 female (NMNH); BRAZIL: Parana: Rio Mãe Catira, 10 km N Porto de Cima, 2521.821'S, 48 52.473'W, 200 m, 8-9.xii.1997, Holzenthal \& Huisman — 14 males, 14 females (UMSP); Rio Jacareí, ca 5 km S BR 277, 25³3'56”'S, 04842'10”W, 80 m, 9.xi.1997, Holzenthal \& Huisman - 1 male, 1 female (MZUSP); Curitiba, Morretes, 30.viii.2000, W. Mey -6 males, 2 females (NMNH); Rio de Janeiro: Rio Macacú (2 ${ }^{\text {nd }}$ order), on RJ 116, km 62, 22²3'12’N, 042³3'57’'W, 840 m, 17.iii.1996, Holzenthal, Rochetti, Oliveira - 2 males (UMSP); Parque Nacional da Serra dos Órgãos, Guapimirim, Rio Soberbo, 22²9'36”S, 042 59'47'W, 950 m, 28.ii.2002, Holzenthal, Blahnik, Paprocki, Prather - 4 males, 4 females (MZUSP); Parque Nacional do Itatiaia, Rio Campo Belo, 22 ${ }^{\circ} 7^{\prime}$ '02”S, 044³6'49”W, 1300 m, 7.iii.2002, Holzenthal, Blahnik, Paprocki, Prather - 9 males, 9 females (UMSP); Parque Nacional do Itatiaia, trib. to Rio Taquaral,

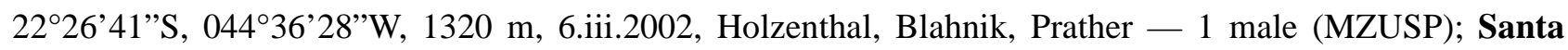
Catarina: Blumenau, Res. Spitzkopf, 4.xii.1975, Exc. Dept. Zool. U.S.P., - 1 male (MZUSP); Parque Ecológica Spitzkopf, Rio Caeté above $1^{\text {st }}$ falls, 2700'21'S, 04906'42”W, 170 m, 4.iii.1998, Holzenthal, Froelich, Paprocki - 18 males, 7 females (UMSP); Parque Ecológica Spitzkopf, confl. Rio Ouro \& Rio Caeté, $27^{\circ} 00.352$ 'S, 4906.693'W, 140 m, 3.iii.1998, Holzenthal, Froelich, Paprocki - 3 males, 1 female (MZUSP); Morro de Igreja, Urubici Cachoeira Veu da Noiva, 2804'36’S, 049³1'05”'W, 1300 m, 5.iii.1998, Holzenthal, Froelich, Paprocki - 1 male, 1 female (UMSP); São Paulo: Est. Biol. Paranapiacaba, \#37, 27.xi.1963, Froehlich — 4 males (MZUSP, NMNH); \#42, 27.i.1964, Froehlich — 4 males (MZUSP, NMNH).

Distribution. Argentina, Brazil, Uruguay.

\section{Rhyacopsyche andina Flint}

Fig. 6

Rhyacopsyche andina Flint, 1991:61 [Type locality: Colombia, Dpto. Antioquia, Quebrada la Agudelo, 2km E El Retiro; NMNH; male]; 1996b:397 [distribution].

Rhyacopysche andina is most similar to $R$. intraspria, new species, but can be diagnosed by the widely separated dorsolateral lobes and the membranous, somewhat serrated apex of the phallus.

Adult (male: $\mathrm{n}=10$, female: $\mathrm{n}=10$ ). Forewing length 4.0-4.9, $4.5 \mathrm{~mm}$ (male), 4.5 -5.2, $4.9 \mathrm{~mm}$ (female). Color of head medium brown, antennae cream, legs cream, wings mottled light and dark brown. Sternum VII with apicomesal point.

Male genitalia. Abdominal segment IX heavily setose, anterior margin deeply rounded; sternum IX, in lateral view, with posterior margin slightly rounded, with connecting membrane to inferior appendage; posterior margin nearly straight; dorsolateral lobe of segment IX elongate, in dorsal view rounded, deeply divided, widely separated, apex bearing several short, dark, peglike setae. Tergum X completely retracted inside segment IX, with rectangular sclerite. Intermediate appendage produced into small slender plate lying mesad of inferior appendage, in ventral view, plate lyriform. Inferior appendage elongate, heavily setose, dorsal margin enlarged at middle, apex bearing 2 peglike setae. Phallus linear, thin membranous sheath surrounding virtually the entire phallus, covered with spicules; central tubule with small apical hook; apex of lateral process membranous.

Material examined. COLOMBIA: Valle: Municipio de Buga, Rio Guadalajara, "La Piscina", 4 km SE La Habana, 352'29”'N, 76¹0'8”'W, 1620 m, 8.i.1998, Fdo. Muñoz-Quesada, et al. - 1 male, 2 females (UMSP); Municipio de Cali, Rio Pichindé, Peñas Blancas, 24 km SW. Cali, 325' 6”'N, 76³9' 4”'W, 2000 m, 18.xii.1997, Fdo. Muñoz-Quesada, et al. -8 males, 33 females (UMSP); Municipio El Cerrito, Rio Cerrito, 7.1 km E. Hacienda “El Paraiso”, 3³8’59”N, 769'10”W, 1950 m, 3.xii.1997, Fdo. Muñoz-Quesada, et al. — 
2 males, 7 females (UMSP). VENEZUELA: Lara: Parque Nacional Dinira, Quebrada Buenos Aires, 09³6'24”N, 07004'11'W, 1850 m, 18-19.vi.2001, Holzenthal, Blahnik, Paprocki \& Cressa — 98 males, 44 females (UMSP); Quebrada Las Minas, 09³6’16”N, 07004'10”'W, 1825 m, 20.vi.2001, Holzenthal, Blahnik, Paprocki \& Cressa - 22 males, 19 females (UMSP).

Distribution. Colombia, Peru, Venezuela.

\section{Rhyacopsyche benwa, new species}

Fig. 7

The dorsolateral lobes closely resemble those of $R$. hasta, new species, both bearing a group of long, light, ventrally directed setae among several peglike setae. The inferior appendage of $R$. benwa is unique in its rounded, bifid apex and the presence of a small pointed process along the ventral margin.

Adult (male: $\mathrm{n}=4$ ). Forewing length 2.9-3.1, 3.0 mm. Color of head dark brown, antennae cream, legs medium brown, wings mottled light and dark brown. Sternum VII with apicomesal point.

Male genitalia. Abdominal segment IX sparsely setose, anterior margin deeply rounded; sternum IX, in lateral view, with posterior margin hooklike; posterior margin nearly straight; dorsolateral lobe of segment IX elongate, in dorsal view slightly truncate, deeply divided, meeting dorsally, apex bearing several short, dark, peglike setae and group of long, light, ventrally directed spines. Tergum X partially retracted inside segment IX, articulating with intermediate appendage. Intermediate appendage produced into small slender plate lying mesad of inferior appendage, in ventral view, plate T-shaped. Inferior appendage elongate, heavily setose, apex bifid with ventral lobe shallowly bifid, apex bearing 2 peglike setae; ventral margin produced into small medial point. Phallus linear, thin membranous sheath surrounding apex; central tubule with small apical hook; apex of lateral process truncate.

Holotype male: PERU: Madre de Dios: Manu, Pakitza, 250 m, 18.ix.1988, Flint \& Adams (UMSP000115098) (MHNJP).

Paratypes: BOLIVIA: Dept. La Paz: ANMI Madidi, Chalalan Ecolodge, Raya Mayo river at Wabacuro trail, 14²6'33"'S, 06754'39'W, 351 m, 28.vii.2003, Robertson \& Blahnik - 1 male (UMSP); ECUADOR: Napo: Pano, 580 m, 12.ix.1990, Flint — 1 male (NMNH); Pastaza: Puyo, 11.v.1977, Spangler \& Givens — 1 male (NMNH).

Distribution. Bolivia, Ecuador, Peru.

Etymology. "Benwa" is the nickname of the senior author's husband, Ben Wasmund.

\section{Rhyacopsyche bulbosa, new species}

Fig. 8

This species is similar to $R$. dikrosa, new species, and $R$. hagenii in sharing bifid dorsolateral lobes. It can be distinguished by the 3 large apical setae of the inferior appendage and the absence of a lobe on the posterior margin of segment IX.

Adult (male: $\mathrm{n}=17$, female: $\mathrm{n}=8$ ). Forewing length 2.8-3.8, 3.1 mm (male), 3.4-3.8, 3.6 mm (female). Color of head dark brown, antennae cream, legs cream, wings mottled medium and dark brown. Sternum VII with apicomesal point.

Male genitalia. Abdominal segment IX heavily setose, anterior margin deeply rounded; sternum IX, in lateral view, with posterior margin produced into small rounded process; posterior margin produced into broad spatulate lobe; dorsolateral lobe of segment IX slightly produced, in dorsal view rounded, shallowly divided, nearly meeting dorsally, apex bearing 2 short, dark, peglike setae. Tergum X completely retracted inside segment IX. Intermediate appendage not evident. Inferior appendage elongate, heavily setose, apex clavate, bear- 
ing 3 long, light, pointed setae. Phallus linear, thin membranous sheath surrounding virtually the entire phallus, covered with spicules; central tubule with small apical hook; apex of lateral process lanceolate.

Holotype male: BRAZIL: Rio de Janeiro: Nova Friburgo, municipal watersupply, 950 m, 24.iv.1977, C M \& O S Flint (UMSP000115100) (MZUSP).

Paratypes: BRAZIL: Minas Gerais: Ibitipoca, sitio of Anestis, Papadopoulos, cachoeira, 2143'26”S, 04354'32”W, 1125 m, 4-5.v.1998, Holzenthal \& Paprocki - 1 male (MZUSP); Rio de Janeiro: same data as holotype - 4 females (NMNH); Parque Nacional Tijuca, Represa dos Ciganos, 7.iv.1977, C M \& O S Flint

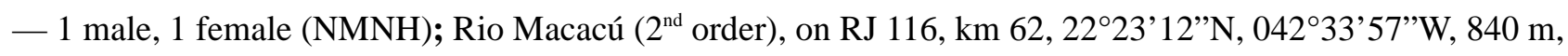
17.iii.1996, Holzenthal, Rochetti, Oliveria - 2 males (UMSP); Parque Nacional da Serra dos Órgãos, Rio Paquequer, 2227’00”S, 04259'54”W, 1000 m, 26.ii.2002, Holzenthal, Blahnik, Paprocki, Prather — 2 males, 3 females (UMSP); São Paulo: Parque Nacional da Serra da Bocaina Cachoeira dos Posses, 2246’26”S, 044³6'15”'W, 1250 m, 3.iii.2002, Holzenthal, Blahnik, Paprocki, Prather - 10 males (MZUSP).

Distribution. Brazil.

Etymology. Bulbosus, Latin for swollen, referring to the apical swelling of the inferior appendages.

\section{Rhyacopsyche chichotla Bueno \& Hamilton}

Fig. 9

Rhyacopsyche chichotla Bueno and Hamilton, 1986:303 [Type locality: Mexico, Oaxaca, 7km NE Huautla de Jimenez; NMNH; male].

Rhyacopsyche chichotla, $R$. colombiana, new species, $R$. mexicana, and $R$. torulosa are all similar in the form of both the dorsolateral lobe and the inferior appendage. Among these, $R$. chichotla is the only species lacking peglike setae on the inferior appendage. It can also be diagnosed by the pointed, hooklike apex of the inferior appendage.

Adult (male: $\mathrm{n}=1$ ). Forewing length $2.6 \mathrm{~mm}$. Color in alcohol, dark brown. Sternum VII without apicomesal point.

Male genitalia. Abdominal segment IX heavily setose, anterior margin slightly rounded; sternum IX, in lateral view, with posterior margin lanceolate; posterior margin nearly straight; dorsolateral lobe of segment IX elongate, in dorsal view narrowed, deeply divided, widely separated, apex bearing several short, dark, peglike setae. Tergum X partially retracted inside segment IX, articulating with intermediate appendage. Intermediate appendage produced into small slender plate lying mesad of inferior appendage, in ventral view, plate slightly cordate. Inferior appendage elongate, sparsely setose, dorsal margin enlarged at middle, narrowing to laterally directed point, bearing no peglike setae. Phallus linear, thin membranous sheath surrounding the middle of the phallus, covered with spicules; central tubule with truncate apex, apex of lateral process rounded.

Material examined. MEXICO: Oaxaca: near junctions of roads to Santa Maria Chichotla and Huautla de Jimenez, along road to Santa Maria Chichotla, 3800-4000 ft, 9.vii.1982, R W Holzenthal - 1 male (holotype, NMNH).

Distribution. Mexico.

\section{Rhyacopsyche colei, new species}

Fig. 10

This species is most similar to $R$. matthiasi, sharing a midlateral process along the posterior margin of segment IX and the presence of thick, plumose setae on the inferior appendage. However, the midlateral process 
is articulated in $R$. matthiasi. Additionally, $R$. colei lacks the prominent, flaring tergum $\mathrm{X}$ of $R$. matthiasi. The transverse bar connecting the lobes of segment IX, and the shorter, truncate inferior appendage distinguishes R. colei from all other species of Rhyacopsyche.

Adult (male: $\mathrm{n}=10$, female: $\mathrm{n}=10$ ). Forewing length 2.7-3.0, $2.9 \mathrm{~mm}$ (male), 2.9-3.2, $3.1 \mathrm{~mm}$ (female). Color of head dark brown, antennae light brown, legs medium brown, wings mottled medium and dark brown. Sternum VII with apicomesal point.

Male genitalia. Abdominal segment IX heavily setose, bearing several plumose setae, anterior margin slightly rounded; sternum IX, in lateral view, with posterior margin produced into small rounded process; posterior margin produced into small, truncate lobe; dorsolateral lobe of segment IX elongate, in dorsal view rounded, deeply divided, widely separated, with thin dorsal bar lying in the transverse plane, without peglike setae. Tergum X completely retracted inside segment IX. Intermediate appendage produced into small slender plate lying mesad of inferior appendage, in ventral view, plate broadly truncate, bearing light pointed setae. Inferior appendage elongate, in lateral view, apex truncate, ventral margin bearing several thick, plumose setae. Phallus base inflated, thin membranous sheath surrounding the middle of the phallus; central tubule with rounded apex; lateral process not evident.

Holotype male: VENEZUELA: Lara: Parque Nacional Dinira, Quebrada Buenos Aires, 09³6’24”N, 07004'11'W, 1850 m, 18-19.vi.2001, Holzenthal, Blahnik, Paprocki \& Cressa (UMSP00074070) (UMSP).

Paratypes: VENEZUELA: Lara: same data as holotype -6 males, 4 females (IZAM), 6 males, 4 females (NMNH), 12 males, 9 females (UMSP).

Distribution. Venezuela.

Etymology. Named in honor of Dr. Eric Cole, professor of biology at St. Olaf College, who deepened the senior author's appreciation for the natural world.

\section{Rhyacopsyche colombiana, new species}

Fig. 11

Rhyacopsyche colombiana most closely resembles $R$. peruviana in the form of the dorsolateral lobe and the absence of peglike setae. They are distinguished by the fusion of the dorsolateral lobes of $R$. peruviana, the lobes only closely meeting in $R$. colombiana. The phallus of this species is unique among Rhyacopsyche in that the apical half surrounded by a few long filaments.

Adult (male: $\mathrm{n}=2$ ). Forewing length 2.8-3.0, $2.9 \mathrm{~mm}$. Color of head dark brown, antennae light brown, legs medium brown, wings mottled light and dark brown. Sternum VII with apicomesal point.

Male genitalia. Abdominal segment IX sparsely setose, anterior margin angulate; sternum IX, in lateral view, with posterior margin produced into small rounded process; posterior margin nearly straight; dorsolateral lobe of segment IX elongate, in dorsal view truncate, deeply divided, meeting dorsally, apex bearing several thin setae. Tergum X partially retracted inside segment IX, articulating with intermediate appendage. Intermediate appendage produced into small slender plate lying mesad of inferior appendage, in ventral view, plate with 2 small posterior points. Inferior appendage broad and elongate, heavily setose, apex bifid with ventral lobe bearing large peglike seta. Phallus linear, thin membranous sheath surrounding the middle of the phallus; central tubule with two opposing apical hooks, apex of lateral process lanceolate.

Holotype male: COLOMBIA: Valle Del Cauca: Municipio El Cerrito, Rio Cerrito $7.1 \mathrm{~km} \mathrm{E.} \mathrm{Hacienda}$ “El Paraiso", 0338'59”N, 07609’10”W, 1950 m, 3.xii.1997, Muñoz-Quesada et al. (UMSP000209393) (UMSP).

Paratype: COLOMBIA: Valle Del Cauca: same data as holotype -1 male (UMSP).

Distribution. Colombia.

Etymology. Named for the country where the type specimens were collected. 


\section{Rhyacopsyche colubrinosa, new species}

Fig. 12

This species is part of the turrialbae species group along with $R$. turrialbae, $R$. jimena, and $R$. mutisi. All species in this group possess a tall dorsal-ventral inferior appendage, a well developed intermediate appendage produced into a pair of processes, and a dorsolateral lobe that is only slightly produced. Rhyacopsyche colubrinosa is most closely related to $R$. jimena when comparing the structure of the inferior appendage and segment IX, especially the dorsolateral lobes. Rhyacopsyche colubrinosa is diagnosed by its upward curving, twisted intermediate appendage and the presence of a membranous sheath surrounding the phallus.

Adult (male: $\mathrm{n}=9$, female: $\mathrm{n}=14$ ). Forewing length 3.0-3.7, $3.4 \mathrm{~mm}$ (male), 3.0-4.0, $3.3 \mathrm{~mm}$ (female). Color of head dark brown, antennae cream, legs medium brown, wings mottled light and dark brown. Sternum VII with apicomesal point.

Male genitalia. Abdominal segment IX heavily setose, anterior margin deeply rounded; sternum IX, in lateral view, with posterior margin lanceolate; posterior margin slightly undulate; dorsolateral lobe of segment IX slightly produced, in dorsal view rounded, shallowly divided, apex bearing several short, dark, peglike setae and several thin setae. Tergum X partially retracted inside segment IX, articulating with intermediate appendage. Intermediate appendage large, developed into long, dorsally directed, elbowed appendages with the apex lanceolate. Inferior appendage tall, heavily setose, divided into dorsal and ventral lobes, the dorsal lobe inflated along dorsal margin and further divided into a posteriorly directed, rounded, setose lobe and a dorsally directed, truncate lobe, the apex bearing large peglike seta. Phallus base inflated, thin membranous sheath surrounding the middle of the phallus; central tubule with small apical hook; apex of lateral process rounded.

Holotype male: PERU: Cuzco: Paucartambo to Pilcopata Rd. streamlet $50 \mathrm{~m}$ E Quiacalzón, $13^{\circ} 01.57^{\text {'S }}$, 71²9.97’W, 1050 m, 26.vi.1993, R Blahnik \& M Pescador (UMSP000115097) (MHNJP).

Paratypes: ECUADOR: Cotopaxi: Latacunga, 133 km W, 2.vii.1975, 1080', Langley \& Cohen - 1 male, 2 females (NMNH); Pastaza: Puyo, 5.v.1977, \#3, P J Spangler \& D R Givens - 1 male, 3 females (NMNH); 10.v.1977, \#31, P J Spangler \& D R Givens - 1 male, 1 female (NMNH); 11.v.1977, \#36, P J Spangler \& D R Givens - 1 male (UMSP); 13.v.1977, \#41, P J Spangler \& D R Givens — 1 male, 4 females (NMNH); 16.v.1977, \#51, P J Spangler \& D R Givens — 1 male (NMNH); Pichincha: Río Umachaca, For. Sta. Maquipucuna, 1250 m, 4-5.ix.1990, O S Flint, Jr. - 1 male (NMNH); Zamora-Chinchipe: 6 km E Zumbi, 980 m, 21.ix.1990, O S Flint, Jr. — 1 male, 4 females (UMSP).

Distribution. Ecuador, Peru.

Etymology. Colubrinus, Latin for snakelike referring to the form of the intermediate appendage.

\section{Rhyacopsyche dikrosa, new species}

Fig. 13

This species resembles $R$. hagenii in general form. Both $R$. hagenii and $R$. dikrosa possess bifid dorsolateral lobes, a midlateral lobe on segment IX, and a single large apical seta on the inferior appendage. The elaborately developed, forked dorsolateral lobes of $R$. dikrosa are unique among all Rhyacopsyche species. In addition, this is the only species with long peglike setae present on tergum $\mathrm{X}$ and a basally bifid inferior appendage.

Adult (male: $\mathrm{n}=11$, female: $\mathrm{n}=12$ ). Forewing length 2.9-3.5, $3.1 \mathrm{~mm}$ (male), 3.0-4.0, $3.5 \mathrm{~mm}$ (female). Color of head dark brown, antennae light brown, legs medium brown, wings mottled medium and dark brown. Sternum VII with apicomesal point.

Male genitalia. Abdominal segment IX heavily setose, anterior margin deeply rounded; sternum IX, in lateral view, with posterior margin produced into small rounded process; posterior margin produced into small 
rounded lobe bearing short, thick setae; dorsolateral lobe of segment IX elongate, in dorsal view narrowed, deeply divided, widely separated, terminating in large fork, the ventral lobe bearing 1 short peglike seta. Tergum X partially retracted inside segment IX, apex rounded, bearing several long, dark, thick setae. Intermediate appendage not evident. Inferior appendage elongate, heavily setose, base bifid, dorsal lobe long and narrow, ventral lobe larger, rounded, bearing 1 large pointed seta. Phallus linear, thin membranous sheath surrounding virtually the entire phallus, covered with spicules; central tubule with two opposing apical hooks; apex of lateral process rounded.

Holotype male: BRAZIL: São Paulo: Pedregulho, 140 km NE Ribeirao Preto, 20.iii.1989, L G Oliveira - 1 male (UMSP000115164) (MZUSP).

Paratypes: BRAZIL: Minas Gerais: Parque Estadual Itacolomi, Rio Belchior, 20²5'02"S, 04325'38”W, 725 m, 2.ii.1998, Holzenthal \& Paprocki - 2 males (MZUSP); 17.xii.1998, Paprocki \& Amarante -2 males, 3 females (UMSP); Corrego Pitanga, upstream of confluence with Rio Santo Antônio, 1905'40”'S, 042³9'54’'W, 238 m, 19.x.2000, Paprocki \& Ferreira - 1 male (UMSP); Rio de Janeiro: Nova Friburgo, municipal water supply, 950 m, 24.iv.1977, C M \& O S Flint - 1 male (NMNH); Rio Sousa, in Cachoeiras de Macacú, 26²6’34”S, 042³7'57’W, 150 m, 16.iii.1996, Holzenthal, Rochetti \& Oliveira — 1 male (MZUSP); São Paulo: Estação Biológica Boraceia, Rio Guaratuba, 2340'02”S, 045 53'46”'W, 775 m, 17.iv.1998, Holzenthal, Melo \& Froehlich — 3 males, 8 females (UMSP); Rio Coruja, 2340'06”'S, 04553'57'W, 850 m, 18.iv.1998, Holzenthal, Melo \& Froehlich - 1 male, 1 female (MZUSP).

Distribution. Brazil.

Etymology. The Greek word dikros, meaning forked, referring to the prominent fork of the dorsolateral lobe of segment IX.

\section{Rhyacopsyche duplicispina Flint}

Fig. 14

Rhyacopsyche duplicispina Flint, 1996a:91 [Type locality: Tobago, Bridge B1/5, 6.5 km N Roxborough; NMNH; male].

This species is similar to R. patulosa, new species, and $R$. yatay based on the very reduced dorsolateral lobe, the anteroventrally produced anterior margin of segment IX, and the complexity of the inferior appendage. While both $R$. duplicispina and $R$. yatay have a trilobate inferior appendage, the composition is quite different. Rhyacopsyche duplicispina bears only a single peglike seta and the lobes are fingerlike, unlike the more setose and spatulate lobes of R. yatay.

Adult (male: $\mathrm{n}=1$ ). Forewing length $2.1 \mathrm{~mm}$. Color in alcohol, brown. Sternum VII without apicomesal point.

Male genitalia. Abdominal segment IX with no apparent setae, anterior margin nearly straight, produced anteroventrally; sternum IX, in lateral view, with posterior margin slightly rounded, with connecting membrane to inferior appendage; posterior margin nearly straight; dorsolateral lobe of segment IX slightly produced, in dorsal view rounded, widely separated, apex bearing several thin setae. Tergum X elongate, with rounded, apicolateral lobes. Intermediate appendage not evident. Inferior appendage semierect, slender, with row of long setae, in ventral aspect, appendage produced into 3 lobes with center lobe bearing 1 large peglike seta. Phallus linear, membranous sheath absent; central tubule with forked apex; apex of lateral process lanceolate.

Material examined. TOBAGO: Bridge B1/5, $6.5 \mathrm{~km} \mathrm{~N}$ Roxborough, $390 \mathrm{~m}, 11^{\circ} 17^{\prime} \mathrm{N}, 60^{\circ} 35^{\prime} \mathrm{W}$, 14.vi.1993, O S Flint \& W N Mathis — 1 male (holotype, NMNH).

Distribution. Tobago. 


\section{Rhyacopsyche flinti, new species}

Fig. 15

This species is unique among Rhyacopsyche. It is distinguished by the basally bifid inferior appendage, divided into a membranous dorsal lobe with a trilobate apex, and an elongate ventral lobe narrowing to a sharp point. Another distinctive feature is the undulate medial margin of the dorsolateral lobe with its small, membranous process lying in the transverse plane.

Adult (male: $\mathrm{n}=5$, female: $\mathrm{n}=3$ ). Forewing length 3.1-3.5, $3.3 \mathrm{~mm}$ (male), 3.2-3.6, $3.4 \mathrm{~mm}$ (female). Color in alcohol, brown. Sternum VII with apicomesal point.

Male genitalia. Abdominal segment IX sparsely setose, anterior margin deeply rounded; sternum IX, in lateral view, with posterior margin produced into small rounded process; posterior margin nearly straight; dorsolateral lobe of segment IX elongate, in dorsal view rounded, deeply divided, widely separated, the medial margin undulate, apex bearing several thin setae. Tergum X completely retracted inside segment IX, articulating with intermediate appendage. Intermediate appendage produced into small slender plate lying mesad of inferior appendage, in ventral view, plate spatulate. Inferior appendage elongate, trianguloid, heavily setose, with strong apical point, long dorsal appendage arising from the base with apex trilobate, the most dorsal lobe bearing several thin setae. Phallus linear, membranous sheath absent; central tubule with 2 opposing apical hooks; apex of with lateral process truncate.

Holotype male: VENEZUELA: Guárico: Parque Nacional Guatopo, Queb. Guatopo, $0.5 \mathrm{~km}$ N Est. La Colina, $600 \mathrm{~m}, 10^{\circ} 0^{\prime} 50^{\prime \prime} \mathrm{N}, 66^{\circ} 21^{\prime} 47^{\prime \prime} \mathrm{W}, 22 . i .1994$, Holzenthal, Cressa \& Rincón (UMSP000206944) (UMSP).

Paratypes: VENEZUELA: Guárico: same data as holotype - 1 male, 1 female (NMNH), 3 males, 2 females (UMSP).

Distribution. Venezuela.

Etymology. Named in honor of Oliver Flint, Jr., Smithsonian Institution in Washington D.C., who has produced the majority of the work on Rhyacopsyche.

\section{Rhyacopsyche hasta, new species}

Fig. 16

This species possesses a cluster of long, light ventrally directed setae among several peglike setae on the dorsolateral lobe, as does $R$. benwa. A combination of the angulate anterior margin of segment IX and the broad, spatulate inferior appendage, bearing several dark peglike setae distinguishes this species among Rhyacopsyche.

Adult (male: $\mathrm{n}=1$ ). Forewing length $2.9 \mathrm{~mm}$. Color of head dark brown, antennae cream, legs medium brown, wings mottled light and dark brown. Sternum VII with apicomesal point.

Male genitalia. Abdominal segment IX sparsely setose, anterior margin angulate; sternum IX, in lateral view, with posterior margin produced into small rounded process; posterior margin nearly straight; dorsolateral lobe of segment IX elongate, in dorsal view narrowed, shallowly divided, nearly meeting dorsally, thin dorsal bar lying in the transverse plane, apex bearing several short, dark, peglike setae and group of long, light, ventrally directed spines. Tergum X completely retracted inside segment IX, articulating with intermediate appendage. Intermediate appendage produced into small slender plate lying mesad of inferior appendage, in ventral view, plate sagittate. Inferior appendage elongate, heavily setose, broadly spatulate, apex bearing several peglike setae; ventral margin undulate. Phallus linear, thin membranous sheath surrounding apex; central tubule terminating in a very long, basally directed filament; apex of lateral process truncate. 
Holotype male: PERU: Cuzco: Paucartambo to Pilcopata rd., streamlet $50 \mathrm{~m}$ E Quiacalzón, $13^{\circ} 01.57^{\prime}$ S, 71²9.97’ W, 1050 m, 26.vi.1993, R Blahnik \& M Pescador (UMSP000115099) (MHNJP).

Distribution. Peru.

Etymology. The Latin word for spear, referring to the group of long, pointed spines occurring on the dorsolateral lobes of the segment IX.

\section{Rhyacopsyche intraspira, new species}

Fig. 17

The form and features of the dorsolateral lobe and inferior appendage of $R$. intraspira, new species, and $R$. andina are very similar. However, the dorsolateral lobes of $R$. intraspira are nearly meeting dorsally, as opposed to widely separated condition exhibited by $R$. andina. This species can also be diagnosed by the apex of the phallus which is produced into a prominent sclerotized boot.

Adult (male: $n=3$, female: $n=2$ ). Forewing length 3.9-4.2, $4.1 \mathrm{~mm}$. Color of head dark brown, antennae cream, legs medium brown, wings mottled medium and dark brown. Sternum VII with apicomesal point.

Male genitalia. Abdominal segment IX heavily setose, anterior margin deeply rounded; sternum IX, in lateral view, with posterior margin produced into small rounded process; posterior margin nearly straight; dorsolateral lobe of segment IX elongate, in dorsal view truncate, deeply divided, nearly meeting dorsally, apex bearing several short, dark, peglike setae. Tergum X partially retracted inside segment IX, articulating with intermediate appendage. Intermediate appendage produced into small slender plate lying mesad of inferior appendage, in ventral view, plate undulate. Inferior appendage elongate, heavily setose, dorsal margin enlarged at middle, apex bearing 2 peglike setae. Phallus linear, thin membranous sheath surrounding the middle of the phallus, covered with spicules; central tubule with large apical hook; apex of lateral process hooked.

Holotype male: PERU: Cuzco: Paucartambo to Pilcopata rd., Rio San Pedro at Puente San Pedro, 1303.30’ S, 71³2.78’ W, 1445 m, 24.vi.1993, R Blahnik \& M Pescador (UMSP000115060) (MHNJP).

Paratypes: PERU: Cuzco: Paucartambo to Pilcopata rd., Rio San Pedro at Puente San Pedro, $13^{\circ} 03.30^{\prime}$ S, 71³2.78' W, 1445 m, 24.vi.1993, R Blahnik \& M Pescador - 1 male, 1 female (UMSP); Paucartambo, Pte. San Pedro ca. 50 km NW Pilcopata, 1600 m, 2-3.ix.1988, O Flint \& N Adams - 1 male, 1 female (NMNH).

Distribution. Peru.

Etymology. Intra - in, spir - tapering point, for several spike-like setae of the male genitalia directed inward.

\section{Rhyacopsyche jimena Flint}

Fig. 18

Rhyacopsyche jimena Flint, 1991:59 [Type locality: Colombia, Dpto. Antioquia, Quebrada la Jimenez, Sopetran; NMNH; male].

This is the second species assigned to the turrialbae group, united by the similarity of the inferior and intermediate appendages. Rhyacopsyche jimena closely resembles $R$. colubrinosa, but can be distinguished by the membranous, hooklike intermediate appendage and the more rounded apices of the inferior appendage.

Adult. (male $\mathrm{n}=1$ ). Forewing length $2.5 \mathrm{~mm}$. Color in alcohol, brown. Sternum VII with apicomesal point.

Male genitalia. Abdominal segment IX sparsely setose, anterior margin slightly rounded; sternum IX, in lateral view, with posterior margin lanceolate; posterior margin slightly inflated midlaterally; dorsolateral lobe of segment IX slightly produced, in dorsal view rounded, deeply divided, widely separated, apex bearing several short, dark, peglike setae. Tergum X partially retracted inside segment IX, with long basal processes, 
articulating with intermediate appendage. Intermediate appendage large, narrowing, in ventral view, hooklike. Inferior appendage tall, heavily setose, divided into dorsal and ventral lobes, the ventral lobe long, apex rounded, the dorsal lobe with slightly lanceolate apex and small dorsal process bearing 1 large peglike seta. Phallus base inflated, membranous sheath absent; central tubule with truncate apex; lateral process not evident.

Material examined. COLOMBIA: Antioquia, Quebrada La Jimenez, Mun. Sopetran, trap C, 780 m, 3.viii.1983, U. Matthias - 1 male (paratype, NMNH).

Distribution. Colombia.

\section{Rhyacopsyche matthiasi Flint}

Fig. 19

Rhyacopsyche matthiasi Flint, 1991:61 [Type locality: Colombia, Dpto. Antioquia, Urrao; NMNH; male].

This species bears some resemblance to $R$. colei with regard to the midlateral process of segment IX and the presence of plumose setae on the inferior appendage. In addition to $R$. matthiasi, 3 other species, $R$. hagenii, $R$. dikrosa, and $R$. colei, bear a process along the posterior margin of segment IX; however, this is the only species with an articulation of that process. The apex of this process, more correctly regarded as an appendage, is also unique with its 4 apicomedial ridges.

Adult (male $\mathrm{n}=2$ ). Forewing length 3.4, $3.8 \mathrm{~mm}$. Color of head dark brown, antennae light brown, legs cream, wings mottled medium and dark brown. Sternum VII with apicomesal point.

Male genitalia. Abdominal segment IX with no apparent setae, anterior margin nearly straight, produced anteroventrally; sternum IX, in lateral view, with posterior margin slightly rounded, with connecting membrane to inferior appendage; posterior margin produced into midlateral appendage with 4 small apicomedial ridges; dorsolateral lobe of segment IX slightly produced, in dorsal view trianguloid, widely separated, apex bearing several thin setae. Tergum X elongate, with rounded, apicolateral lobes. Intermediate appendage not evident. Inferior appendage elongate, trianguloid, heavily setose, bearing several thick, plumose setae. Phallus base inflated, membranous sheath absent; central tubule with small apical hook; apex of lateral process lanceolate.

Material examined. VENEZUELA: Barinas: Parque Nacional Sierra Nevada, Rio Sinigüis at Tres Quebradas, 08³1'26”N, 07053'46”'W, 1900 m, 19.iii.1997, Holzenthal - 1 male (UMSP); Merida: Laguna de Mucubaji, Paramos zone, 3300 m, site 3, rocky stream below lake, 10.vii.1991, G S Vick - 1 male (NMNH).

Distribution. Colombia.

\section{Rhyacopsyche mexicana (Flint, 1967)}

Fig. 20

Rhyacopsyche mexicana (Flint, 1967:12) [Type locality: Mexico, Vera Cruz, Rio Tacolapan; NMNH; male; in Metrichia]. -Flint, 1971:519 [distribution, male, female, larva, case, to Rhyacopsyche].

This species most closely resembles $R$. obliqua. Both species have a bifid apex of the inferior appendage, bearing 1 large peglike seta. The rounded dorsolateral lobes distinguish $R$. mexicana from the truncate lobes of $R$. obliqua.

Adult (male $\mathrm{n}=10$, female $\mathrm{n}=10$ ). Forewing length 2.2-3.4, $2.6 \mathrm{~mm}$ (male), 2.6-3.5, 3.0 mm (female). Color of head dark brown, antennae cream, legs cream, wings mottled light and dark brown. Sternum VII without apicomesal point. 
Male genitalia. Abdominal segment IX heavily setose, anterior margin slightly rounded; sternum IX, in lateral view, with posterior margin slightly rounded, with connecting membrane to inferior appendage; posterior margin nearly straight; dorsolateral lobe of segment IX elongate, in dorsal view rounded, deeply divided, nearly meeting dorsally, apex bearing several short, dark, peglike setae. Tergum X partially retracted inside segment IX, with long basal processes, articulating with intermediate appendage. Intermediate appendage produced into small slender plate lying mesad of inferior appendage, in ventral view, plate deltoid. Inferior appendage elongate, sparsely setose, apex bifid with ventral lobe bearing 1 large peglike seta. Phallus base inflated, thin membranous sheath surrounding apex, covered with spicules; central tubule with 2 opposing apical hooks; apex of lateral process lanceolate.

Material examined. COSTA RICA: Alajuela: Reserva Forestal San Ramón, Río San Lorencito \& tribs., $10^{\circ} 12^{\prime} 58^{\prime}$ 'N, 084³6'25'W, 980 m, 6-10.iii.1991, Holzenthal, Muñoz \& Huisman — 1 male, 3 females (UMSP); Límon: Parque Nacional Braulio Carrillo, Quebrada González, 1009’36”N, 08356’20”W, 480 m, 12-14.v.1990, Holzenthal \& Blahnik — 5 males, 5 females (UMSP); Puntarenas: Río Cotón, in Las Alturas, 0856'17”N, 08249'34”W, 1360 m, 12.viii.1990, Holzenthal, Blahnik \& Muñoz - 1 male, 1 female (UMSP); Río Bellavista: ca. 1.5 km NW Las Alturas, 0857’04”N, 08250’46”'W, 1400 m, 8-9.iv.1987, Holzenthal, Hamilton \& Heyn — 1 female (UMSP); 2-3.viii.1987, Holzenthal, Morse \& Clausen — 1 male, 3 females (UMSP); San José: Río Chirripó Pacífico, 9.5 km NE Rivas, 09²8’12”N, 083³5’28”W, 1370 m, 23.ii.1986, Holzenthal, Morse \& Fasth - 1 male, 1 female (UMSP); NICARAGUA: Zelaya: Río Las Latas, 1404'00”'N, 088³3'00”'W, 220 m, 2.vi.1998, Maes \& Hernandez — 1 male (UMSP).

Distribution. Costa Rica, Guatemala, Mexico, Nicaragua.

\section{Rhyacopsyche mutisi Mey \& Joost}

Fig. 21

Rhyacopsyche mutisi Mey and Joost, 1990:134 [Type locality: Colombia, Dept. Tolima, Mariquita, Rio Medina; ZMHU; male, larva, case].

The third species in the turrialbae group, it is most closely related to $R$. turrialbae. The inferior appendage and the truncate dorsolateral lobe of segment IX are very similar. Rhyacopsyche mutisi is diagnosed by the very long posteroventral process of segment IX, the medially directed ventral lobe of the inferior appendage, and the absence of peglike setae on the dorsolateral lobe. Additionally, the intermediate appendage has a diverging, lanceolate basal process.

Adult (male $\mathrm{n}=1$ ). Color in alcohol, brown.

Male genitalia. Abdominal segment IX sparsely setose, anterior margin slightly rounded; sternum IX, in lateral view, with posterior margin lanceolate; posterior margin slightly inflated midlaterally; dorsolateral lobe of segment IX slightly produced, in dorsal view trianguloid, shallowly divided, meeting dorsally, apex bearing several thin setae. Tergum X partially retracted inside segment IX. Intermediate appendage produced into dorsal and ventral pair, the dorsal appendage twisted and ventrally directed, the ventral pointed and laterally directed. Inferior appendage tall, divided into dorsal and ventral lobes, the ventral lobe bearing several thin setae, the dorsal lobe with 2 fingerlike processes, the more dorsal bearing 1 large pointed seta. Phallus linear, membranous sheath absent; central tubule with apex truncate; apex of lateral process rounded.

Material examined. COLOMBIA: Mariquita, Rio Medina, 3.xii.1987, W Joost - 1 pharate adult male, 2 pupae (paratypes, ZMHU).

Distribution. Colombia. 


\section{Rhyacopsyche obliqua Flint}

Fig. 22

Rhyacopsyche obliqua Flint, 1971:523 [Type locality: Mexico, Veracruz, Fortin de las Flores; NMNH; male; female].

This species somewhat resembles $R$. peruviana. They both possess an elongate, apically bifid inferior appendage. However, the inferior appendage of $R$. obliqua is distinct with its truncate and somewhat clavate apex.

Adult (male $\mathrm{n}=10$, female $\mathrm{n}=10$ ). Forewing length 2.5-3.3, $2.9 \mathrm{~mm}$ (male), 3.0-3.6, $3.3 \mathrm{~mm}$ (female). Color in alcohol, brown. Sternum VII without apicomesal point.

Male genitalia. Abdominal segment IX heavily setose, anterior margin slightly rounded; sternum IX, in lateral view, with posterior margin slightly rounded, with connecting membrane to inferior appendage; posterior margin slightly undulate; dorsolateral lobe of segment IX elongate, in dorsal view truncate, deeply divided, widely separated, apex bearing several short, dark, peglike setae. Tergum X partially retracted inside segment IX, with long basal processes, articulating with intermediate appendage. Intermediate appendage produced into small slender plate lying mesad of inferior appendage, in ventral view, plate cuneate. Inferior appendage broad, elongate, heavily setose, apex bifid with ventral lobe shallowly bifid, the apex bearing 1 large peglike seta. Phallus linear, membranous sheath absent; central tubule with an anteriorly directed, apical hook; lateral process not evident.

Material examined. MEXICO: Veracruz: Barranca de Metlac, 6 km W. Fortin, 1.v.1981, C M \& O S Flint, Jr. - 1 male, 6 females (NMNH); Fortin de las Flores, 17.v.1964, Blanton et al - 41 males, 19 females (paratypes, $\mathrm{NMNH}$ ).

Distribution. Mexico.

\section{Rhyacopsyche otarosa, new species}

Fig. 23

This species is unique within Rhyacopsyche. The lobes of segment IX originate laterally, rather than dorsolaterally. The anterior margin of segment IX is extremely anteroventrally produced. Tergum $\mathrm{X}$ is exposed and plate-like in dorsal view. In addition, the bifid apex of the inferior appendage is distinct with a large spatulate dorsal lobe and a hooked, truncate ventral lobe.

Adult (male: $\mathrm{n}=2$ ). Forewing length 2.0, $2.2 \mathrm{~mm}$. Color of head dark brown, antennae light brown, legs medium brown, wings mottled medium and dark brown. Sternum VII without apicomesal point.

Male genitalia. Abdominal segment IX with no apparent setae, anterior margin nearly straight, produced anteroventrally; sternum IX, in lateral view, with posterior margin produced into small rounded process; posterior margin nearly straight; dorsolateral lobe of segment IX elongate, in dorsal view acicular, widely separated, bearing 2 long, dorsal setae. Tergum $\mathrm{X}$ elongate, in dorsal view, spatulate. Intermediate appendage not evident. Inferior appendage elongate, heavily setose, apex bifid with ventral lobe truncate, the dorsal lobe inflated and spatulate, bearing several thin setae; ventral margin produced into small medial point. Phallus linear, membranous sheath absent; central tubule with small apical hook; apex of lateral process lanceolate.

Holotype male: VENEZUELA: T. F. A. [Amazonas], Camp IV, Cerro d.1. Neblina, $0^{\circ} 58^{\prime}$ N, 6557’ W, 760 m, 15-18.iii.1984, O S Flint, Jr. (UMSP000115112) (NMNH).

Paratype: VENEZUELA: same data as holotype - 1 male (IZAM).

Distribution. Venezuela.

Etymology. The Greek word otaros meaning large-eared, referring to the prominent "ear lobe" on the inferior appendage. 


\section{Rhyacopsyche patulosa, new species}

Fig. 24

This species resembles $R$. yatay in the virtual absence of a dorsolateral lobe and presence of a heavily setose inferior appendage. Rhyacopsyche patulosa is diagnosed by the extremely reduced dorsolateral lobe, the lanceolate tergum $\mathrm{X}$, the broad, almost bilobate inferior appendage, and the long, narrow phallus.

Adult (male: $\mathrm{n}=1$, female: $\mathrm{n}=5$ ). Forewing length $2.9 \mathrm{~mm}$ (male), 3.0-3.2, $3.1 \mathrm{~mm}$ (female). Color of head dark brown, antennae light brown, legs medium brown, wings mottled light and dark brown. Sternum VII with apicomesal point.

Male genitalia. Abdominal segment IX heavily setose, anterior margin nearly straight, produced anteroventrally; sternum IX, in lateral view, with posterior margin produced into small rounded process; posterior margin nearly straight; dorsolateral lobe of segment IX not evident, in dorsal view segment IX rounded, deeply divided, widely separated. Tergum $\mathrm{X}$ elongate, lanceolate. Intermediate appendage produced into small slender plate lying inside segment IX. Inferior appendage tall, divided into dorsal and ventral lobes, with small apicomesal point, heavily setose, medial face of dorsal and ventral lobes bearing several peglike setae. Phallus linear, thin membranous sheath surrounding the middle of the phallus, covered with spicules; central tubule with small apical hook; apex of lateral process lanceolate.

Holotype male: BRAZIL: Rio de Janeiro: Parque Nacional da Serra dos Órgãos, Rio Beija-flor, 2227’04”S, 04300’04”W, 1125 m, 27.ii.2002, Holzenthal, Blahnik, Paprocki \& Prather (UMSP000069469) (MZUSP).

Paratypes: BRAZIL: Rio de Janeiro: same data as holotype -3 females (MZUSP), 2 females (UMSP).

Distribution. Brazil.

Etymology. The Latin word patulus meaning spread-out, broad, in reference to the inferior appendage.

\section{Rhyacopsyche peruviana Flint}

Fig. 25

Rhyacopsyche peruviana Flint, 1975:568 [Type locality: South-Peru, Sivia; ZSZMH; male; female].

The species resembles $R$. obliqua and $R$. colombiana. It is easily diagnosed by the fused dorsolateral lobes when viewed from the dorsal aspect.

Adult (male $\mathrm{n}=10$, female $\mathrm{n}=10$ ). Forewing length 2.6-3.0, $2.5 \mathrm{~mm}$ (male), 3.2-3.6, $3.4 \mathrm{~mm}$ (female). Color of head dark brown, antennae cream, legs cream, wings mottled light and dark brown. Sternum VII with apicomesal point.

Male genitalia. Abdominal segment IX sparsely setose, anterior margin deeply rounded; sternum IX, in lateral view, with posterior margin slightly rounded, with connecting membrane to inferior appendage; posterior margin slightly inflated midlaterally; dorsolateral lobe of segment IX fused, elongate, in dorsal view truncate, apex bearing several thin setae. Tergum X partially retracted inside segment IX, apex truncate. Intermediate appendage produced into small slender plate lying mesad of inferior appendage, in ventral view, plate spatulate. Inferior appendage broad, elongate, heavily setose, apex bifid with ventral lobe bearing 1 large pointed seta. Phallus linear, thin membranous sheath surrounding apex, covered with spicules; central tubule with rounded apex; apex of lateral process lanceolate.

Material examined. ECUADOR: Pastaza: Puyo, riverside at blacklights, 29.v.1975, Cohen \& Langley - 6 males, 5 females (NMNH); $16 \mathrm{~km} \mathrm{W,} \mathrm{3.ii.1976,} \mathrm{Spangler} \mathrm{et} \mathrm{al.}-1$ male (NMNH); $3 \mathrm{~km} \mathrm{~W}$, 15.vii.1976, Jeffrey Cohen - 2 males (NMNH); 11.v.1977, \#36, P J Spangler \& D R Givens - 1 male 
(NMNH); 1.5 km S, 21.v.1977, P J Spangler \& D R Givens — 4 males (NMNH); 21.v.1977, \#67, P J Spangler \& D R Givens - 2 males, 1 female (NMNH); Zamora-Chinchipe: Yanzaza, 15.vi.1976, A Langley et al. — 74 males, 16 females (NMNH), 20males, 20 females (UMSP); Yanzaza, 5 km N, 29.xi.1978, Jos. J Anderson - 5 males, 2 females (UMSP).

Distribution. Ecuador, Peru.

\section{Rhyacopsyche rhamphisa, new species}

Fig. 26

Resembling $R$. cole $i$ in the form of the dorsolateral lobe, $R$. rhamphisa, new species, is easily diagnosed by the narrow, hooklike inferior appendage, as well as the complex, many lobed apex of the phallus.

Adult (male: $\mathrm{n}=2$, female: $\mathrm{n}=1$ ). Forewing length 2.3, $2.8 \mathrm{~mm}$ (male), $3.4 \mathrm{~mm}$ (female). Color of head dark brown, antennae light brown, legs medium brown, wings mottled light and dark brown. Sternum VII with apicomesal point.

Male genitalia. Abdominal segment IX heavily setose, anterior margin deeply rounded; sternum IX, in lateral view, with posterior margin slightly rounded, with connecting membrane to inferior appendage; posterior margin slightly inflated midlaterally; dorsolateral lobe of segment IX elongate, in dorsal view rounded, deeply divided, widely separated, apex bearing several short, dark, peglike setae. Tergum X completely retracted inside segment IX. Intermediate appendage produced into small slender plate lying mesad of inferior appendage, in dorsal view, plate spatulate. Inferior appendage elongate, heavily setose, with strong apical point bearing 1 large pointed seta. Phallus linear, thin membranous sheath surrounding the middle of the phallus, apex produced into several acicular processes; central tubule with forked apex; apex of lateral process undulate.

Holotype male: COLOMBIA: Valle Del Cauca: Municipio El Cerrito, Rio Cerrito $7.1 \mathrm{kms}$ E. Hacienda “El Paraiso", 03³8'59”'N, 07609’10”W, 1950 m, 3.xii.1997, Muñoz-Quesada et al. (UMSP000209391) (UMSP).

Paratypes: COLOMBIA: Valle Del Cauca: same data as holotype -1 female (UMSP); COSTA RICA: Guanacaste: Parque Nacional Guanacaste, Estación Maritza, Rio Tempisquito, 1057’29'N, 085²9'49”'W, 550 m, 30-31.viii.1990, Huisman, Blahnik, Quesada - 1 male (UMSP), (UMSP000076395): differs in that the inferior appendages are slightly more slender, and the base of the inferior appendages is only slightly more truncate.

Distribution. Colombia, Costa Rica.

Etymology. Rhamphis is the Greek word for hook, referring to the strongly hooked inferior appendages.

\section{Rhyacopsyche tanylobosa, new species}

Fig. 27

The extremely long dorsolateral lobe and inferior appendage distinguishes this species from all other species of Rhyacopsyche. The general form is similar to $R$. andina, an elongate inferior appendage and dorsolateral lobe, along with the absence of peglike setae on the dorsolateral lobe. In addition to the long length of the dorsolateral lobe and inferior appendage, $R$. tanylobosa can also be diagnosed by the bifid lobe along the posterior margin of the inferior appendage, the ventral lobe bearing a sclerotized tip.

Adult (male: $\mathrm{n}=10$, female: $\mathrm{n}=10$ ). Forewing length 2.5-3.5, $3.3 \mathrm{~mm}$ (male), 3.0-3.7, $3.4 \mathrm{~mm}$ (female). Color of head dark brown, antennae light brown, legs medium brown, wings mottled medium and dark brown. Sternum VII with apicomesal point.

Male genitalia. Abdominal segment IX heavily setose, anterior margin slightly rounded; sternum IX, in lateral view, with posterior margin produced into small rounded process; posterior margin slightly inflated 
midlaterally; dorsolateral lobe of segment IX elongate, in dorsal view clavate, deeply divided, widely separated, apex truncate, meeting along median line, apex bearing several thin setae. Tergum X partially retracted inside segment IX, articulating with intermediate appendage. Intermediate appendage produced into small slender plate lying mesad of inferior appendage, in ventral view, plate a narrow rod lying in the transverse plane. Inferior appendage elongate, slightly inflated along lateral margin, heavily setose, in lateral view, apex truncate, bearing 1 large peglike seta; ventral margin produced into bifid lobe, the ventral most lobe with slightly sclerotized tip. Phallus base inflated, thin membranous sheath surrounding the middle of the phallus; central tubule terminating in very long basally directed filament; apex of lateral process truncate.

Holotype male: VENEZUELA: Barinas: Parque Nacional Sierra Nevada, Queb. San Juan in Sta. Rosa, 0827.87’ N, 07050.92’W, 1000 m, 21.iii.1997, Holzenthal (UMSP000075084) (UMSP).

Paratypes: ECUADOR: Napo: Rio Jondachi, 30 km N Tena, 950 m, 10.ix.1990, O S Flint, Jr. — 1 male, 2 females (NMNH); Pastaza: Puyo, 30.i.1976, Spangler et al. -1 male (NMNH); 3 km W, 15.vii.1976, Jeffrey Cohen — 10 males, 20 females (NMNH); 8.v.1977, \#22, P J Spangler \& D R Givens — 1 male (NMNH); 1.5 km S, 14.v.1977, \#43, P J Spangler \& D R Givens — 1 male, 1 female (NMNH); 18.v.1977, \#56, P J Spangler \& D R Givens - 1 male (NMNH); Pichincha: N. Perucho, 18-19.ix.1977, L E Pena G - 8 males, 2 females (NMNH); Río Umachaca, For. Sta. Maquipucuna, 5 km E Nanegal, 0075’ N, 78³7’ W, 1250 m, 45.ix.1990, O S Flint, Jr. - 6 males, 3 females (UMSP); Zamora-Chinchipe: 6 km E Zumbi, $980 \mathrm{~m}$, 21.ix.1990, O S Flint, Jr. — 4 males (NMNH); Río Jamboe, 21 km S Zamora, 1340 m, 22.ix.1990, O S Flint, Jr. -8 males, 1 female (NMNH); PERU: Cuzco: Paucartambo to Pilcopata rd., river at Puente Union, 1304.22’'S, 71³4.00’W, 1670 m, 21-23.vi.1993, R Blahnik \& M Pescador — 1 male (NMNH); Paucartambo to Pilcopata rd., Quebrada Quitacalzon at Puente Quitacalzon, $13^{\circ} 01.57^{\prime} \mathrm{S}, 7^{\circ} 29.97^{\prime} \mathrm{W}, 1050 \mathrm{~m}, 25-$ 27.vi.1993, R Blahnik \& M Pescador - 13 males, 2 females (NMNH); Paucartambo to Pilcopata rd., streamlet $50 \mathrm{~m}$ E Quitacalzon, 1301.57'S, 71²9.97'W, $1050 \mathrm{~m}$, 26.vi.1993, R Blahnik \& M Pescador — 6 males, 8 females (UMSP); Madre de Dios: Amazonia Lodge, Toma del Agua (stream), 1252.22'S, 71²2.56' W, 415 m, 29.vi.1993, R Blahnik \& M Pescador — 1 male, 1 female (NMNH).

Distribution. Ecuador, Peru, Venezuela.

Etymology. Tany, Greek for long; lobos, Greek for a rounded projection, referring to the very long dorsolateral lobe and inferior appendage.

\section{Rhyacopsyche torulosa Flint}

Fig. 28

Rhyacopsyche torulosa Flint, 1971:521 [Type locality: Guatemala, Escuintla, Rio Metapa, 10 km SE Escuintla; NMNH; male; female]. - Holzenthal, 1988:63 [distribution].

Rhyacopsyche torulosa most closely resembles $R$. peruviana. This species can be diagnosed by the small medially directed lobe of the dorsolateral lobe and the apices of the inferior appendages which virtually meet along the median line.

Adult (male $\mathrm{n}=10$, female $\mathrm{n}=10$ ). Forewing length 2.6-2.9, $2.8 \mathrm{~mm}$ (male), 2.8-3.4, 3.2 $\mathrm{mm}$ (female). Color in alcohol, brown. Sternum VII without apicomesal point.

Male genitalia. Abdominal segment IX heavily setose, anterior margin slightly rounded; sternum IX, in lateral view, with posterior margin produced into small rounded process; posterior margin slightly undulate; dorsolateral lobe of segment IX elongate, in dorsal view rounded, deeply divided, nearly meeting dorsally, with small medially directed lobe, apex bearing several short, dark, peglike setae. Tergum X partially retracted inside segment IX, with long basal processes, articulating with intermediate appendage. Intermediate appendage produced into thin ribbonlike filaments. Inferior appendage elongate, heavily setose, apex bifid with ventral lobe bearing 1 small pointed seta. Phallus linear, membranous sheath absent; central tubule with anteriorly directed, apical hook; apex of lateral process lanceolate. 
Material examined. COSTA RICA: Alajuela: Río Toro, $3.0 \mathrm{~km}$ (road) SW Bajos del Toro, 10²' 14”N, 084¹8'58'W, 1530 m, 3-4.ix.1990, Holzenthal, Blahnik \& Huisman - 1 male (UMSP); Cartago: Suiza, 980 m, 5.xii.1998, P A Opler - 1 male (NMNH); GUATEMALA: Alta Verapaz: Rio Cahabon, Chibite, 3.i.1989, B C Kondratieff - 26 males, 3 females (NMNH); Rio Metapa: 10 km SE Esquintla, 56.iii.1970, 275 m, E J Fee — 15 males, 20 females (paratypes, NMNH).

Distribution. Costa Rica, Guatemala.

\section{Rhyacopsyche turrialbae Flint}

Fig. 29

Rhyacopsyche turrialbae Flint, 1971:523 [Type locality: Costa Rica, Cartago, Chitaria; NMNH; male; female].

This species resembles $R$. mutisi, based on the form of the inferior appendage and the truncate dorsolateral lobe, and is the fourth and final species in the turrialbae group. It is distinguished by the elongate ventral lobes of the inferior appendage, and the thick, twisted intermediate appendage which articulates basally with a membranous plate.

Adult (male $\mathrm{n}=10$, female $\mathrm{n}=10$ ). Forewing length 3.0-4.0, $3.6 \mathrm{~mm}$ (male), 3.7-4.3, $4.0 \mathrm{~mm}$ (female). Color of head dark brown, antennae cream, legs medium brown, wings mottled light and dark brown. Sternum VII with apicomesal point.

Male genitalia. Abdominal segment IX heavily setose, anterior margin slightly rounded; sternum IX, in lateral view, with posterior margin lanceolate; posterior margin slightly inflated midlaterally; dorsolateral lobe of segment IX slightly produced, in dorsal view truncate, shallowly divided, nearly meeting dorsally, apex bearing several short, dark, peglike setae. Tergum X partially retracted inside segment IX, with long basal processes, articulating with intermediate appendage. Intermediate appendage large, sclerotized, produced into narrow, twisted point, articulating basally with membranous plate, in lateral view, plate truncate. Inferior appendage tall, heavily setose, divided into dorsal and ventral lobes, the dorsal lobe with posterior margin produced into fingerlike process, the dorsal margin developed into small setose lobe bearing 1 large peglike seta. Phallus base inflated, thin membranous sheath surrounding apex; central tubule with small apical hook; apex of lateral process truncate.

Material examined. COSTA RICA: Alajuela: unnamed river, Cerro Campana ca. 6 km (air) NW Dos Rios, 10 $54^{\prime} 00^{\prime} \mathrm{N}, 085^{\circ} 24^{\prime} 00^{\prime}$ 'W, 640 m, 15-16.iii.1986, Holzenthal \& Fasth - 1 male (UMSP); Cartago: Río Platanillo, 2.2 km E Tayutic, 0949'12”N, 083³3’00”W, 730 m, 30.i.1986, Holzenthal, Morse \& Fasth — 1 male (UMSP); Quebrada Platanillo, ca. 5 km E Moravia de Chirripó, 0949’16”N, 083²4’25”W, 1130 m, 6.viii.1987, Holzenthal, Morse \& Clausen —2 males, 6 females (UMSP); Reserva Tapantí, Quebrada Palmitos \& falls, ca. 9 km (road) NW tunnel, 0943'12”N, 08346’48”'W, 1400 m, 1-2.viii.1990, Holzenthal, Blahnik \& Muñoz - 1 male (UMSP); Quebrada Segunda @ administration building, 0945'40"N, 08347'13”'W, 1250 m, 9-10.v.1990, Holzenthal \& Blahnik — 2 males, 6 females (UMSP); Puntarenas: Río

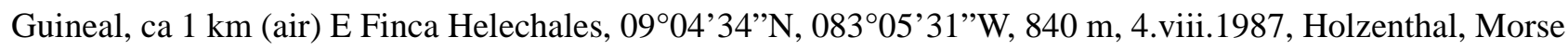
\& Clausen - 13 females (UMSP); Río Singrí, ca 2 km (air) S Finca Helechales, 0903'25”N, 08304'55”W, 720 m, 21.ii.1986, Holzenthal, Morse \& Fasth -3 males, 2 females (UMSP).

Distribution. Costa Rica.

\section{Rhyacopsyche yatay Angrisano}

Fig. 30

Rhyacopsyche yatay Angrisano, 1989:157 [Type locality: Argentina, Entre Rios, Parque Nacional el Palmar; MACN; male; female]. - Angrisano, 2002:395 [larva]. 
This species is very unique, although it shares the reduced dorsolateral lobe with $R$. patalusa, and the trilobate apex of the inferior appendage with $R$. duplicispina. This species is easily diagnosed by the form of the 3 large spatulate lobes of the inferior appendage. The outer lobe is sclerotized, the middle lobe bears several peglike setae, and the inside lobe has several long setae.

Adult (male $\mathrm{n}=0$, female $\mathrm{n}=0$ ). Color in alcohol, dark brown.

Male genitalia. Abdominal segment IX with no apparent setae, anterior margin nearly straight, produced anteroventrally; sternum IX, in lateral view, with posterior margin slightly rounded, with connecting membrane to inferior appendage; posterior margin nearly straight; dorsolateral lobe of segment IX not evident, dorsal lobes meeting along medial line, but not fused. Tergum X completely retracted inside segment IX. Intermediate appendage produced into small slender plate lying mesad of inferior appendage, in ventral view, plate semiconical, lying between pair of membranous lobes. Inferior appendage elongate, trilobate, the outermost lobe sclerotized, lanceolate, the middle lobe spatulate, bearing several short, dark, peglike setae, the inside lobe clavate, bearing several long setae. Phallus base inflated, membranous sheath absent; central tubule with rounded apex, apex of lateral process lanceolate.

Material examined. Attempts to obtain loan material were unsuccessful. Therefore, the illustrations are after the description by E. B. Angrisano (1989).

Distribution. Argentina.

\section{Key to males of Rhyacopsyche}

1 Inferior appendage bearing 1 or more peglike seta (Figs. 6A, 12A, 16A) ……................................... 2

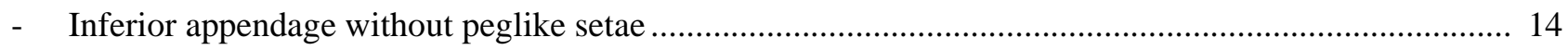

2 Dorsolateral lobe of segment IX slightly produced (Figs. 14B, 29B) …............................................. 3

- Dorsolateral lobe of segment IX elongate (Figs. 6B, 7B, 9B) ........................................................ 6

- Dorsolateral lobe of segment IX greatly reduced or not evident (Figs. 24B, 30B) ….............................. 13

3 Dorsolateral lobe of segment IX widely separated (Figs. 12B, 14B); in dorsal view, rounded (Figs. 14B, 18B)

- Dorsolateral lobe of segment IX meeting, or nearly meeting dorsally; in dorsal view, truncate or trianguloid (Fig. 29)..... Rhyacopsyche turrialbae Flint

4 Inferior appendage divided into a dorsal and ventral lobe (Fig. 12A); dorsolateral lobe bearing 2 or more short, dark, peglike setae; inferior appendage tall (Fig. 18A); anterior margin of segment IX rounded .... 5

- Inferior appendage divided into 3 lobes; dorsolateral lobe without peglike setae; inferior appendage semierect, slender; anterior margin of segment IX nearly straight, produced anteroventrally (Fig. 14).......

Rhyacopsyche duplicispina Flint

5 Abdominal segment IX heavily setose; phallus surrounded by a thin membranous sheath, with or without spicules; apex of phallic central tubule hooklike; the dorsal lobe of the inferior appendage inflated along the dorsal margin and further divided into a posteriorly directed, rounded, setose lobe and a dorsally directed truncate lobe (Fig. 12) ................................................ Rhyacopsyche colubrinosa, new species

- Abdominal segment IX sparsely setose or with no apparent setae; phallus with no membranous sheath; apex of phallic central tubule truncate; the dorsal lobe of the inferior appendage with a slightly lanceolate apex and a small dorsal process (Fig. 18)........................................................ Rhyacopsyche jimena Flint

6 Apex of inferior appendage bifurcate (Figs. 11A, 22A) …................................................................ 7

- Apex of inferior appendage with no bifurcation (Figs. 6A, 27A) .................................................... 10

7 Dorsolateral lobes widely separated; phallus with no membranous sheath; posterior margin of segment IX slightly inflated midlaterally (Fig. 22). Rhyacopsyche obliqua Flint

- Dorsolateral lobes meeting, or nearly meeting dorsally (Fig. 7B); phallus surrounded by a thin membra- 
nous sheath, with or without spicules (Fig. 20D); posterior margin of segment IX nearly straight

8 Inferior appendage broad, bearing a single large peglike seta (Fig. 11)

Rhyacopsyche colombiana, new species

- Inferior appendage elongate (Fig. 20A).

9 Sternum VII with apicomesal point; abdominal segment IX sparsely setose or with no apparent setae; dorsolateral lobe of segment IX, in dorsal view, truncate or trianguloid; inferior appendage heavily setose (Fig. 7)

Rhyacopsyche benwa, new species

- Sternum VII without apicomesal point; abdominal segment IX heavily setose; dorsolateral lobe of segment IX, in dorsal view, rounded or clavate; inferior appendage sparsely setose (Fig. 20).

Rhyacopsyche mexicana (Flint)

10 Dorsolateral lobes widely separated (Figs. 6B, 27B) 11

- Dorsolateral lobes meeting, or nearly meeting dorsally (Figs. 16B, 17B)

11 Dorsolateral lobe bearing 2 or more short, dark, peglike setae; apex of phallic central tubule hooklike; posterior margin of segment IX nearly straight; tergum $\mathrm{X}$ with a rectangular sclerite (Fig. 6)

Rhyacopsyche andina Flint

- Dorsolateral lobe without peglike setae; apex of phallic central tubule terminating in a very long basally directed filament; posterior margin of segment IX slightly inflated midlaterally; tergum X articulating with intermediate appendage (Fig. 27) Rhyacopsyche tanylobosa, new species

12 Abdominal segment IX heavily setose; apex of phallic central tubule hooklike; dorsolateral lobe of segment IX, in dorsal view, truncate or trianguloid (Fig. 17) Rhyacopsyche intraspira, new species

- Abdominal segment IX sparsely setose or with no apparent setae; apex of phallic central tubule terminating in a very long basally directed filament; dorsolateral lobe of segment IX, in dorsal view, narrowed (Fig. 16)

Rhyacopsyche hasta, new species

13 Inferior appendage divided into a dorsal and ventral lobe; inferior appendage tall; abdominal segment IX heavily setose; phallus surrounded by a thin membranous sheath, with or without spicules (Fig. 24) ........

Rhyacopsyche patulosa, new species

- Inferior appendage divided into 3 lobes; inferior appendage elongate; abdominal segment IX sparsely setose or with no apparent setae; phallus with no membranous sheath (Fig. 30)

Rhyacopsyche yatay Angrisano

14 Apex of inferior appendage bifurcate (Figs. 23A, 28A)...

Apex of inferior appendage with no bifurcation (Fig. 19A).....

15 Dorsolateral lobe bearing 2 or more short, dark, peglike setae; abdominal segment IX heavily setose (Fig. 28). Rhyacopsyche torulosa Flint

- Dorsolateral lobe without peglike setae; abdominal segment IX sparsely setose or with no apparent setae (Fig. 23A, 25A)...

16 Inferior appendage bearing 1 or more thick, pointed setae; anterior margin of segment IX rounded or angulate; dorsolateral lobe fused; sternum VII with apicomesal point (Fig. 25)

Rhyacopsyche peruviana Flint

- Inferior appendage without a thick, pointed seta; anterior margin of segment IX nearly straight, produced anteroventrally; dorsolateral lobe divided; sternum VII without apicomesal point (Fig. 23)

Rhyacopsyche otarosa, new species

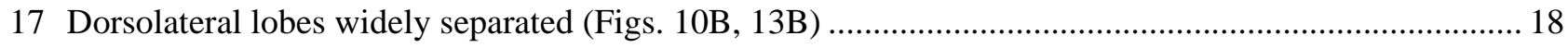

- Dorsolateral lobes meeting, or nearly meeting dorsally (Fig. 8B)....................................................... 24

18 Inferior appendage bearing thick, plumose setae (Figs. 10C, 19A) ….............................................. 19

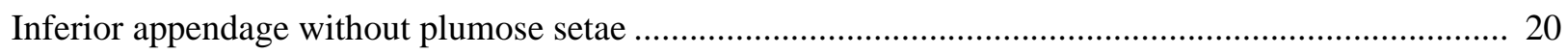

19 Dorsolateral lobe of segment IX slightly produced; anterior margin of segment IX nearly straight, produced anteroventrally; abdominal segment IX sparsely setose or with no apparent setae; phallus with no 
membranous sheath (Fig. 19)

- Dorsolateral lobe of segment IX elongate; anterior margin of segment IX rounded or angulate; abdominal segment IX bearing plumose setae; phallus surrounded by a thin membranous sheath, with or without spicules (Fig. 10) Rhyacopsyche colei, new species

20 Inferior appendage bearing 1 or more thick, pointed setae (Figs. 4A, 8A) 21

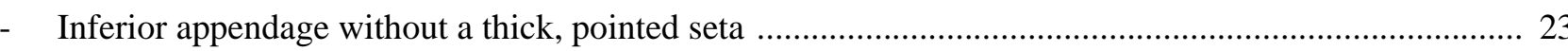

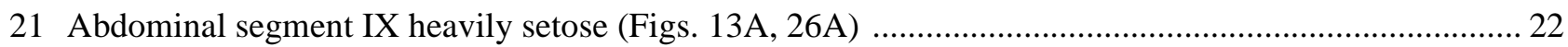

- Abdominal segment IX bearing plumose setae (Fig. 4)

Rhyacopsyche hagenii Müller

22 Apex of phallic central tubule hooklike; dorsolateral lobe of segment IX, in dorsal view, narrowed; posterior margin of segment IX produced into a small lobe (Fig. 13) ... Rhyacopsyche dikrosa, new species

- Apex of phallic central tubule forked; dorsolateral lobe of segment IX, in dorsal view, rounded or clavate; posterior margin of segment IX slightly inflated midlaterally (Fig. 26)

Rhyacopsyche rhamphisa, new species

23 Inferior appendage divided into a dorsal and ventral lobe; dorsolateral lobe without peglike setae; sternum VII with apicomesal point; abdominal segment IX sparsely setose or with no apparent setae (Fig. 15) ......

Rhyacopsyche flinti, new species

- Inferior appendage dorsal margin enlarged at middle; dorsolateral lobe bearing two or more short, dark, peglike setae; sternum VII without apicomesal point; abdominal segment IX heavily setose (Fig. 9) ....... Rhyacopsyche chichotla Beuno \& Hamilton

24 Dorsolateral lobe bearing two or more short, dark, peglike setae; inferior appendage elongate; abdominal segment IX heavily setose; phallus surrounded by a thin membranous sheath, with or without spicules (Fig. 8) Rhyacopsyche bulbosa, new species

- Dorsolateral lobe without peglike setae; inferior appendage tall; abdominal segment IX sparsely setose or with no apparent setae; phallus with no membranous sheath (Fig. 21).

Rhyacopsyche mutisi Mey \& Joost

\section{Phylogenetic analysis}

\section{Methods}

Using the DELTA character file as a basis, 20 morphological characters of the male genitalia were used in a phylogenetic analysis. A matrix was constructed using MacClade 4.06 OS X (Table 1). All characters were binary and equally weighted. Two species were included as outgroups, a representative from 2 other genera in the tribe Ochrotrichiini: Ochrotrichia flagellata Flint, 1972 and Metrichia pakitza Flint \& Beuno-Soria, 1998. Paratrichia and Rhyacopsyche yatay were excluded from the analysis due to the lack of study specimens. The MacClade file was opened using PAUP* 4.0b 10 (Swofford 2001) and a heuristic search for the most parsimonious tree was conducted using the following parameters: 100 random addition replications, 10 trees retained at each step, starting from a random tree. After rooting on the 2 outgroups, a strict consensus was generated. The strict consensus was saved as a tree file and opened in MacClade where the characters were traced on the tree under ACCTRAN character optimization.

\section{Character analysis}

Character 1: Dorsolateral lobes of segment IX: (0) absent, (1) present. The lobes vary greatly in shape and size, most often bearing modified setae.

Character 2: Anterior margin of segment IX: (0) nearly straight, produced anteroventrally, (1) rounded.

Character 3: Posterior margin of segment IX: (0) nearly straight or slightly inflated midlaterally, (1) pro- 
duced into a lobe or appendage.

Character 4: Dorsolateral lobe of segment IX: (0) reduced or slightly produced, (1) elongate.

Character 5: Dorsolateral lobes of segment IX: (0) meeting or nearly meeting, (1) widely separated.

Character 6: Peglike setae of segment IX: (0) absent, (1) present. One or more setae are present on the apex of segment IX; setae are short or long.

Character 7: $\quad$ Tergum X: (0) strongly developed, sclerotized (1) mostly membranous.

Character 8: Intermediate appendage: (0) small or inconspicuous, (1) large, paired. The large, paired intermediate appendages are usually prominent, sclerotized, and extend as far as the inferior appendage.

Character 9: Inferior appendage: (0) elongate, (1) tall.

Character 10: $\quad$ Base of inferior appendage: (0) undivided, (1) divided into 2 or 3 lobes.

Character 11: Apex of inferior appendage: (0) not bifurcate, (1) bifurcate.

Character 12: Large, modified setae of inferior appendage: (0) absent, (1) present. One or more setae are often present on the apex of the inferior appendage and variously modified from short and peglike to long and pointed.

Character 13: Plumose setae on segment IX: (0) absent, (1) present. A plumose seta is illustrated in Figure $4 \mathrm{E}$.

Character 14: Membranous sheath of phallus: (0) absent, (1) present. The thin sheath surrounds either a small center section of the phallus or the entire apex.

Character 15: Dorsolateral lobe of segment IX, in dorsal view: (0) rounded or truncate (1) narrowed.

Character 16: Long, light, ventrally directed spines on the dorsolateral lobe of segment IX: (0) absent, (1) present. These modified setae occur in a group of 4 or 5 on the ventral side of the dorsolateral lobe.

Character 17: Relative length of inferior appendage and segment IX: (0) inferior appendage extending well beyond segment IX, (1) equal or inferior appendage extending slightly beyond segment IX.

Character 18: Plumose setae on inferior appendage: (0) absent, (1) present. A plumose seta is illustrated in Figure 4E.

Character 19: Ventral margin of inferior appendage: (0) unmodified, or generally straight, (1) produced into a small point or lobe.

Character 20: Spicules covering the membranous sheath which surrounds the phallus: (0) absent, (1) present. These small needlelike spines are illustrated in Figure 4D.

\section{Results}

The phylogenetic analysis resulted in 23 equally parsimonious trees, each with a tree length of 50 steps, consistency index of 0.40 , retention index of 0.67 , and a rescaled consistency index of 0.27 . A strict consensus cladogram of these trees is shown in Figure 31. Morphological characters with a consistency index of 1.00 are illustrated on the consensus cladogram and listed here along with the defining character state. Character 1 $($ C.I. $=1.00)$ : dorsolateral lobes of segment IX present; character 7 (C.I. $=1.00)$ : tergum X mostly membranous; character 8 (C.I. = 1.00): intermediate appendage large, paired; character 16 (C.I. = 1.00): long, light, ventrally directed spines present on the dorsolateral lobe of segment IX; character 17 (C.I. $=1.00)$ : inferior appendage meeting or extending slightly beyond segment IX. Character 9 (C.I. $=0.50$ ) is also noted on the cladogram. This character selected for a tall (1) rather than elongate (0) inferior appendage. Although the inferior appendages of $R$. duplicispina and the 4 species included in the turrialbae group are considered tall, the remaining characteristics are quite different. 
TABLE 1. Phylogenetic character matrix. "““" indicates a character that is inapplicable to a taxon.

\begin{tabular}{|c|c|c|c|c|c|c|c|c|c|c|c|c|c|c|c|c|c|c|c|c|}
\hline \multirow[b]{2}{*}{ Taxon } & \multicolumn{20}{|c|}{ Character } \\
\hline & 1 & 2 & 3 & 4 & 5 & 6 & 7 & 8 & 9 & 10 & 11 & 12 & 13 & 14 & 15 & 16 & 17 & 18 & 19 & 20 \\
\hline Ochrotrichia & 0 & 0 & 0 & - & - & - & 0 & 0 & 0 & 0 & 0 & 1 & 0 & 0 & - & 0 & 0 & 0 & 0 & - \\
\hline Metrichia & 0 & 0 & 0 & - & - & - & 0 & 0 & 0 & 0 & 0 & 0 & 0 & 0 & - & 0 & 0 & 0 & 0 & - \\
\hline$R$. andina & 1 & 1 & 0 & 1 & 1 & 1 & 1 & 0 & 0 & 0 & 0 & 1 & 0 & 1 & 0 & 0 & 1 & 0 & 0 & 1 \\
\hline R. benwa & 1 & 1 & 0 & 1 & 0 & 1 & 1 & 0 & 0 & 0 & 1 & 1 & 0 & 1 & 1 & 1 & 1 & 0 & 1 & 0 \\
\hline R. bulbosa & 1 & 1 & 1 & 0 & 0 & 1 & 1 & 0 & 0 & 0 & 0 & 1 & 0 & 1 & 0 & 0 & 1 & 0 & 0 & 1 \\
\hline R. chichotla & 1 & 1 & 0 & 1 & 1 & 1 & 1 & 0 & 0 & 0 & 0 & 0 & 0 & 1 & 1 & 0 & 1 & 0 & 0 & 1 \\
\hline R. colei & 1 & 1 & 1 & 1 & 1 & 0 & 1 & 0 & 0 & 0 & 0 & 1 & 1 & 1 & 0 & 0 & 1 & 1 & 0 & 0 \\
\hline R. colombiana & 1 & 1 & 0 & 1 & 0 & 0 & 1 & 0 & 0 & 0 & 1 & 1 & 0 & 1 & 1 & 0 & 1 & 0 & 0 & 0 \\
\hline R. colubrinosa & 1 & 1 & 0 & 0 & 0 & 1 & 1 & 1 & 1 & 1 & 1 & 1 & 0 & 1 & 0 & 0 & 1 & 0 & 0 & 0 \\
\hline R. dikrosa & 1 & 1 & 1 & 1 & 1 & 1 & 1 & 0 & 0 & 1 & 0 & 1 & 0 & 1 & 1 & 0 & 1 & 0 & 0 & 1 \\
\hline R. duplicispina & 1 & 0 & 0 & 0 & 1 & 0 & 1 & 0 & 1 & 1 & 0 & 1 & 0 & 0 & 0 & 0 & 1 & 0 & 0 & - \\
\hline R. flinti & 1 & 1 & 0 & 0 & 1 & 0 & 1 & 0 & 0 & 1 & 0 & 0 & 0 & 0 & 0 & 0 & 1 & 0 & 0 & - \\
\hline R. hagenii & 1 & 1 & 1 & 1 & 1 & 1 & 1 & 0 & 0 & 0 & 0 & 1 & 1 & 1 & 1 & 0 & 1 & 0 & 0 & 1 \\
\hline R. hasta & 1 & 1 & 0 & 0 & 0 & 1 & 1 & 0 & 0 & 0 & 0 & 1 & 0 & 1 & 1 & 1 & 1 & 0 & 0 & 0 \\
\hline R. intraspira & 1 & 1 & 0 & 0 & 0 & 1 & 1 & 0 & 0 & 0 & 0 & 1 & 0 & 1 & 0 & 0 & 1 & 0 & 0 & 1 \\
\hline R. jimena & 1 & 1 & 0 & 0 & 1 & 1 & 1 & 1 & 1 & 1 & 1 & 1 & 0 & 0 & 0 & 0 & 1 & 0 & 0 & - \\
\hline R. matthiasi & 1 & 0 & 1 & 1 & 1 & 0 & 1 & 0 & 0 & 0 & 0 & 1 & 0 & 0 & 0 & 0 & 1 & 1 & 0 & - \\
\hline R. mexicana & 1 & 1 & 0 & 0 & 0 & 1 & 1 & 0 & 0 & 0 & 1 & 1 & 0 & 1 & 0 & 0 & 1 & 0 & 0 & 1 \\
\hline R. mutisi & 1 & 1 & 0 & 0 & 0 & 0 & 1 & 1 & 1 & 1 & 1 & 1 & 0 & 0 & 0 & 0 & 1 & 0 & 0 & - \\
\hline R. obliqua & 1 & 1 & 0 & 0 & 1 & 1 & 1 & 0 & 0 & 0 & 1 & 1 & 0 & 0 & 0 & 0 & 1 & 0 & 0 & - \\
\hline R. otarosa & 1 & 0 & 0 & 0 & 1 & 0 & 1 & 0 & 0 & 0 & 1 & 0 & 0 & 0 & 1 & 0 & 1 & 0 & 1 & - \\
\hline R. patulosa & 1 & 0 & 0 & 0 & 1 & 0 & 1 & 0 & 1 & 0 & 1 & 1 & 0 & 1 & 0 & 0 & 1 & 0 & 0 & 1 \\
\hline$R$. peruviana & 1 & 1 & 0 & 0 & 0 & 0 & 1 & 0 & 0 & 0 & 1 & 1 & 0 & 1 & 0 & 0 & 1 & 0 & 0 & 1 \\
\hline R. rhamphisa & 1 & 1 & 0 & 0 & 1 & 1 & 1 & 0 & 0 & 0 & 0 & 1 & 0 & 1 & 0 & 0 & 1 & 0 & 0 & 0 \\
\hline R. tanylobosa & 1 & 1 & 0 & 0 & 1 & 0 & 1 & 0 & 0 & 0 & 0 & 1 & 0 & 1 & 0 & 0 & 1 & 0 & 1 & 0 \\
\hline R. torulosa & 1 & 1 & 0 & 0 & 0 & 1 & 1 & 0 & 0 & 0 & 1 & 1 & 0 & 0 & 0 & 0 & 1 & 0 & 0 & - \\
\hline R. turrialbae & 1 & 1 & 0 & 0 & 0 & 1 & 1 & 1 & 1 & 1 & 1 & 1 & 0 & 1 & 0 & 0 & 1 & 0 & 0 & 0 \\
\hline
\end{tabular}

Monophyly of Rhyacopsyche is supported by 3 characters of the male genitalia as revealed in the phylogenetic analysis (Figure 31): presence of a dorsolateral lobe on segment IX, a weakly developed or retracted tergum X, and an inferior appendage meeting, or extending slightly beyond, segment IX. Further characters supporting a monophyletic Rhyacopsyche, as described in the literature are: female tergite VIII with posterior lobes, and a larval foretarsus bearing 1 or 2 enlarged, plate-like setae (Marshall 1979, after Flint 1971). Possible characters of wing venation have not been documented.

Two species groups, the mexicana and turrialbae groups, have been recognized within Rhyacopsyche (Flint 1971). The current analysis supports the monophyly of one of these groups, namely the turrialbae group, which includes the species: $R$. colubrinosa n. sp., $R$. jimena, $R$. mutisi, and $R$. turrialbae. The turrialbae group is easily diagnosed by the prominent intermediate appendage that is developed into large, paired, and usually sclerotized appendages. The tall inferior appendage with dorsal and ventral lobes also distinguishes this group from the remaining Rhyacopsyche species that possess an elongate, upward-curving infe- 
rior appendage. Monophyly of Flint's mexicana group, including $R$. andina, $R$. chichotla, $R$. mexicana, $R$. obliqua, $R$. peruviana and torulosa, was not supported in the current analysis.

It is clear further phylogenetic studies of this genus, utilizing characters from all life stages, should be conducted. A study of this nature would of course only be possible upon the collection and description of the immatures and females of Rhyacopsyche. This study has contributed an important framework for such a study. The description and illustration of 13 new species contributes to our knowledge of the biodiversity in the Neotropics and will promote biomonitoring efforts in the region.

\section{Acknowledgments}

The senior author is grateful to the members of her M.S. thesis advisory committee, Dr. Susan J. Weller and Dr. Leonard C. Ferrington, for their support and guidance. This research would not have been completed without the material provided by Dr. Oliver S. Flint, Jr. and the Smithsonian Institution, Washington DC. Dr. Wolfram Mey, at the Museum für Naturkunde in Berlin, kindly provided paratypes of Rhyacopsyche mutisi. We are thankful for advice and guidance from the following individuals: Dr. Roger J. Blahnik, Lourdes Chamorro-Lacayo, Dr. Henrique Paprocki, Desiree Robertson, and Dr. Philip J. Clausen. This material is based upon work supported by the National Science Foundation under Grant Nos. DEB-9971885 and DEB0117772. The senior author also received support from the Allan Peterson \& University of Minnesota Graduate School Fellowship and the Dayton-Wilkie Fund of the Bell Museum of Natural History. This support is gratefully acknowledged.

\section{References}

Angrisano, E.B. (1989) Rhyacopsyche yatay, una nueva especie de Hydroptilidae de la Argentina (Trichoptera). Revista de la Sociedad Entomologica Argentina, 46, 157-159.

Angrisano, E.B. (1995) Contribuicion al conocimiento de los Trichoptera del Uruguay. II. Familia Hydroptilidae. Revista Brasileira de Entomologia, 39 (3), 501-516.

Angrisano, E.B. (2002) Contribution to the knowledge on Trichoptera of El Palmar National Park (Argentina). Description of the immature stages of Bredinia sp. and Rhyacopsyche yatay (Hydroptilidae). In: Mey, W. (Ed.), Proceedings of the $10^{\text {th }}$ International Symposium on Trichoptera. Goecke \& Evers, Keltern, Germany, pp. 395-406.

Bueno-Soria, J. \& Hamilton, S.W. (1986) Estudios de insectos acuaticos VI. Cinco especies nuevas de Tricopteros de Mexico: (Trichoptera: Polycentropodidae: Hydroptilidae: Hydropsychidae). Anales del Instituto de Biologia, Universidad Nacional Autónoma de México, Series de Zoologia, 57, 299-310.

Colwell, R.K. (1996) Biota: The Biodiversity Database Manager. Sinauer Associates, Inc., Sunderland, Massachusetts, CD-ROM.

Comstock, J.H. \& Needham, J.G. $(1898,1899)$ The wings of insects. American Naturalist, 32, (374, 376-378, 380, 382, 384), 33, (386, 391, 395).

Dallwitz, M.L., Paine, T.A., \& Zurcher, E.J. (1999 onwards) User's guide to the DELTA Editor. Available from http:// www.delta-intkey.com/ (accessed 25 September 2007)

Flint, O.S., Jr. (1967) Studies of Neotropical caddis flies, IV: new species from Mexico and Central America. Proceedings of the United States National Museum, 123 (3608), 1-24.

Flint, O.S., Jr. (1971) Studies of Neotropical caddisflies, XI: the genus Rhyacopsyche in Central America (Hydroptilidae). Proceedings of the Biological Society of Washington, 83, 515-526.

Flint, O.S., Jr. (1972) Studies of Neotropical caddisflies, XIII: the genus Ochrotrichia from Mexico and Central America (Trichoptera: Hydroptilidae). Smithsonian Contributions to Zoology, 118, 1-28.

Flint, O.S., Jr. (1975) Studies of Neotropical caddisflies XX: Trichoptera collected by the Hamburg South-Peruvian Expedition. Entomologische Mitteilungen aus dem Zoologischen Museum Hamburg, 4, 565-573.

Flint, O.S., Jr. (1991) Studies of Neotropical caddisflies XLV: the taxonomy, phenology, and faunistics of the Trichoptera of Antioquia, Colombia. Smithsonian Contributions to Zoology, 520, 1-113.

Flint, O.S., Jr. (1996a) Studies of Neotropical caddisflies, LV: Trichoptera of Trinidad and Tobago. Transactions of the American Entomological Society, 122, 67-113. 
Flint, O.S., Jr. (1996b) Trichoptera collected on the expeditions to Parque Manu, Madre de Dios, Peru. In: Wilson, D.E. \& Sandoval, A. (Eds.), Manu: The biodiversity of southeastern Peru. Smithsonian Institution Press, Washington DC, pp. 369-430.

Flint, O.S., Jr. \& Bueno-Soria, J. (1998) Studies of Neotropical caddisflies, LVI: descriptions of five new species of the genus Metrichia Ross (Trichoptera:Hydroptilidae) from Pakitza, Peru, with a checklist and bibliography of the described species of the genus. Proceedings of the Entomological Society of Washington, 100, 489-496.

Harris, S.C. \& Armitage, B.J. (1997) New member of the Chilean genus Nothotrichia from North America (Trichoptera: Hydroptilidae). In: Holzenthal, R.W. \& Flint, O.S. (Eds.), Proceedings of the $8^{\text {th }}$ International Symposium on Trichoptera. Ohio Biological Survey, Columbus, Ohio, pp. 123-128.

Holzenthal, R.W. (1988) Catalogo sistematico de los Tricopteros de Costa Rica (Insecta: Trichoptera). Brenesia, 29, 5182.

Marshall, J.E. (1979) A review of the genera of the Hydroptilidae (Trichoptera). Bulletin of the British Museum (Natural History) Entomology Series, 39(3), 135-239.

Mey, W. \& Joost, W. (1990) Rhyacopsyche mutisi n.sp. - a new microcaddisfly with an unusual larva from Colombia (Trichoptera, Hydroptilidae). Studies on Neotropical Fauna and Environment, 25, 133-138.

Möller, A. (1921) Briefe und noch nicht veröffenliche Abhandlungen aus dem Nachlass 1854-1897. In: Möller, A. (Ed.), Fritz Müller: Werke, Briefe und Leben, Vol.2. G. Fischer, Jena, pp. 383-642.

Morse, J.C. (2006) Trichoptera World Checklist, International Symposia on Trichoptera, Trichoptera Checklist Coordinating Committee. Available from http://entweb.clemson.edu/database/trichopt/ (accessed 25 September 2007)

Müller, F. (1879a) Über Phryganiden. Zoologischer Anzeiger, 2, 38-40, 180-182, 283-284, 405-407.

Müller, F. (1879b) Notes on the cases of some south Brazilian Trichoptera. Transactions of the Entomological Society of London, 1879, 131-144.

Müller, F. (1880a) Sobre as casas construidas pelas larvas de insectos Trichopteros da Provincia de Santa Catharina. Archivos do Museu Nacional, Rio de Janeiro, 3, 99-134, 210-214, plates 8-11.

Müller, F. (1880b) Über die von den Trichopterenlarven der Provinz Santa Catharina verfertigen Gehäuse. Zeitschrift für Wissenschaftliche Zoologie, 35, 47-87.

Swofford, D.L. (2001) PAUP*. Phylogenetic Analysis Using Parsimony (*and Other Methods), Version 4.0. Sinauer Associates, Sunderland, Massachusetts,CD-ROM.

Thienemann, A. (1905) Trichopterenstudien II. Rhyacopsyche hageni Fr. Müller. Zeitschrift für Wissenschaftliche Insektenbiologie, 1, 287-289.

Ulmer, G. (1957) Köcherfliegen (Trichopteren) von den Sunda Inseln. Teil III. Archiv für Hydrobiologie, 23 (Supplement), 109-470.

Wiggins, Glenn B. (1996) Larvae of the North American Caddisfly Genera (Trichoptera). Second Edition. University of Toronto Press, Toronto and Buffalo, $457 \mathrm{pp}$. 

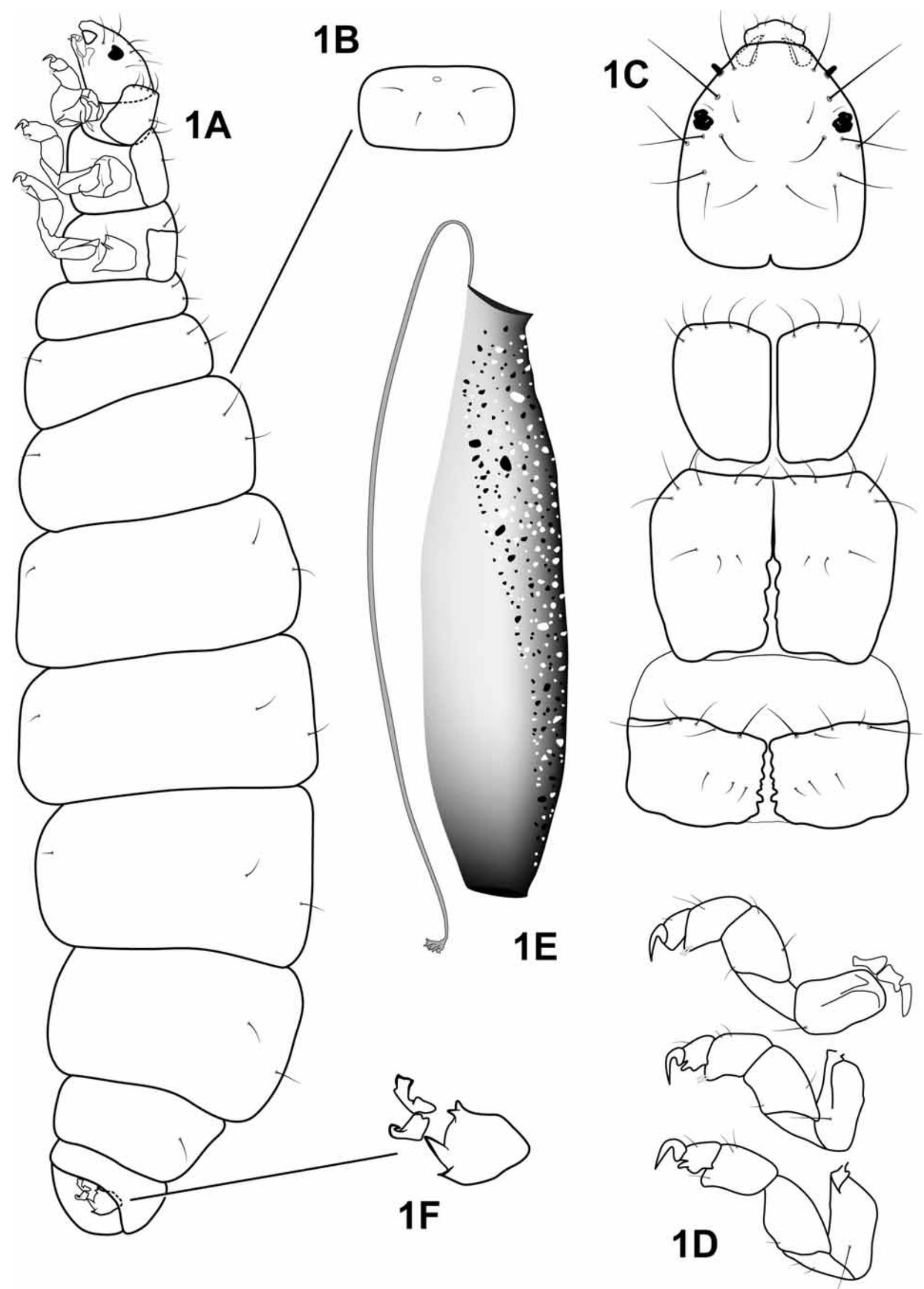

FIGURE 1. Rhyacopsyche sp. Larva: A-lateral; B—abdominal segment, dorsal; C—head and thorax, dorsal; D—pro-, meso-, and metathoracic legs, lateral; E—case; F-anal claw. 

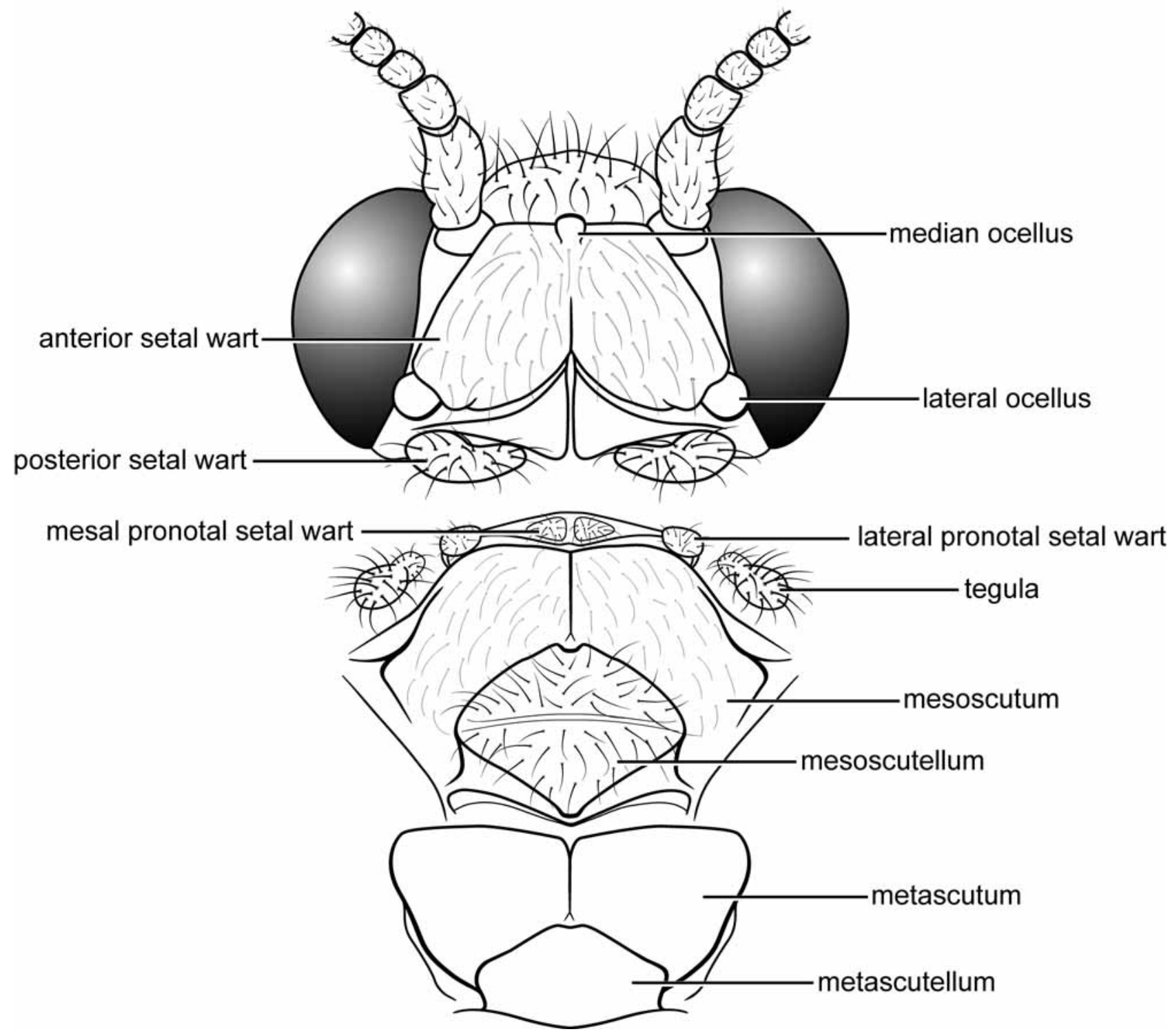

FIGURE 2. Rhyacopsyche hagenii Müller. Adult: head and thorax, dorsal. 


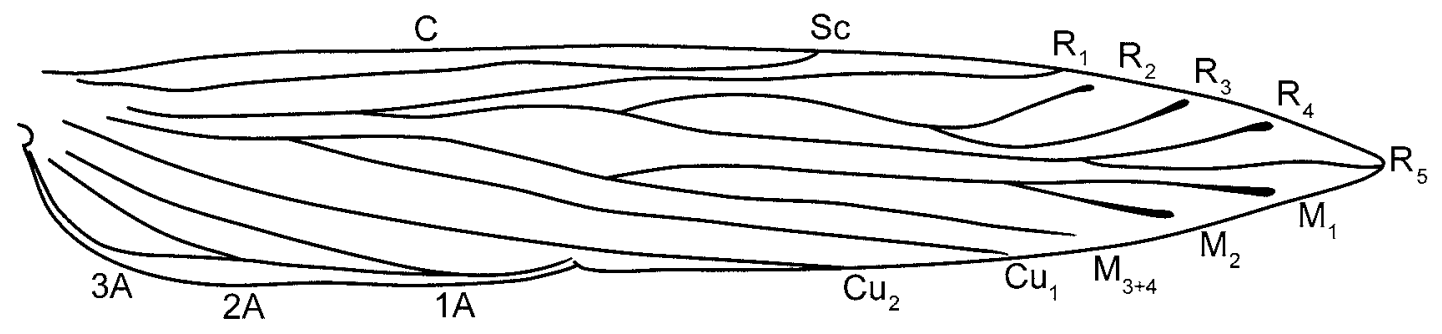

\section{$3 A$}

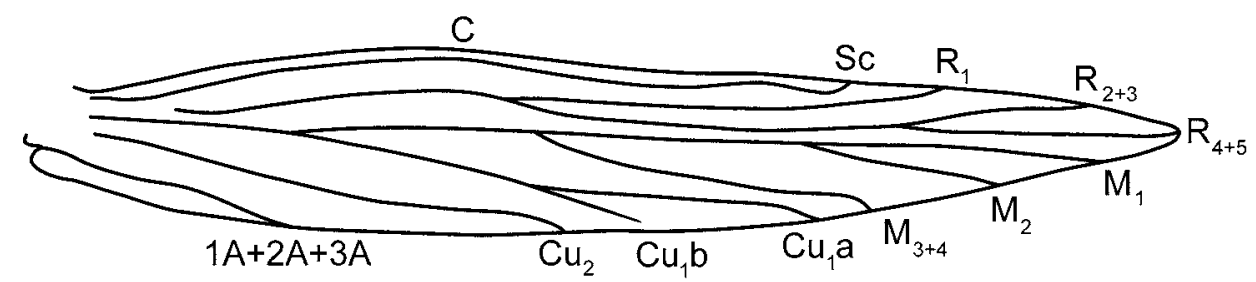

3B

FIGURE 3. Rhyacopsyche andina Flint. Wings: A-forewing; B-hind wing. 


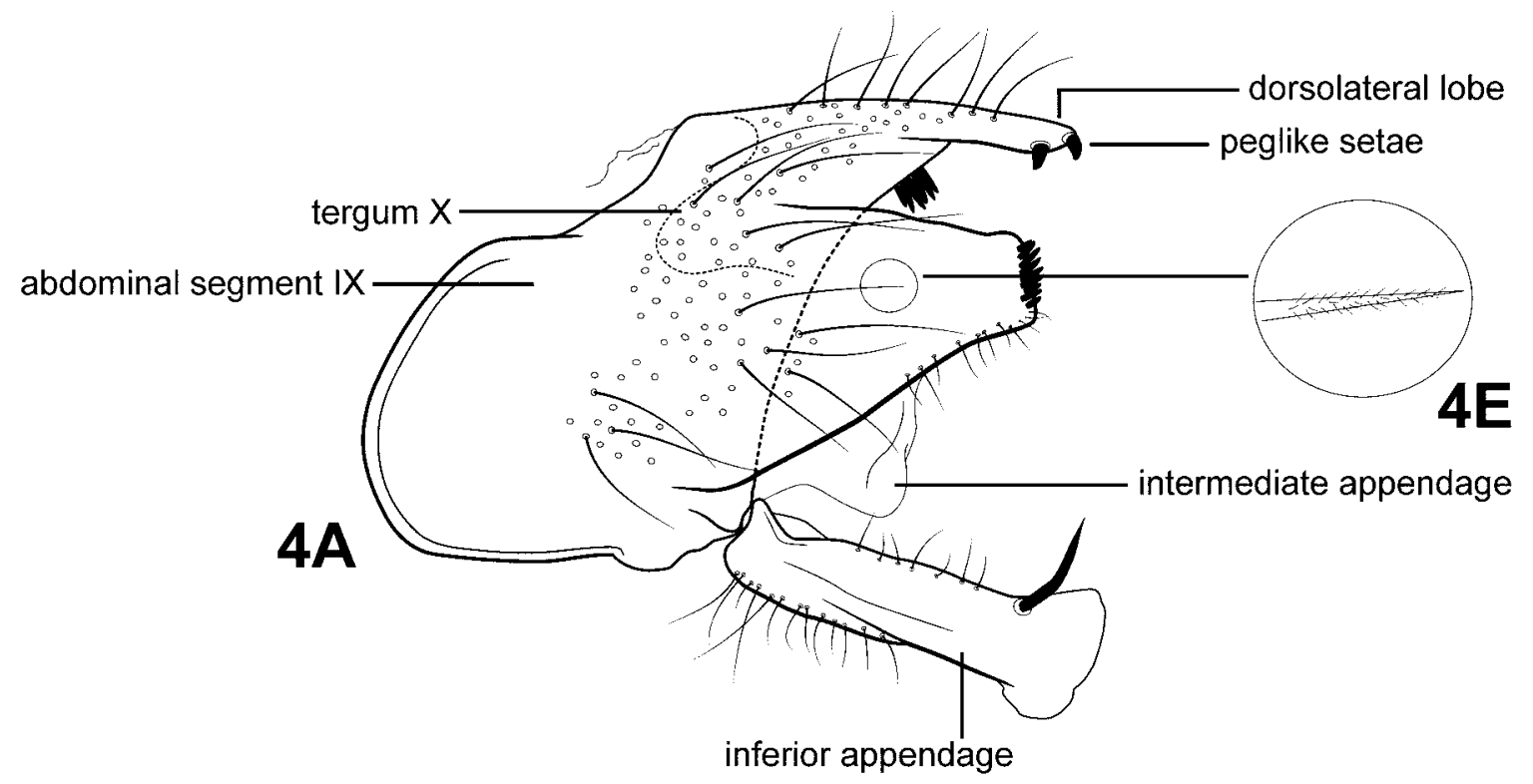

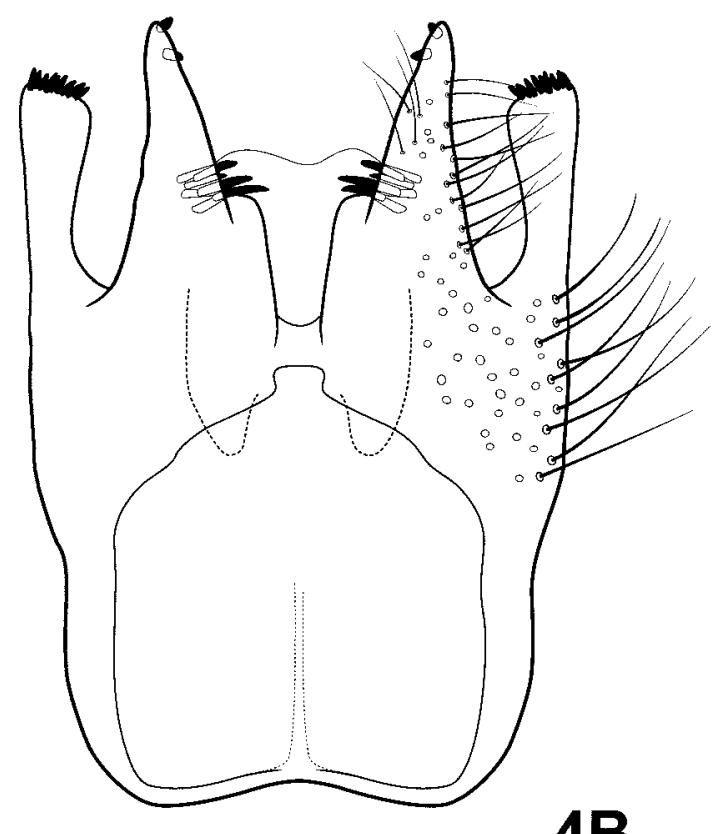

4B

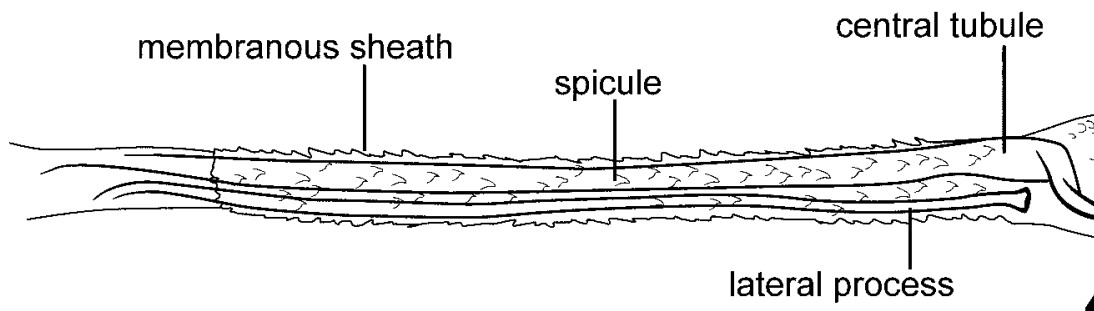

4D

FIGURE 4. Rhyacopsyche hagenii Müller. Male genitalia: A-lateral; B—dorsal; C—ventral; D—phallus, dorsal; Eplumose seta. 


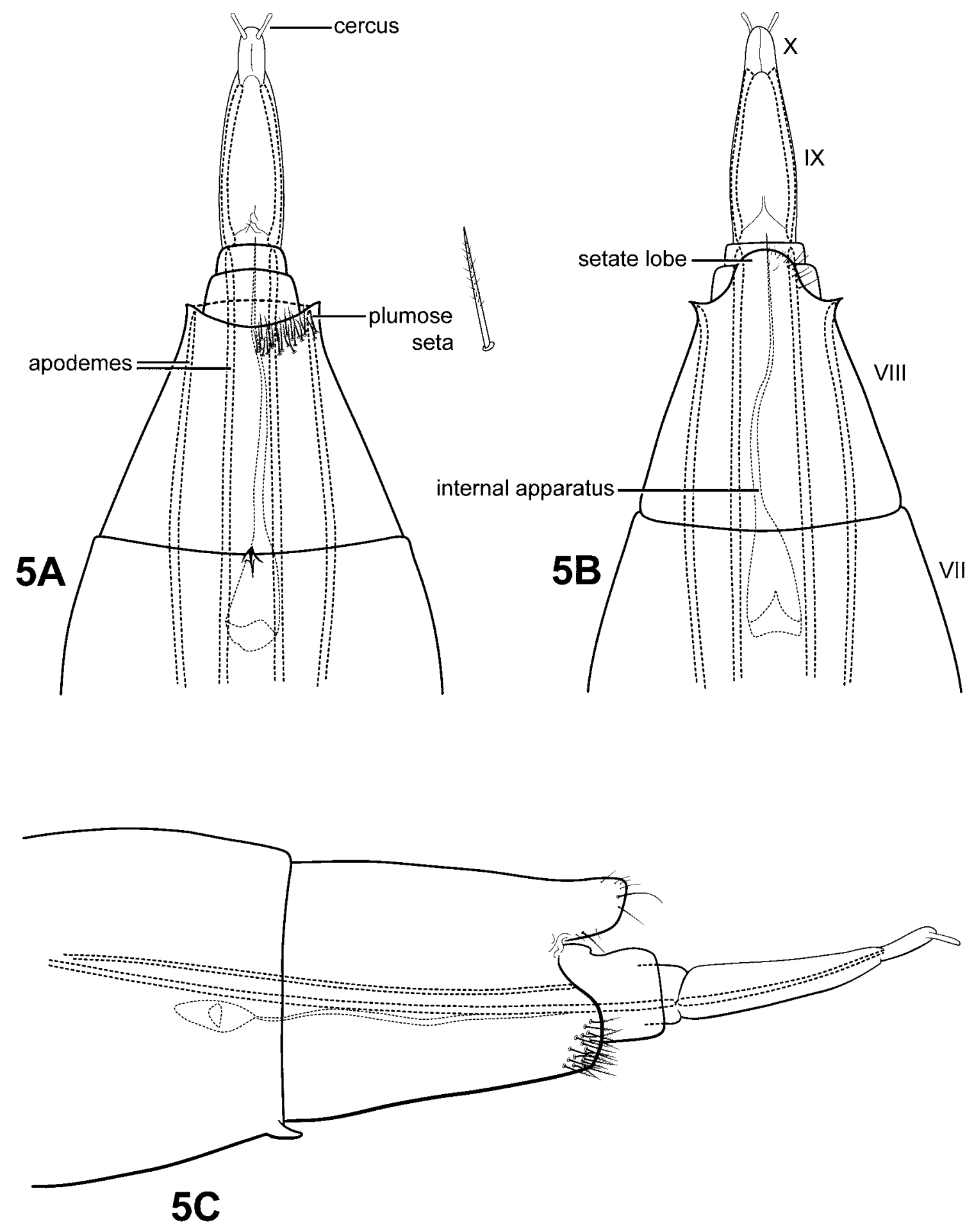

FIGURE 5. Rhyacopsyche hagenii Müller. Female genitalia: A-ventral; B-dorsal; C-lateral. 

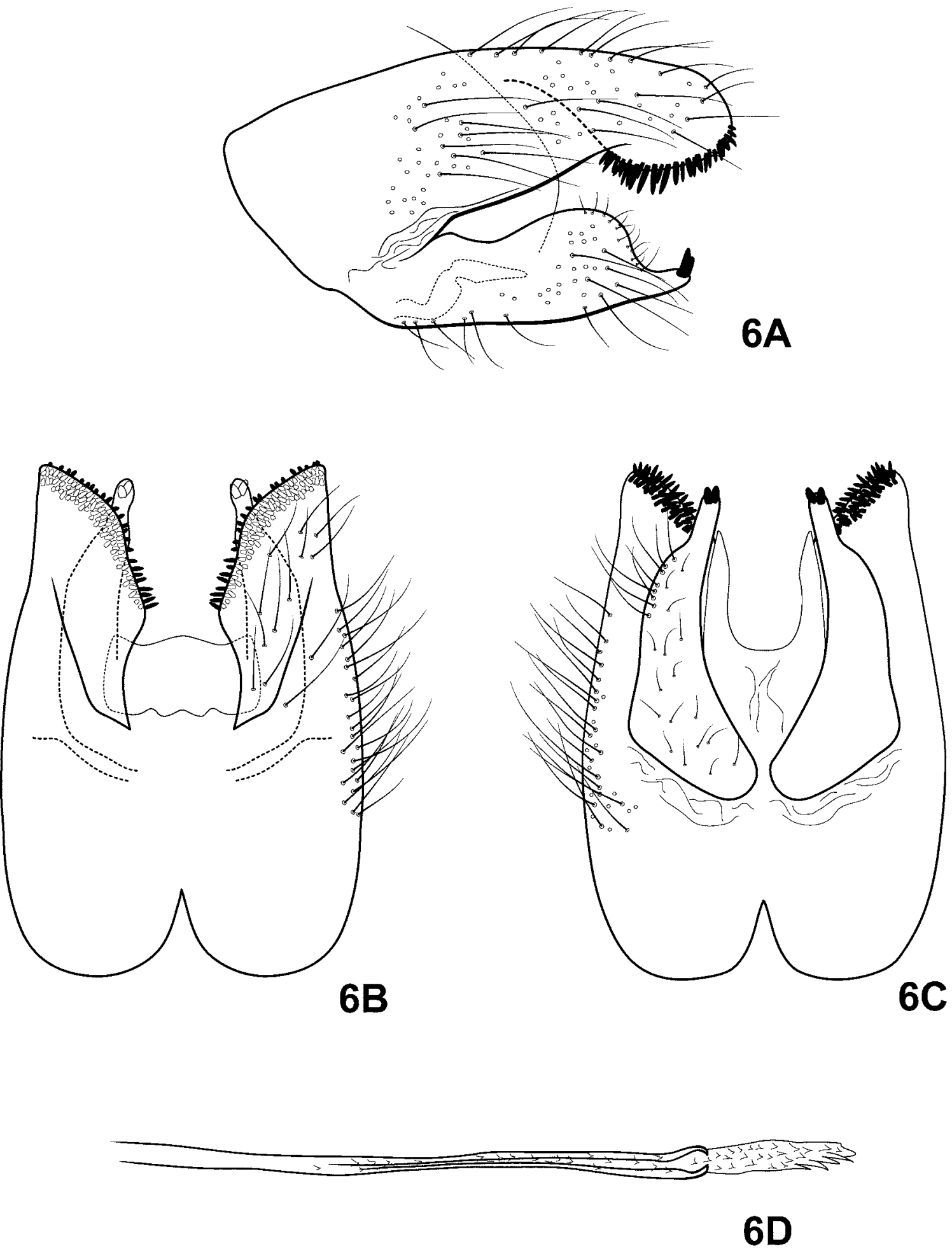

FIGURE 6. Rhyacopsyche andina Flint. Male genitalia: A-lateral; B-dorsal; C—ventral; D—phallus, dorsal. 

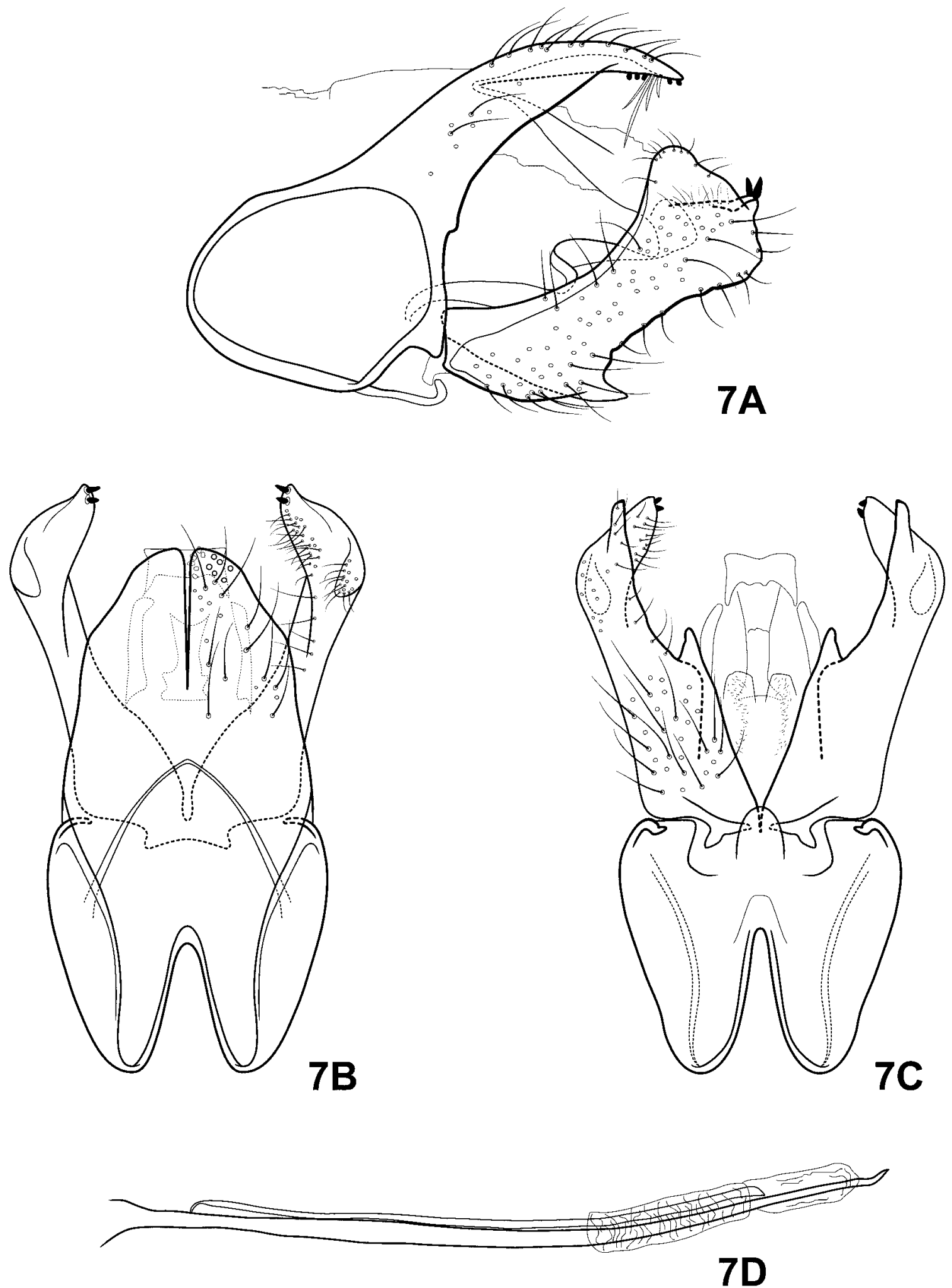

FIGURE 7. Rhyacopsyche benwa, new species. Male genitalia: A-lateral; B—dorsal; C—ventral; D—phallus, dorsal. 

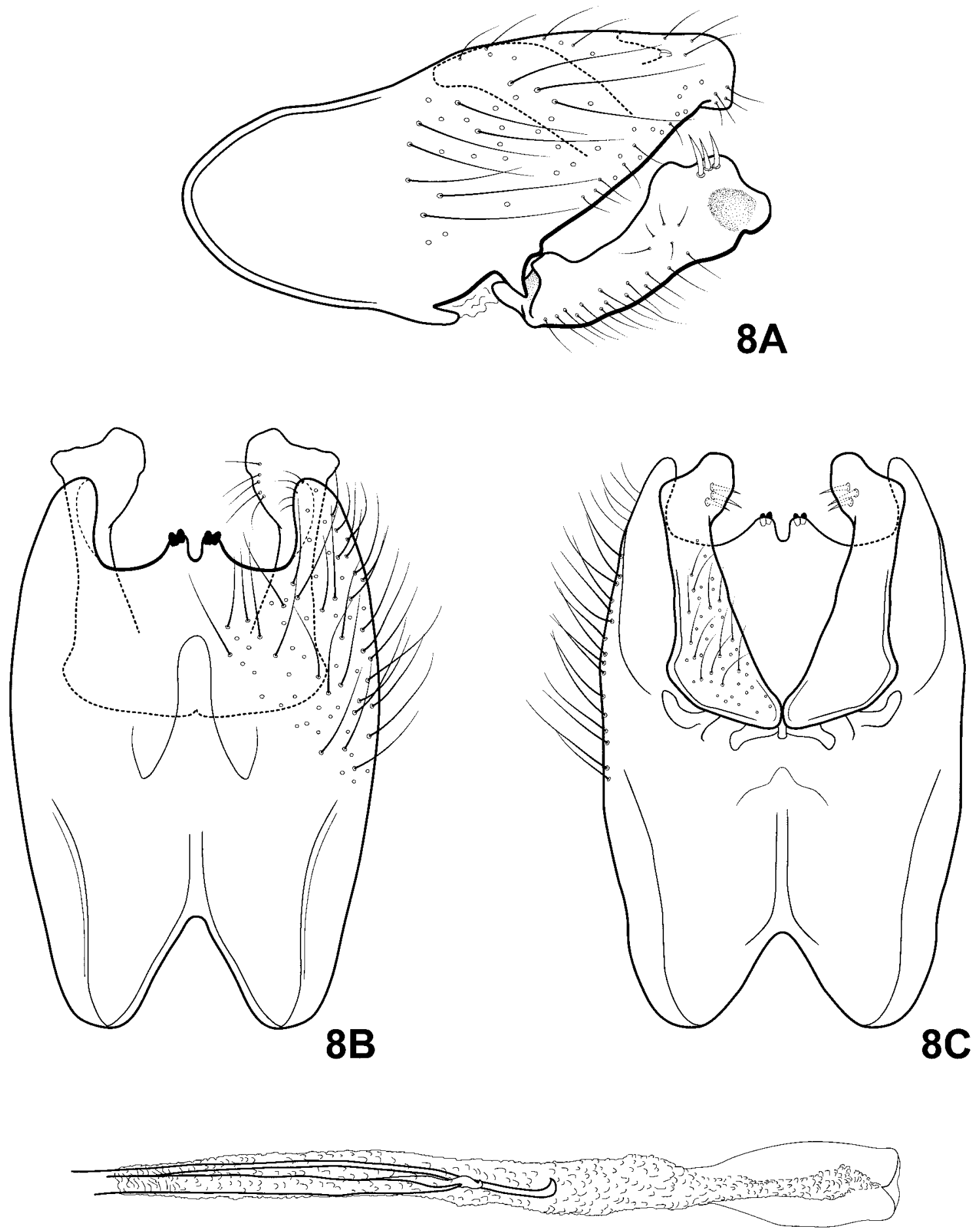

8D

FIGURE 8. Rhyacopsyche bulbosa, new species. Male genitalia: A-lateral; B—dorsal; C—ventral; D—phallus, dorsal. 

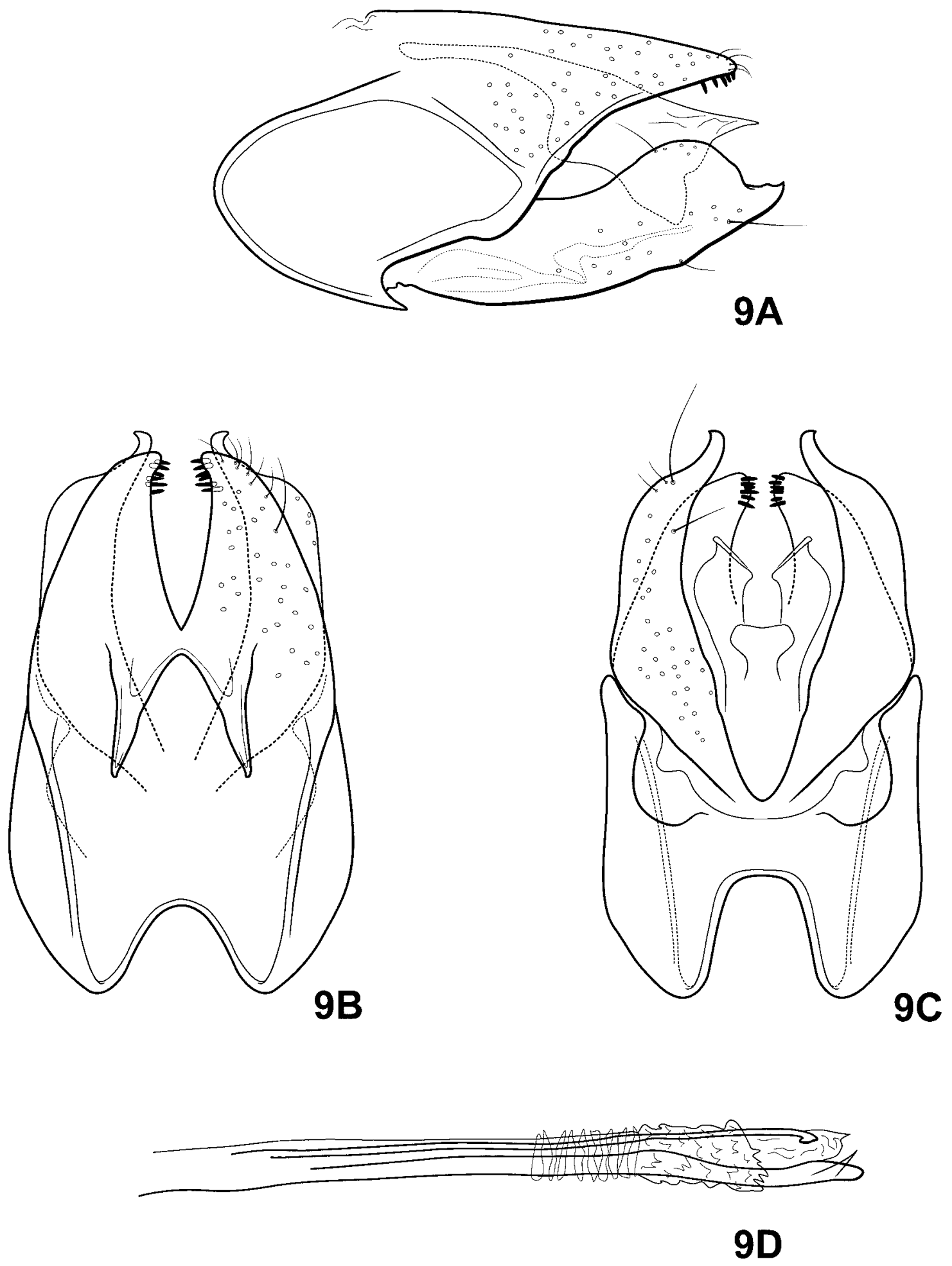

FIGURE 9. Rhyacopsyche chichotla Bueno \& Hamilton. Male genitalia: A-lateral; B-dorsal; C—ventral; D—phallus, dorsal. 

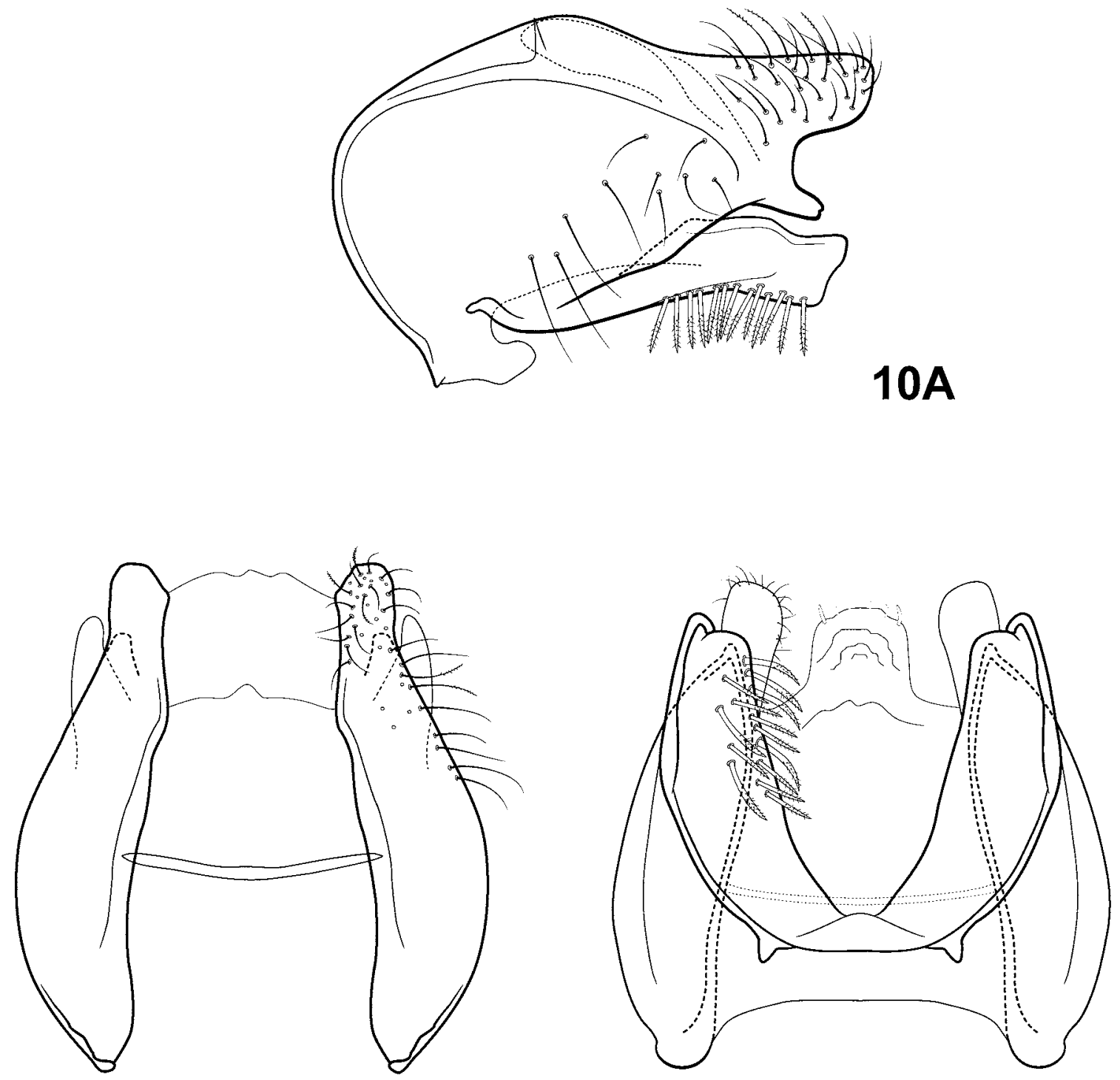

10B

$10 \mathrm{C}$

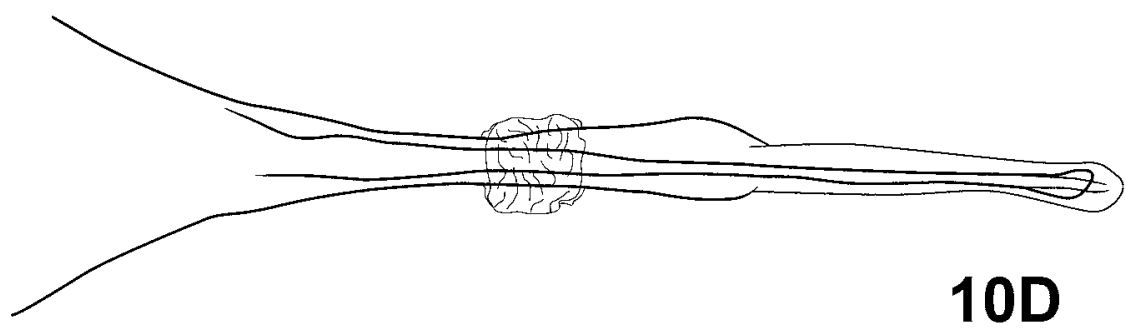

FIGURE 10. Rhyacopsyche colei, new species. Male genitalia: A—lateral; B—dorsal; C—ventral; D—phallus, dorsal. 

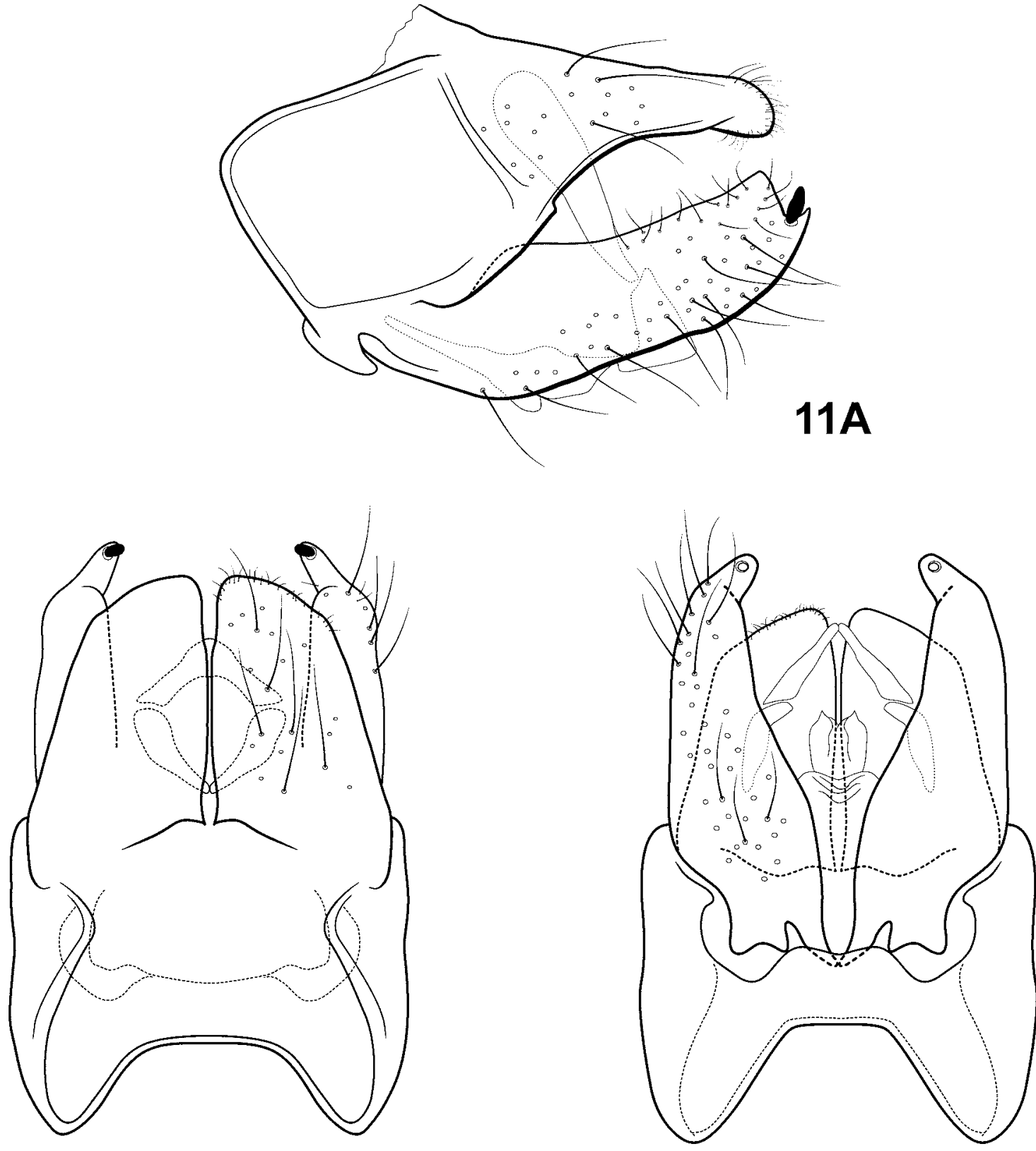

11B

$11 \mathrm{C}$

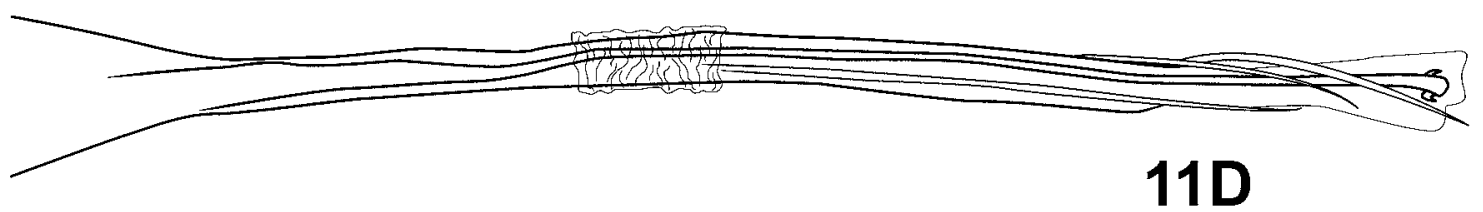

FIGURE 11. Rhyacopsyche colombiana, new species. Male genitalia: A—lateral; B-dorsal; C—ventral; D—phallus, dorsal. 


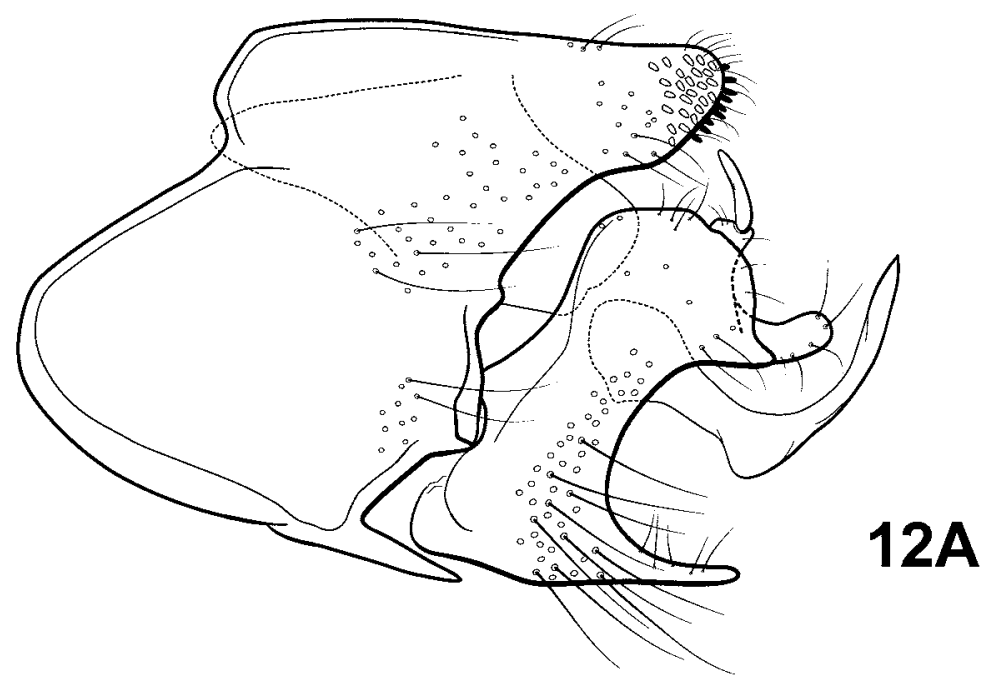

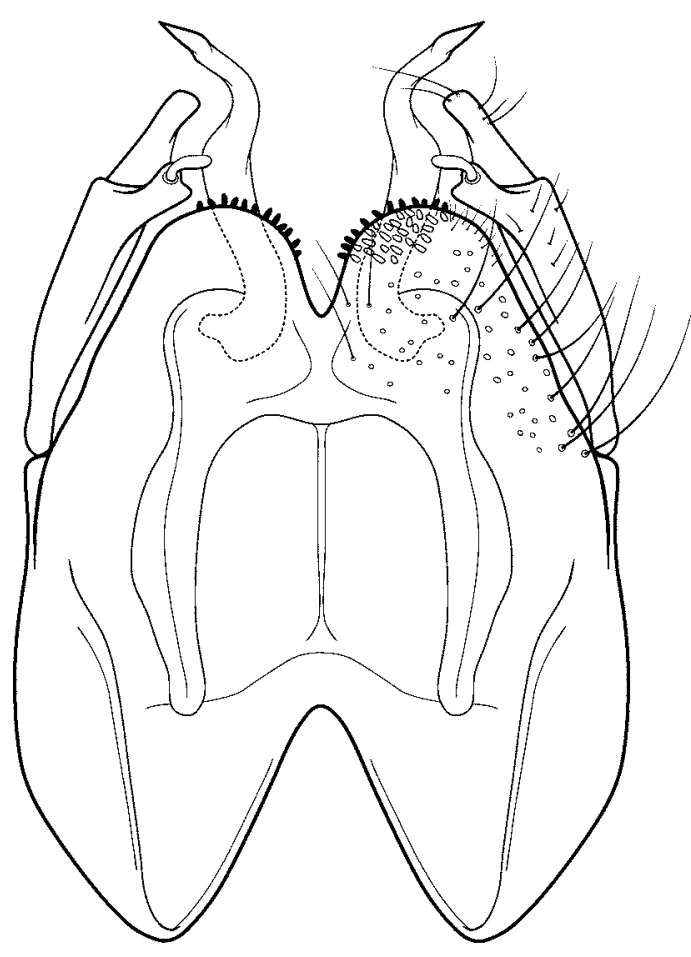

12B

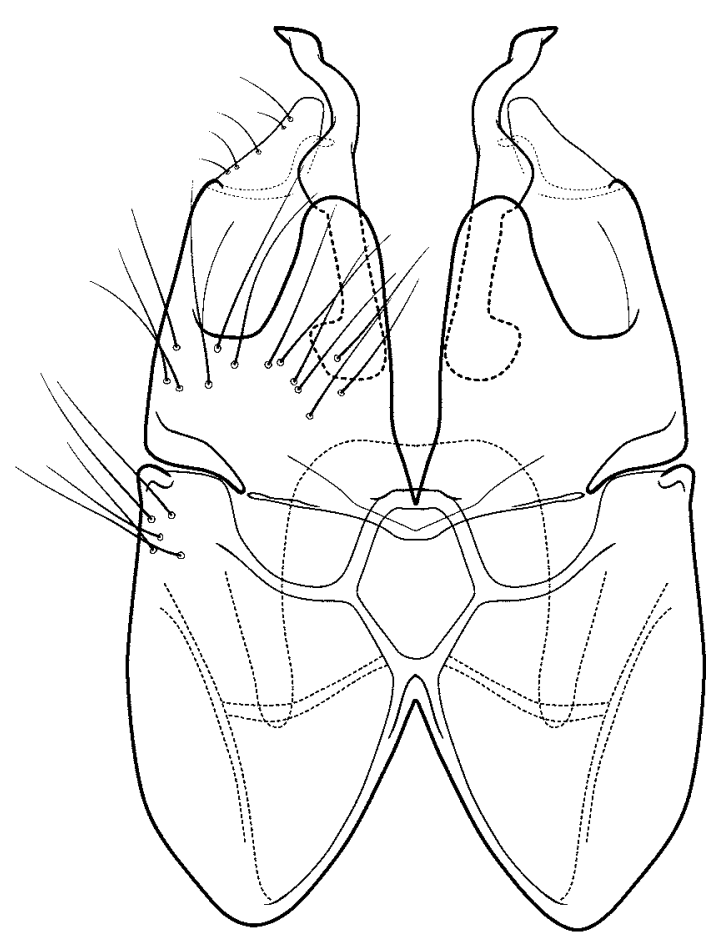

12C

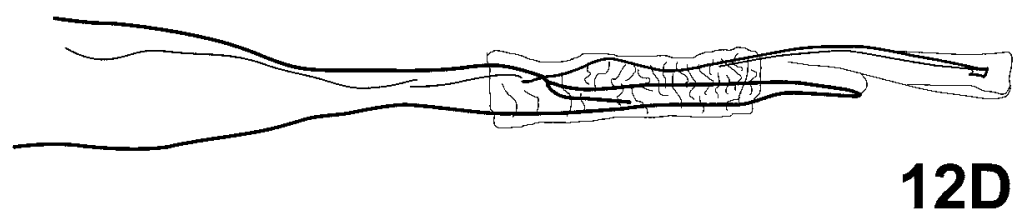

FIGURE 12. Rhyacopsyche colubrinosa, new species. Male genitalia: A—lateral; B—dorsal; C—ventral; D—phallus, dorsal. 

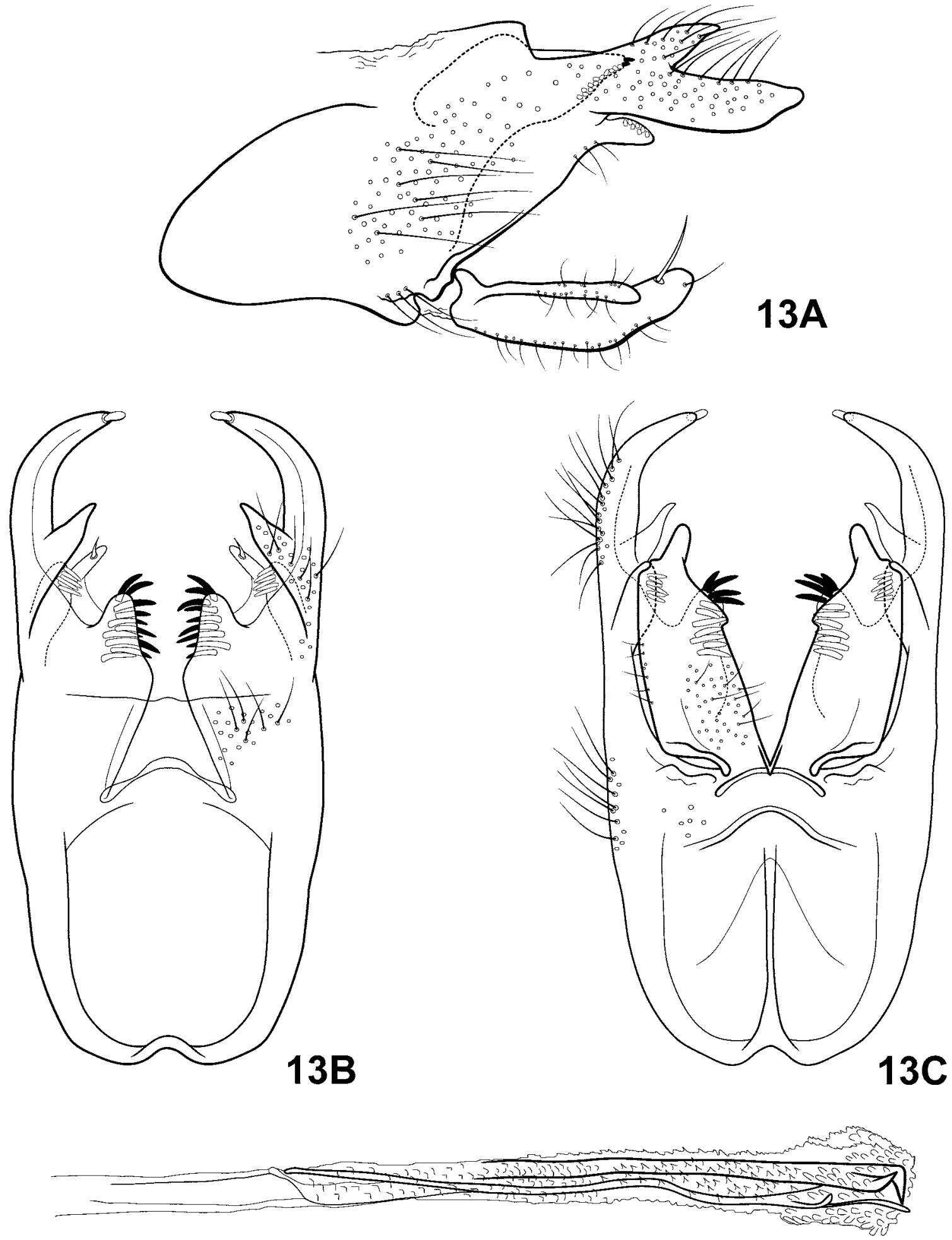

13D

FIGURE 13. Rhyacopsyche dikrosa, new species. Male genitalia: A—lateral; B—dorsal; C—ventral; D—phallus, dorsal. 


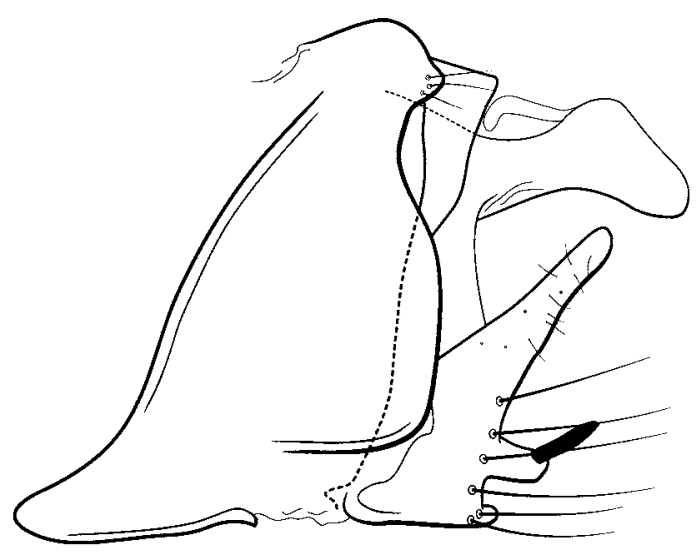

$14 \mathrm{~A}$
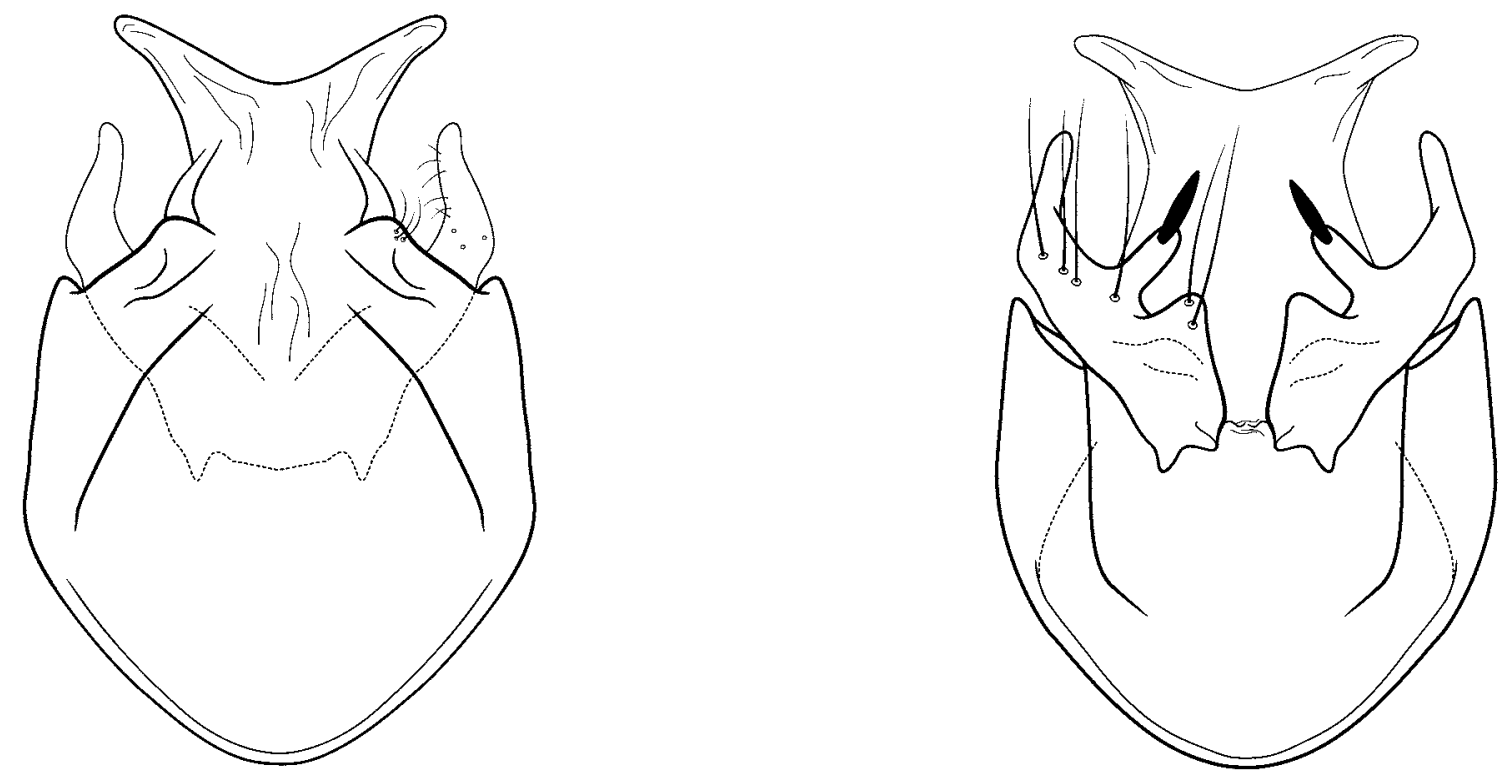

14B

$14 \mathrm{C}$

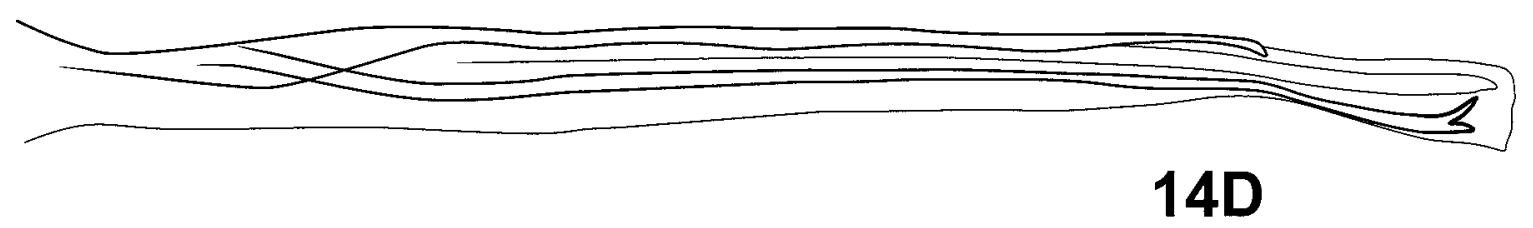

FIGURE 14. Rhyacopsyche duplicispina Flint. Male genitalia: A-lateral; B—dorsal; C—ventral; D—phallus, dorsal. 


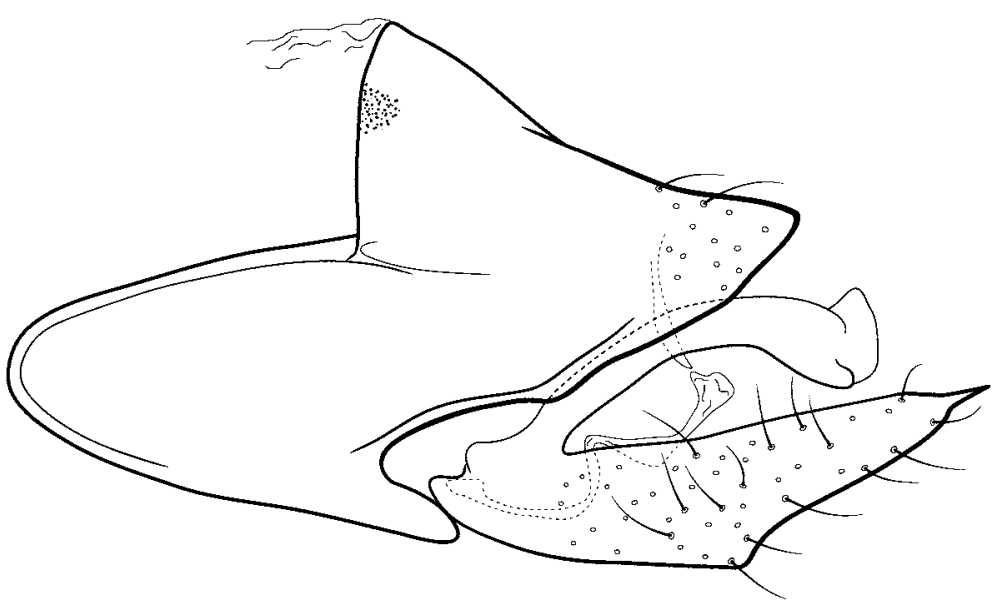

15A
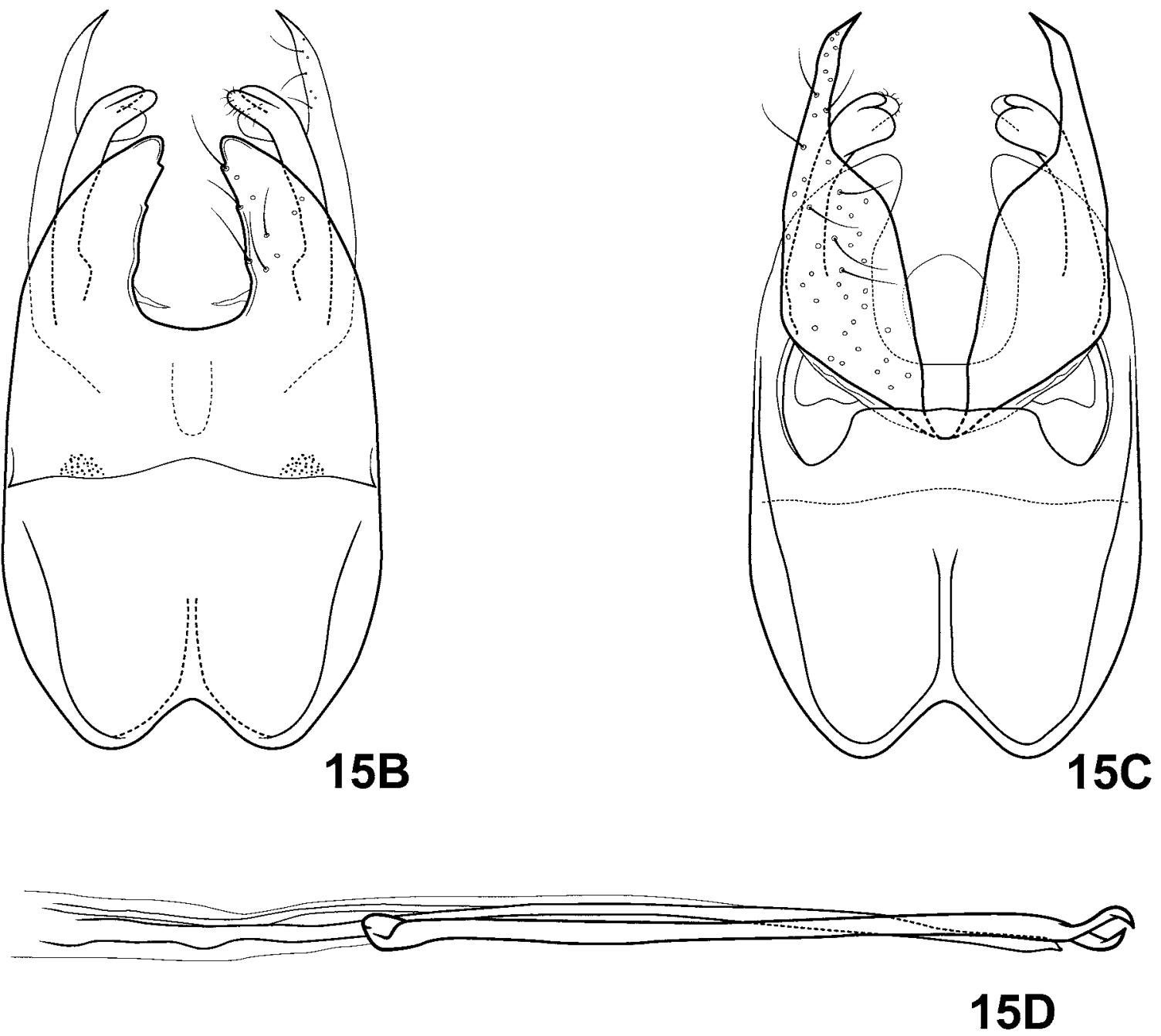

FIGURE 15. Rhyacopsyche flinti, new species. Male genitalia: A—lateral; B—dorsal; C—ventral; D—phallus, dorsal. 

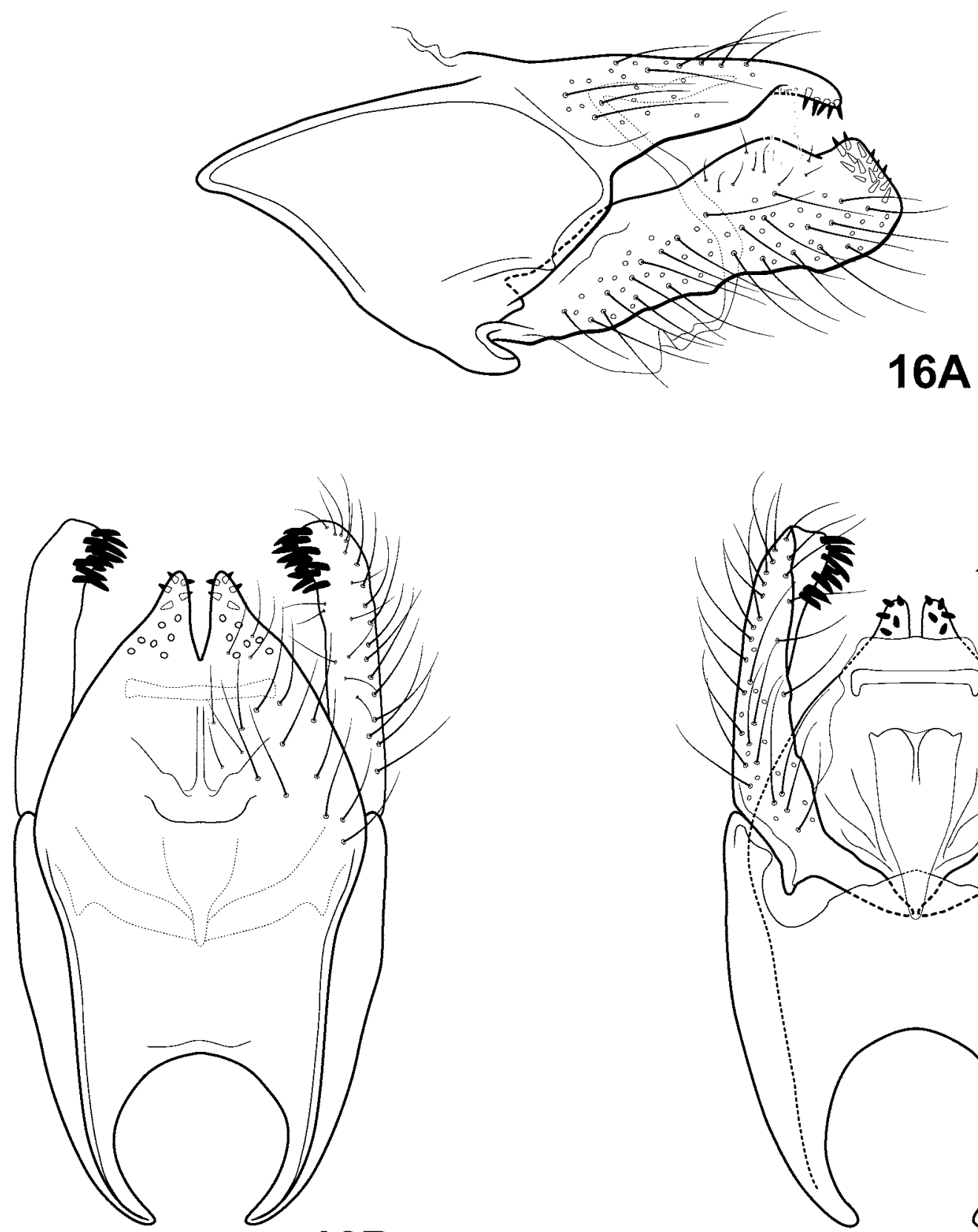

16B
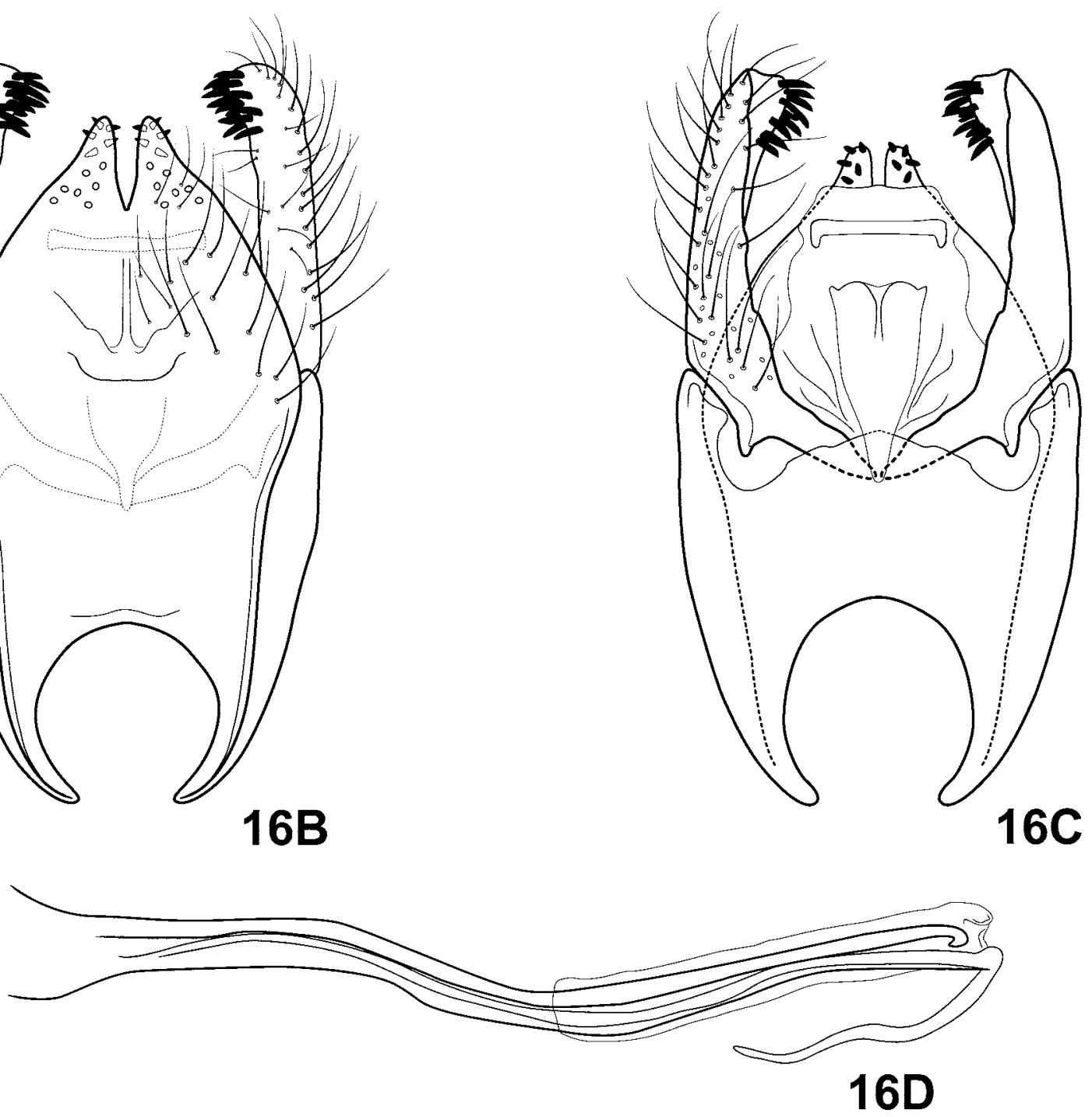

FIGURE 16. Rhyacopsyche hasta, new species. Male genitalia: A—lateral; B—dorsal; C—ventral; D—phallus, dorsal. 


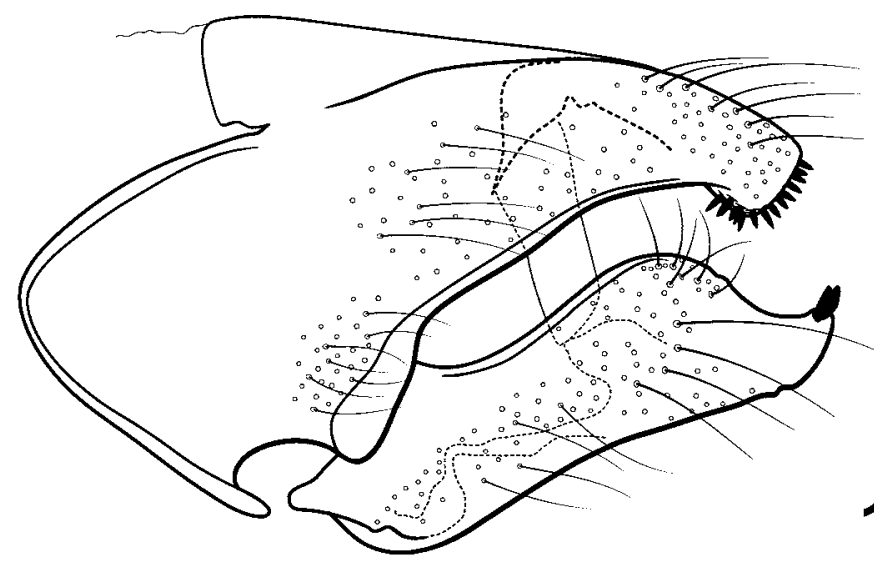

17A
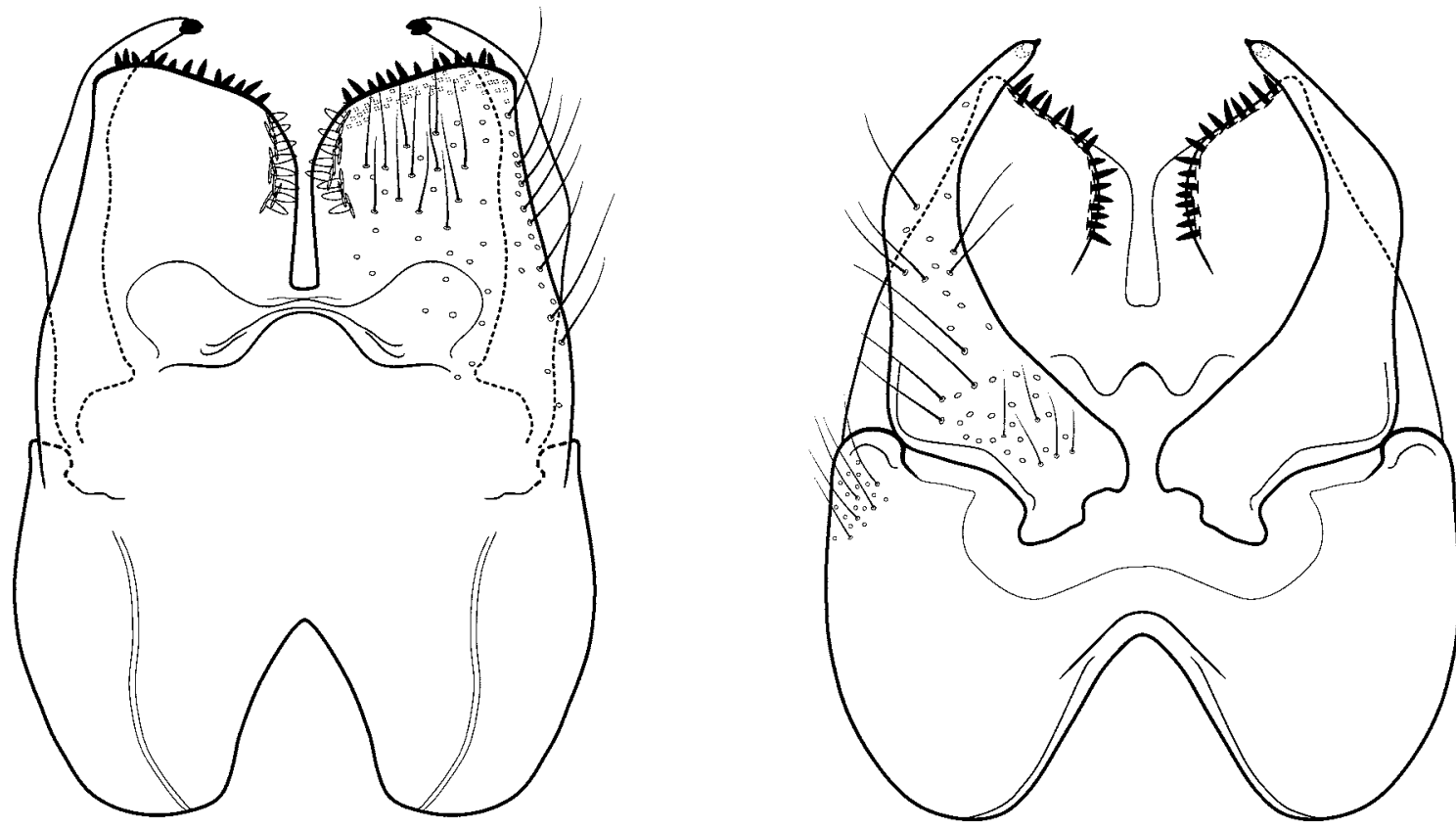

17B

17C

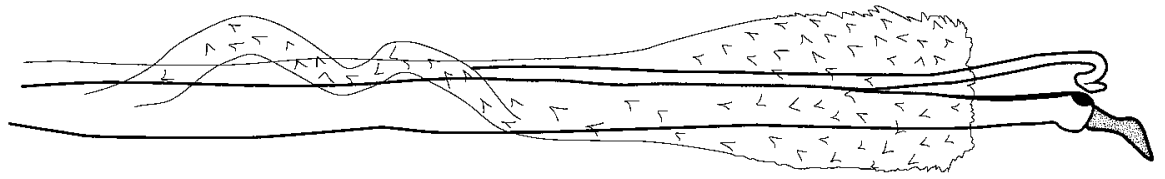

17D

FIGURE 17. Rhyacopsyche intraspira, new species. Male genitalia: A-lateral; B-dorsal; C-ventral; D—phallus, dorsal. 


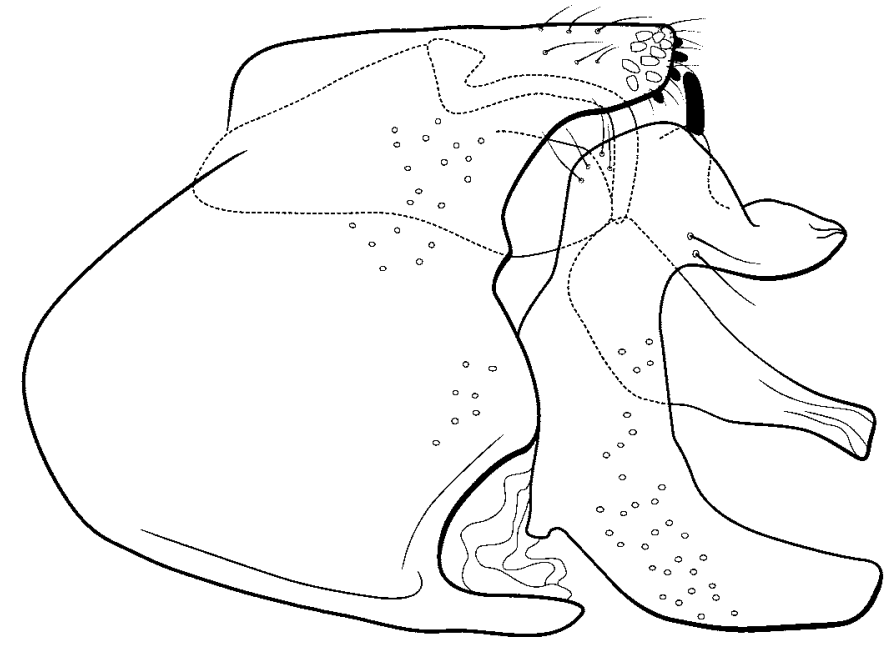

18A

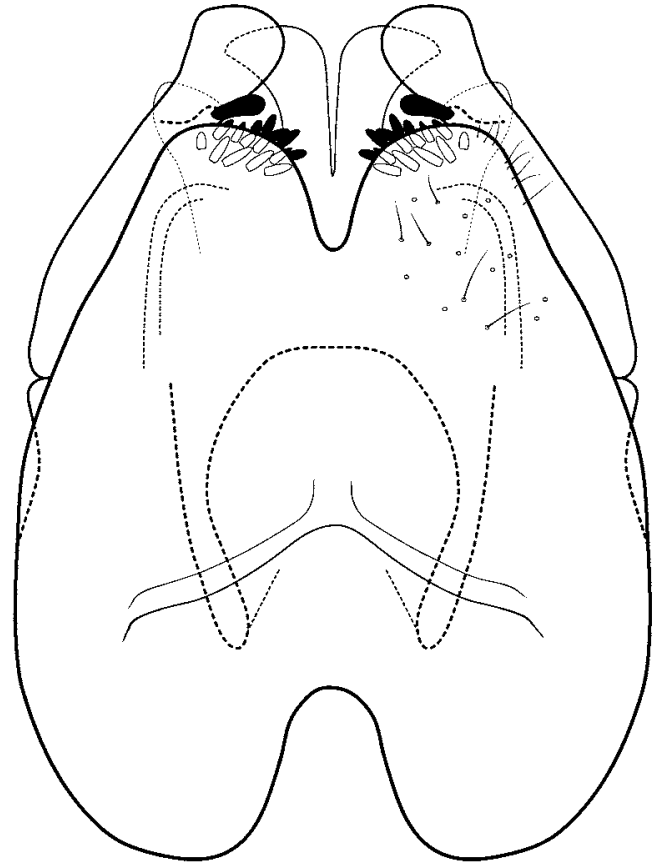

18B

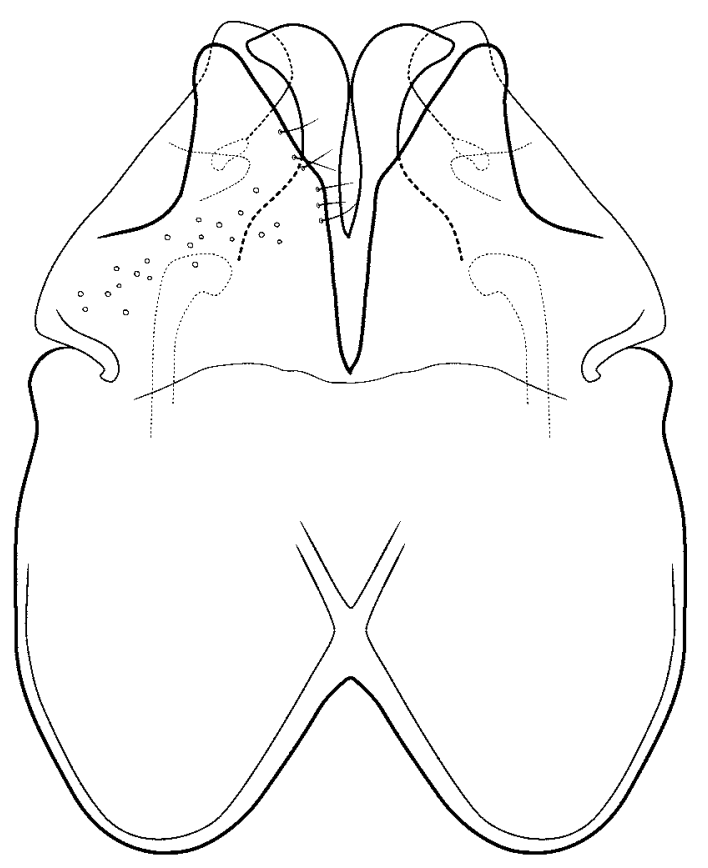

$18 \mathrm{C}$

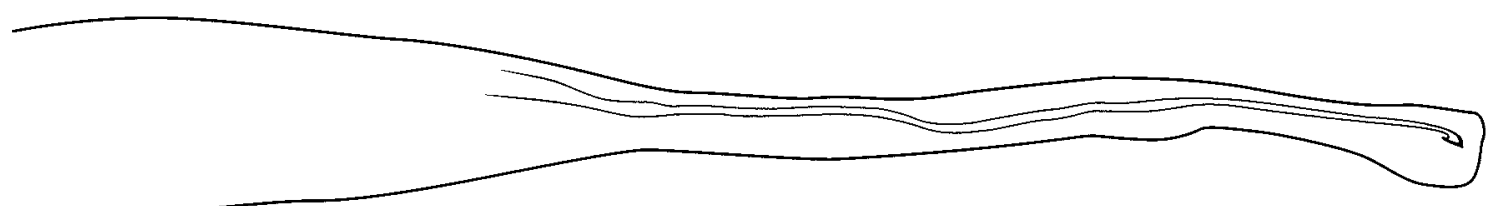

18D

FIGURE 18. Rhyacopsyche jimena Flint. Male genitalia: A—lateral; B—dorsal; C—ventral; D—phallus, dorsal. 


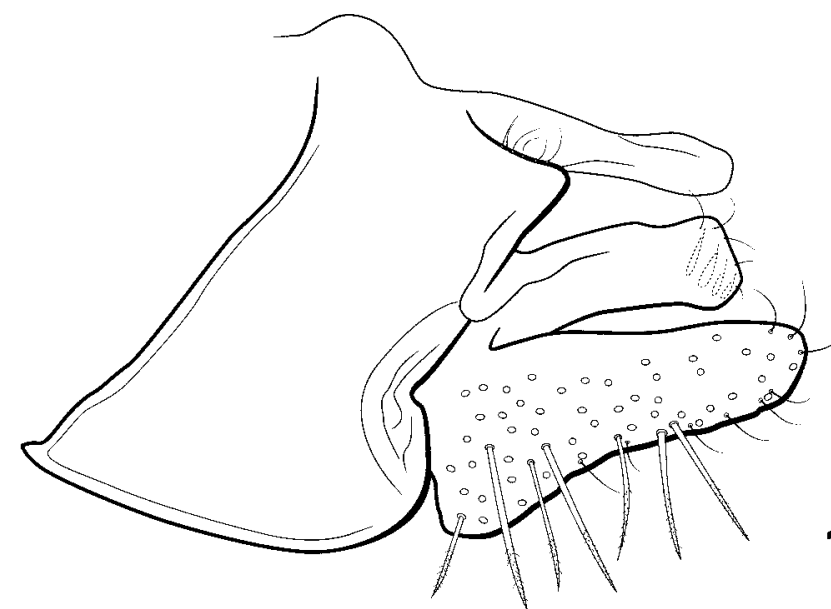

19A

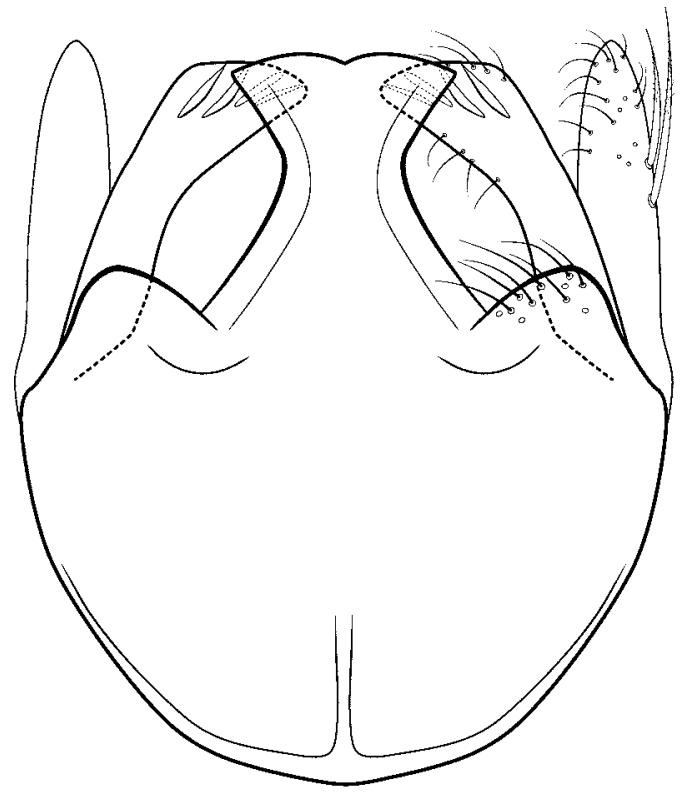

19B
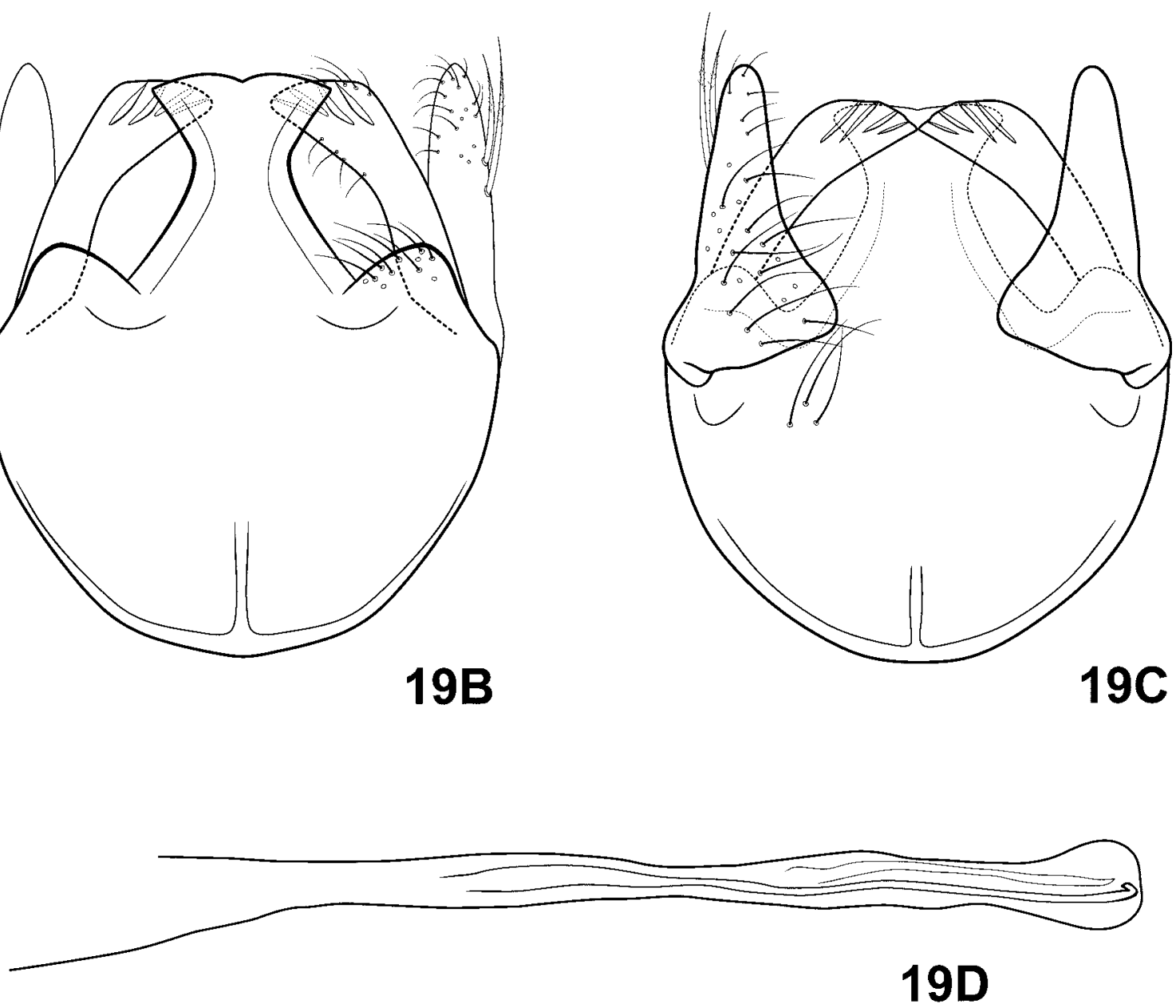

FIGURE 19. Rhyacopsyche matthiasi Flint. Male genitalia: A—lateral; B-dorsal; C—ventral; D—phallus, dorsal. 

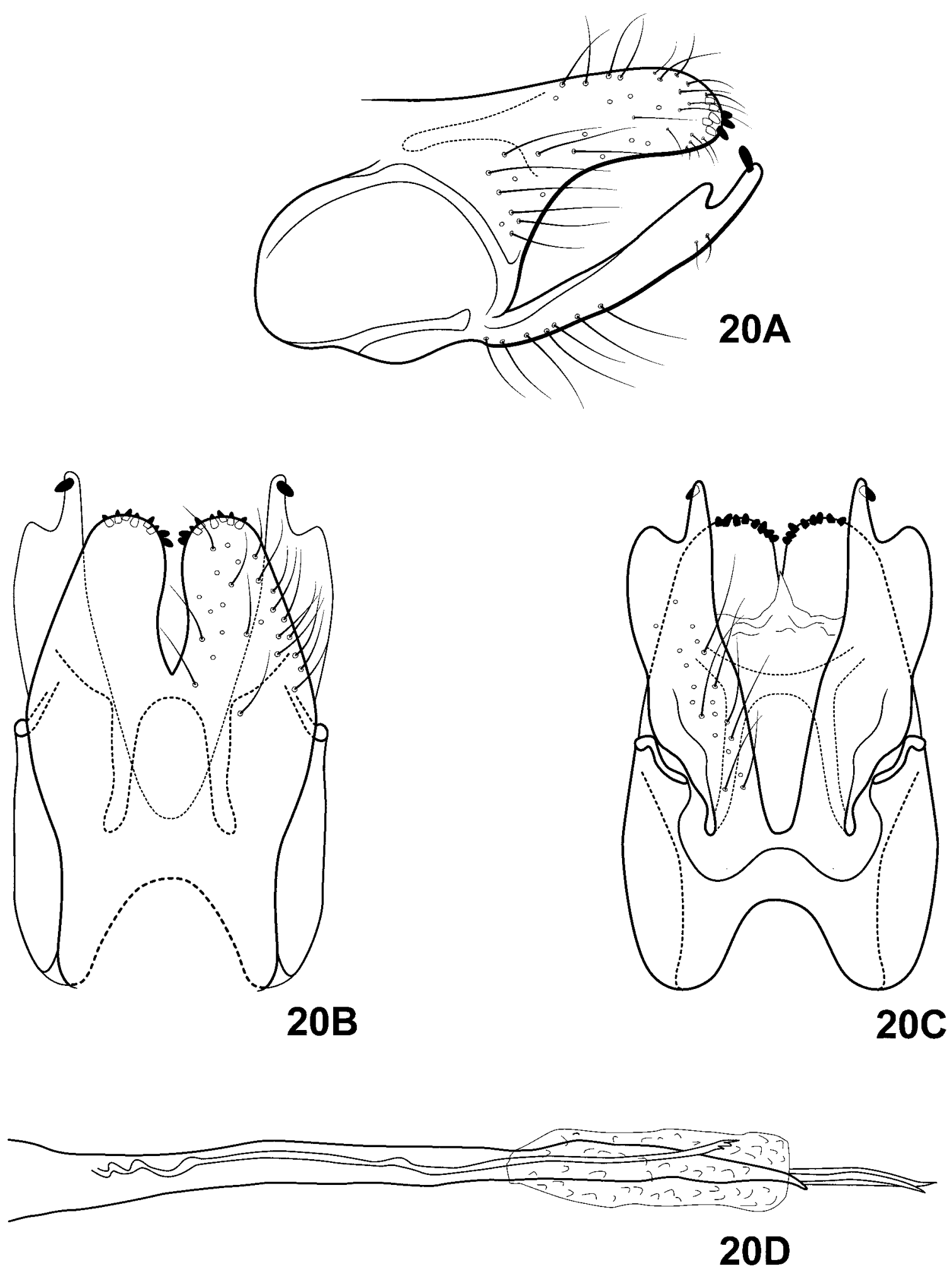

FIGURE 20. Rhyacopsyche mexicana (Flint). Male genitalia: A—lateral; B—dorsal; C—ventral; D—phallus, dorsal. 


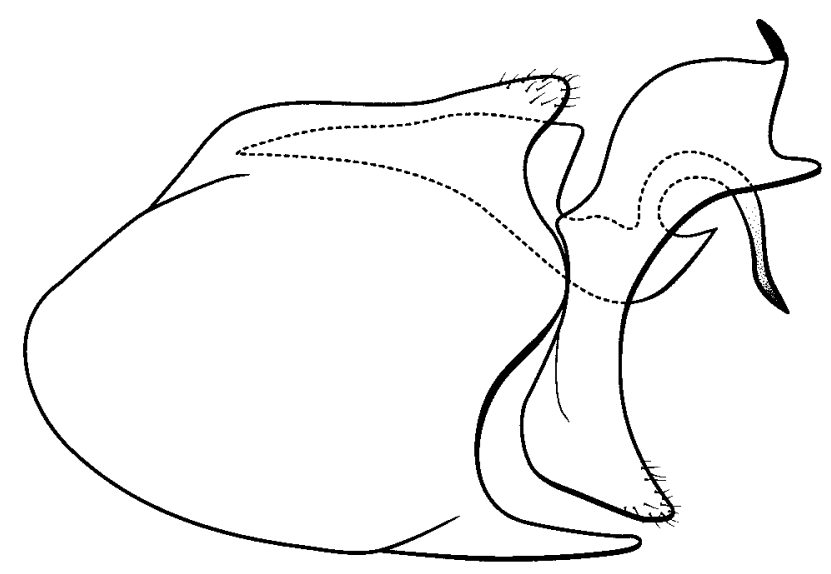

21A
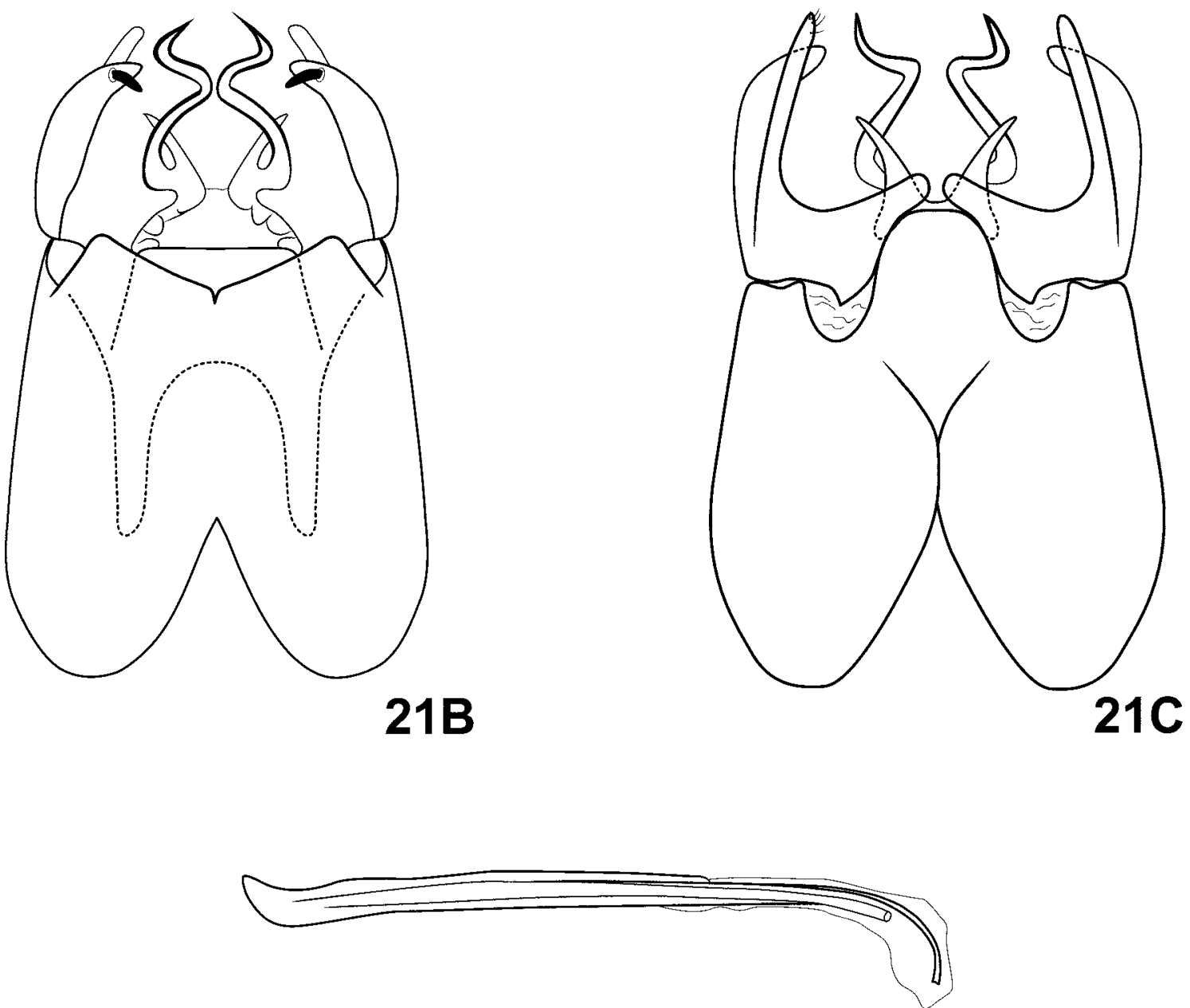

21D

FIGURE 21. Rhyacopsyche mutisi Mey \& Joost. Male genitalia: A—lateral; B—dorsal; C—ventral; D—phallus, ventral. Illustration after Mey \& Joost 1990. 

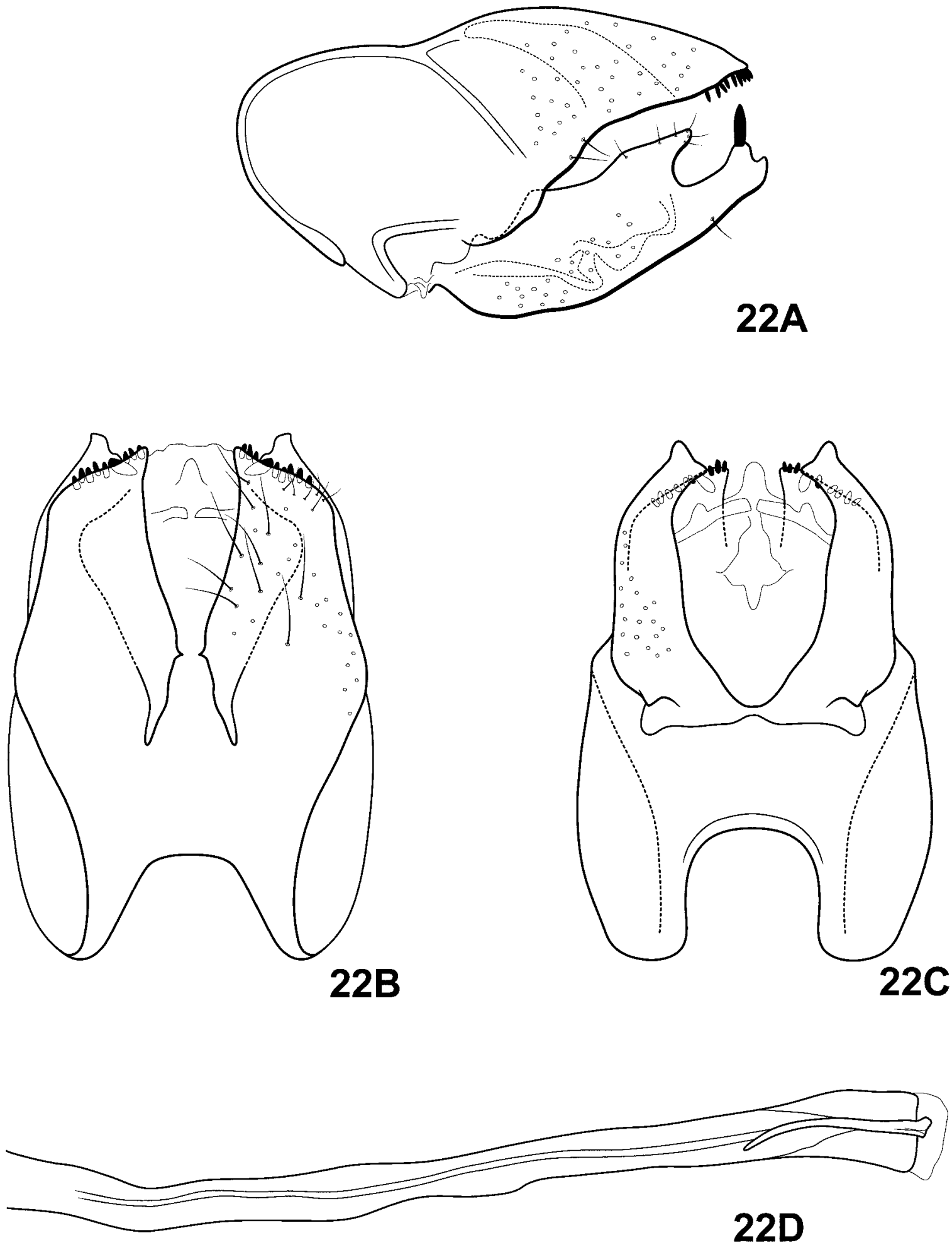

FIGURE 22. Rhyacopsyche obliqua Flint. Male genitalia: A-lateral; B—dorsal; C—ventral; D—phallus, dorsal. 


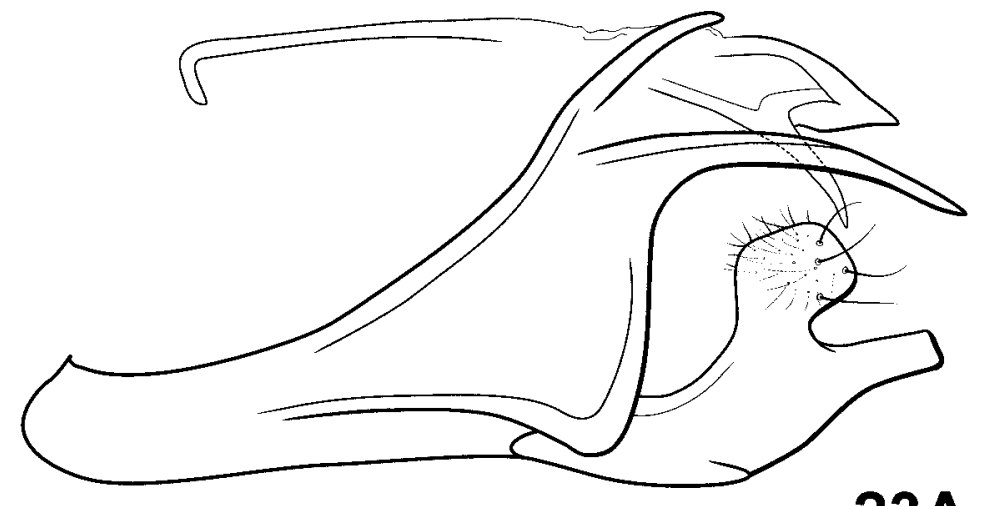

23A
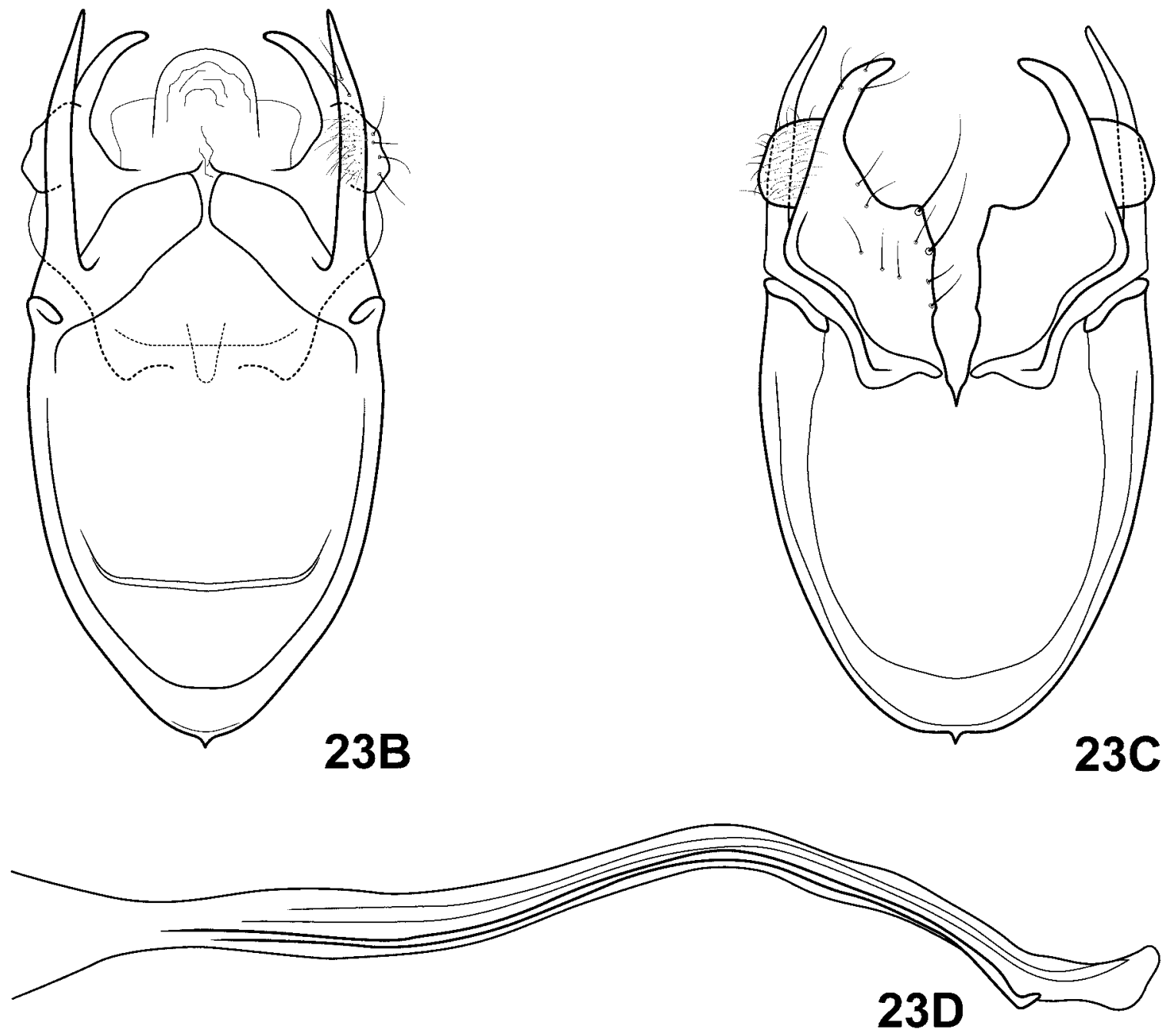

FIGURE 23. Rhyacopsyche otarosa, new species. Male genitalia: A—lateral; B-dorsal; C—ventral; D—phallus, dorsal. 


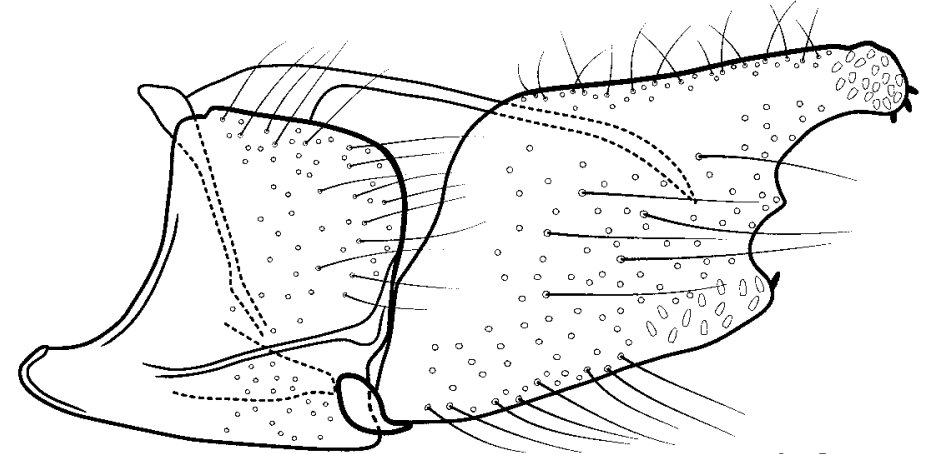

24A
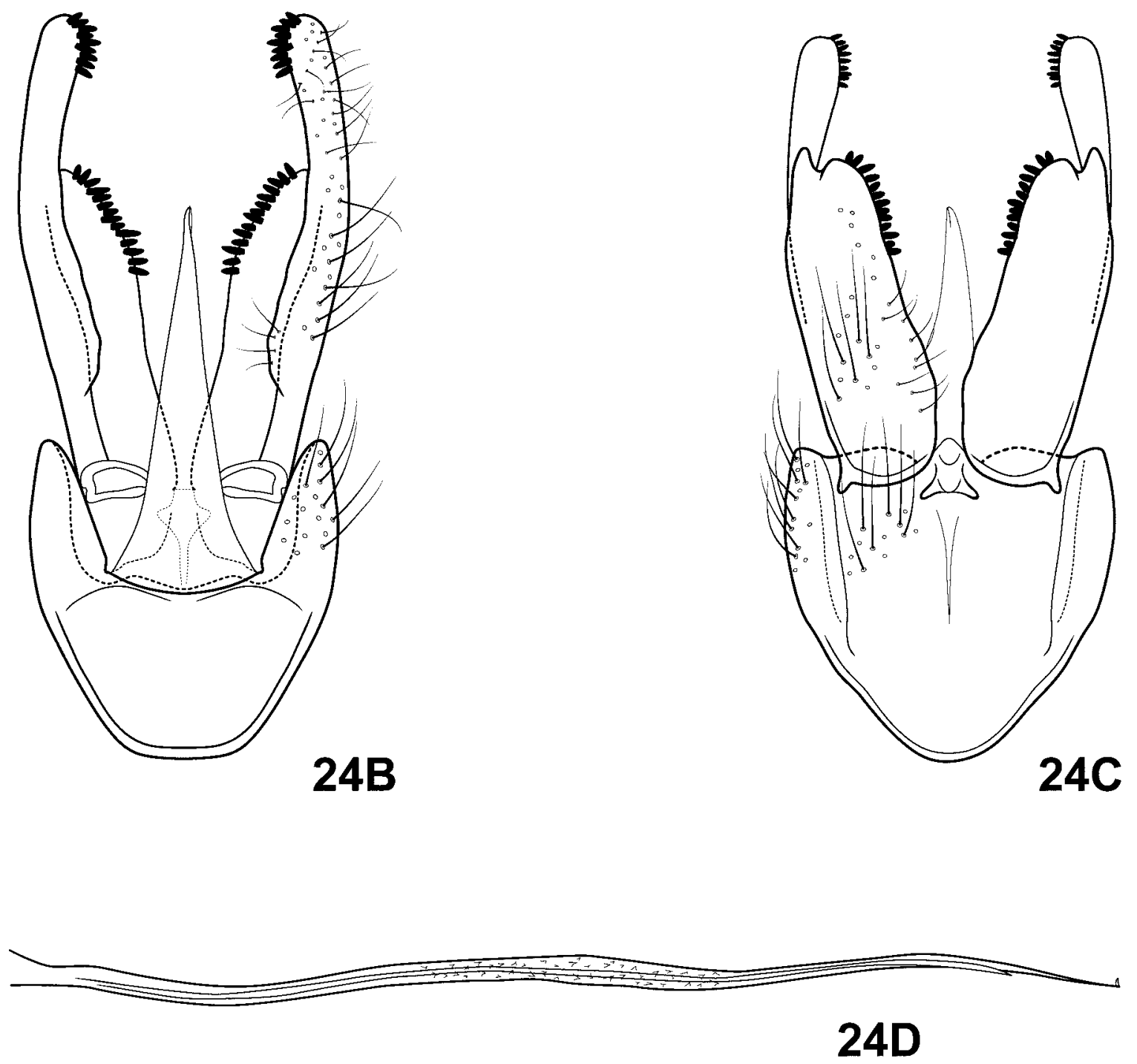

FIGURE 24. Rhyacopsyche patulosa, new species. Male genitalia: A—lateral; B-dorsal; C—ventral; D—phallus, dorsal. 

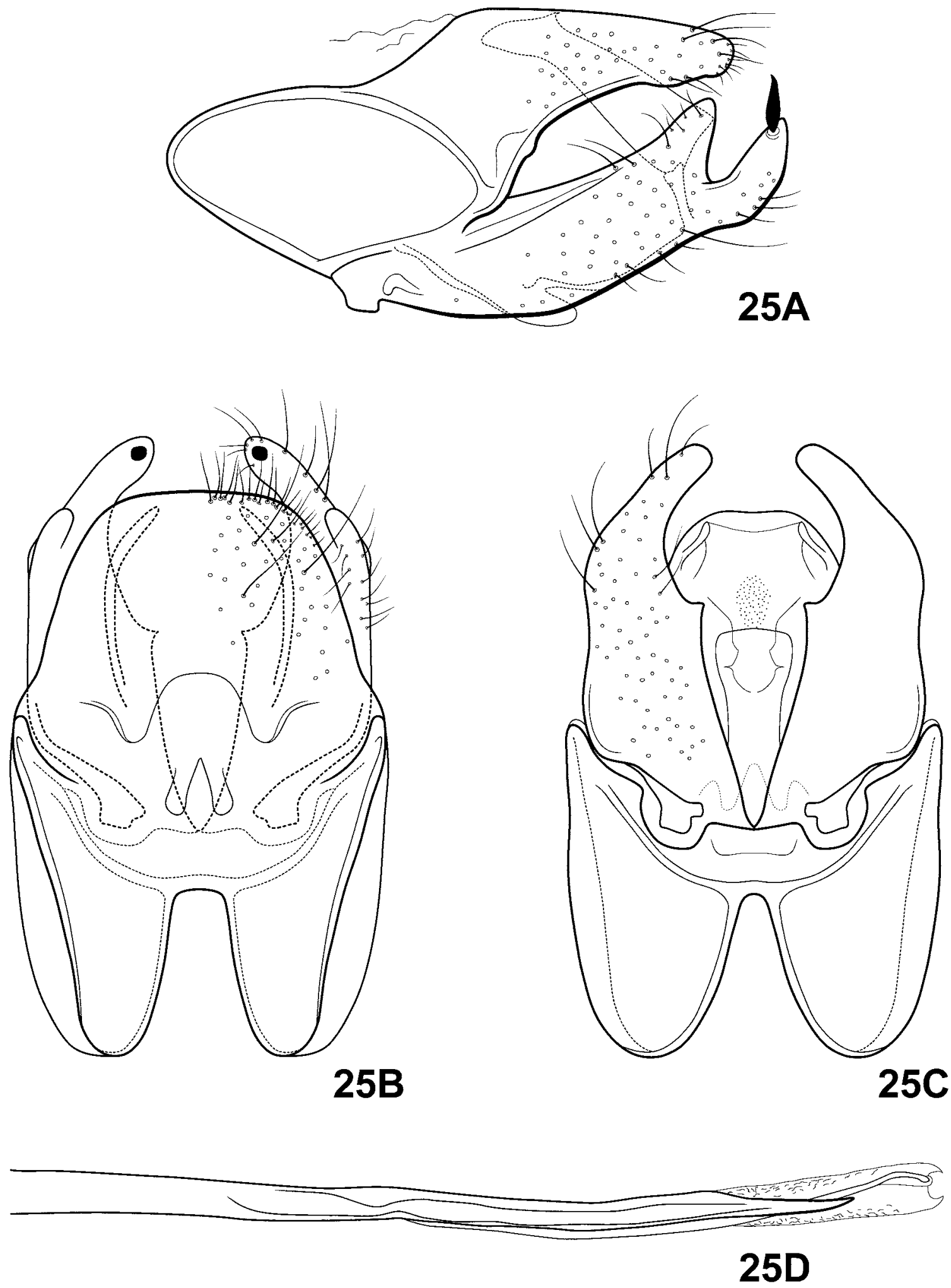

FIGURE 25. Rhyacopsyche peruviana Flint. Male genitalia: A—lateral; B—dorsal; C—ventral; D—phallus, dorsal. 

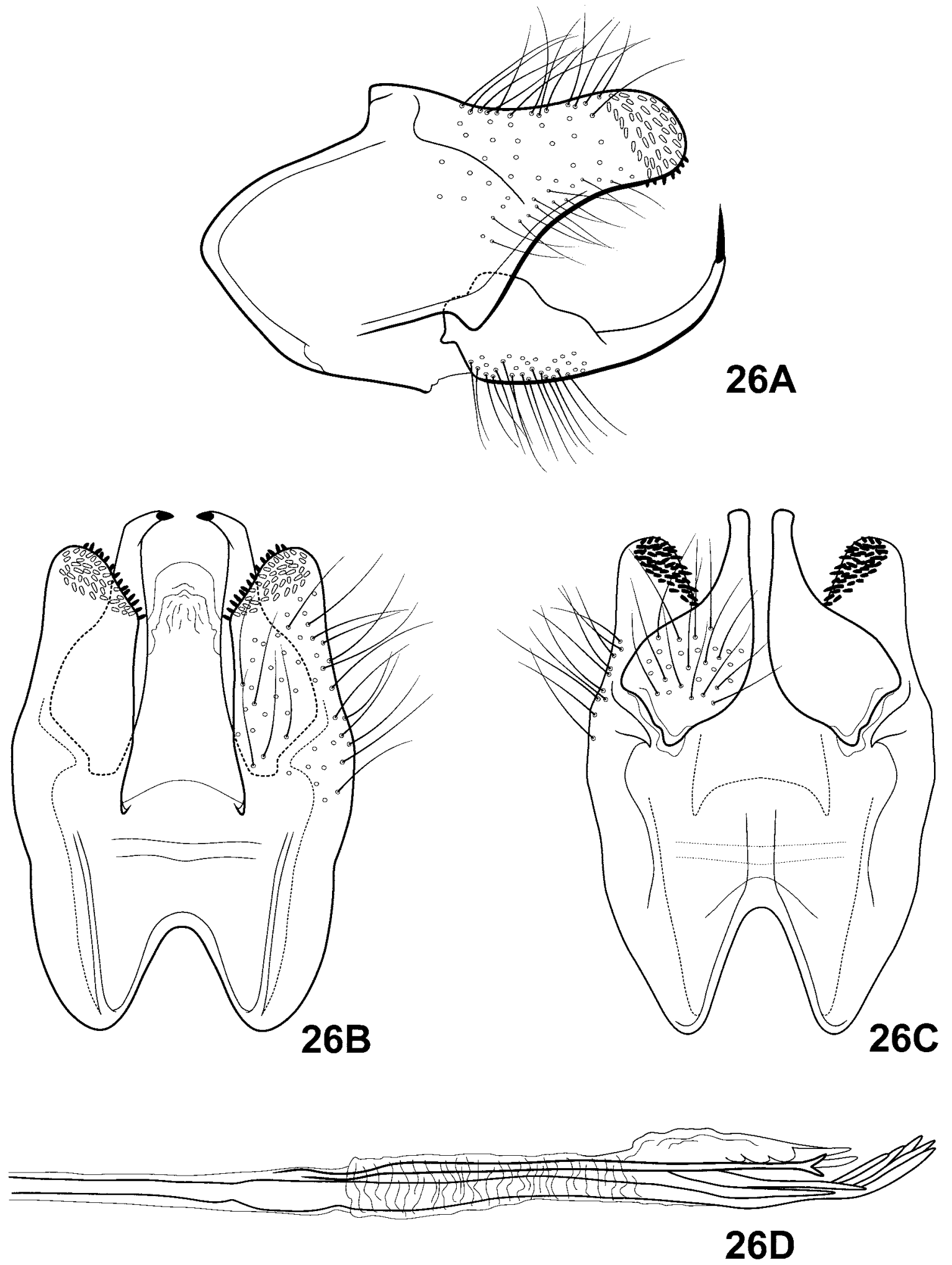

FIGURE 26. Rhyacopsyche rhamphisa, new species. Male genitalia: A-lateral; B—dorsal; C—ventral; D—phallus, dorsal. 

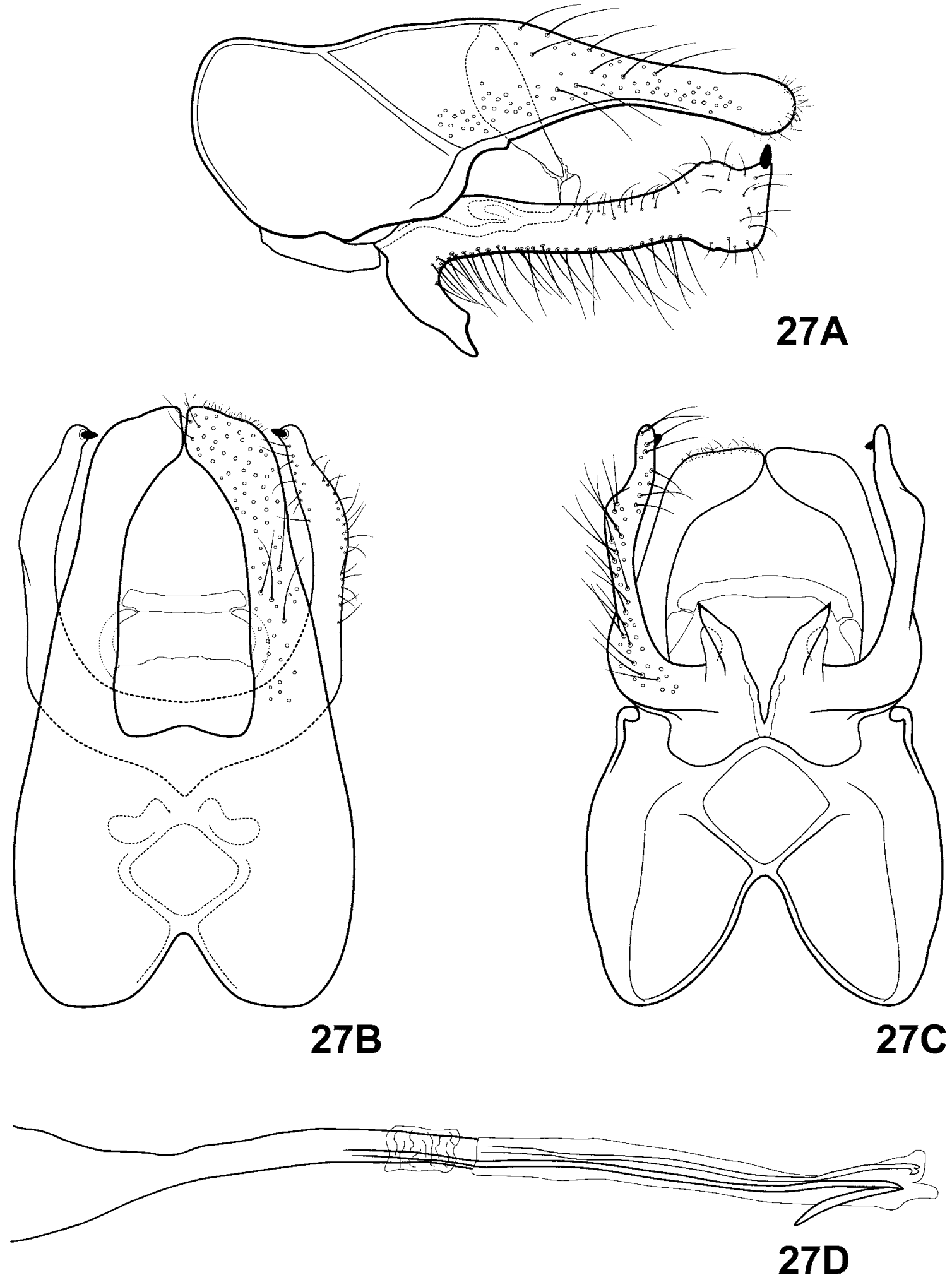

FIGURE 27. Rhyacopsyche tanylobosa, new species. Male genitalia: A—lateral; B-dorsal; C—ventral; D—phallus, dorsal. 

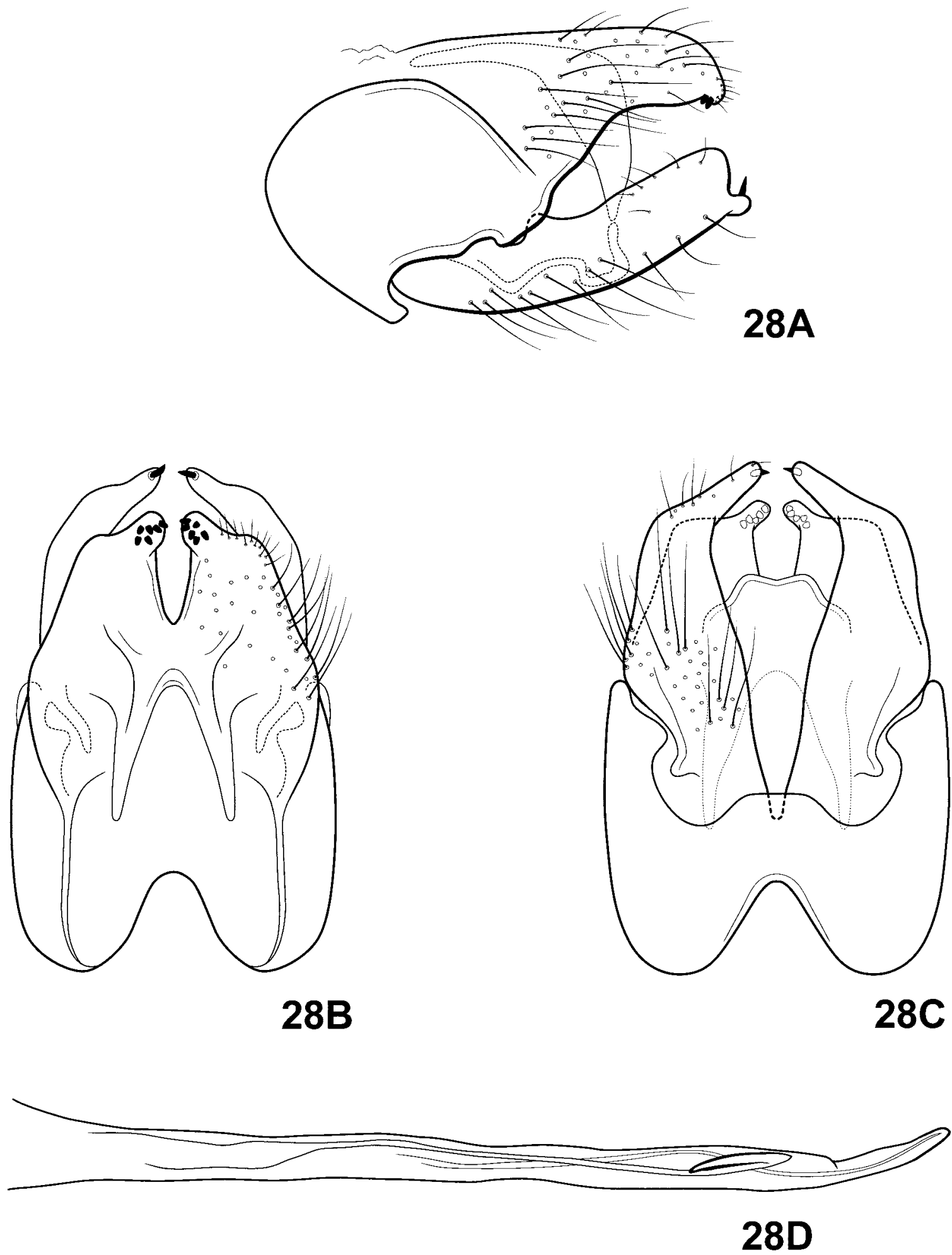

FIGURE 28. Rhyacopsyche torulosa Flint. Male genitalia: A—lateral; B—dorsal; C—ventral; D—phallus, dorsal. 


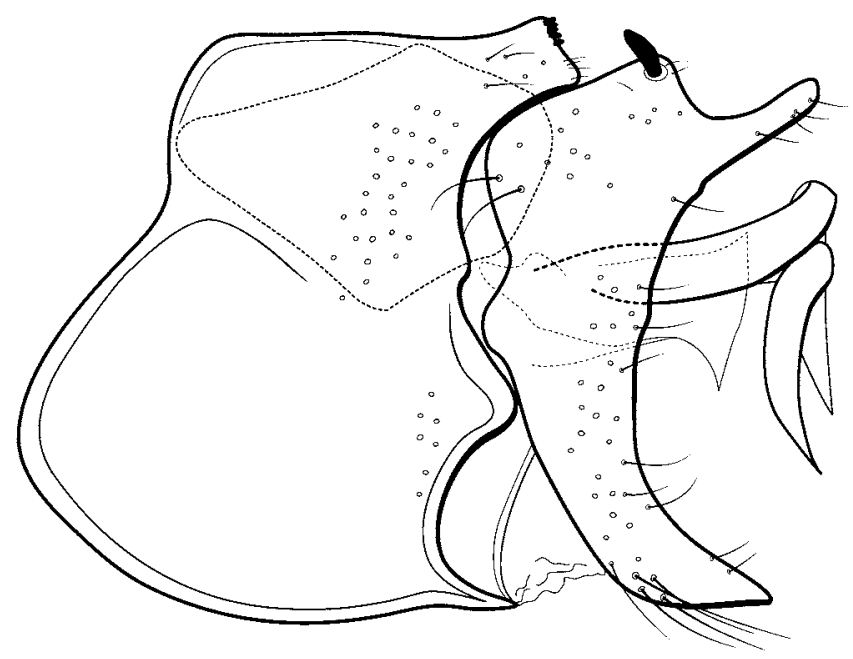

29A
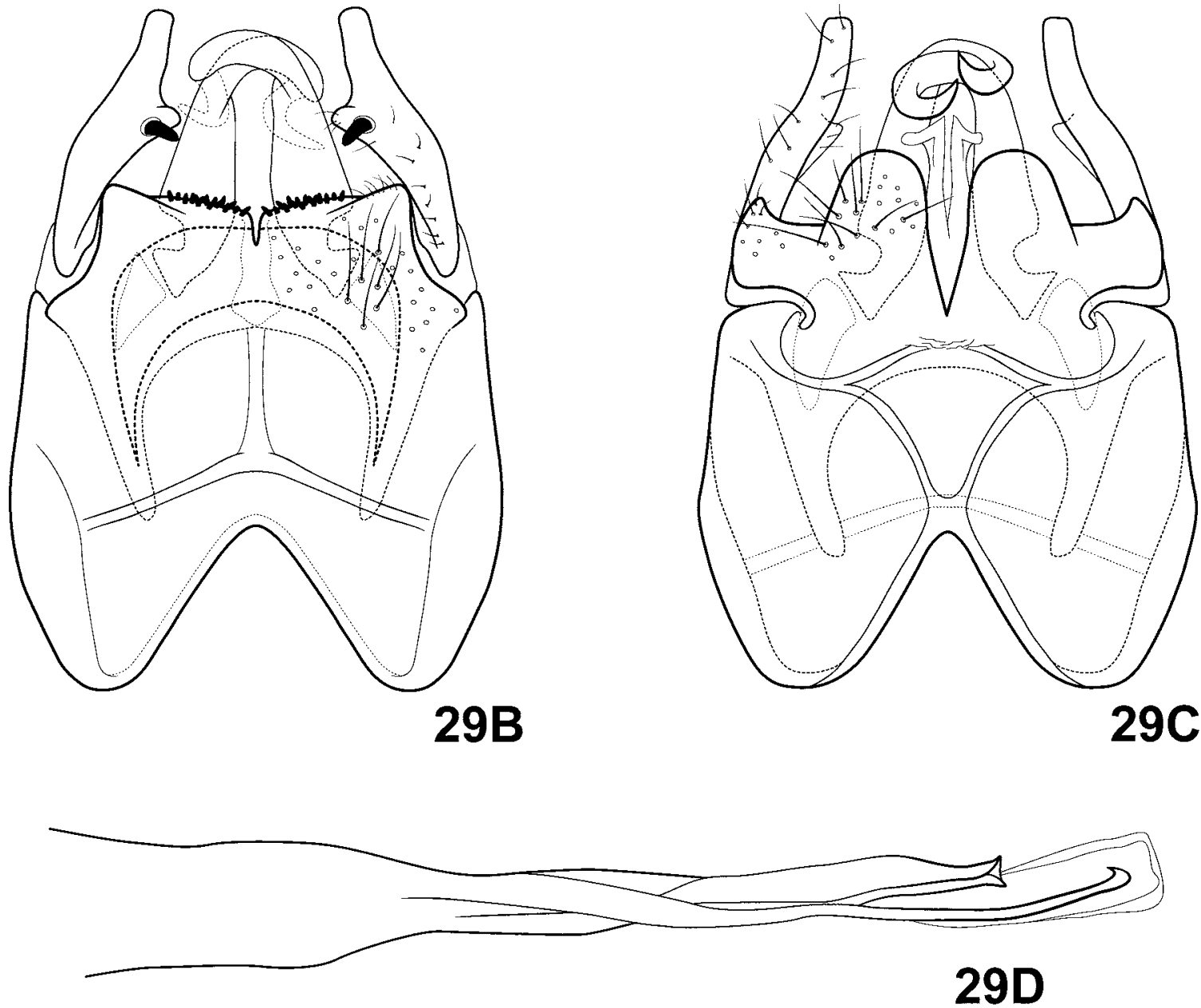

FIGURE 29. Rhyacopsyche turrialbae Flint. Male genitalia: A-lateral; B—dorsal; C-ventral; D—phallus, dorsal. 


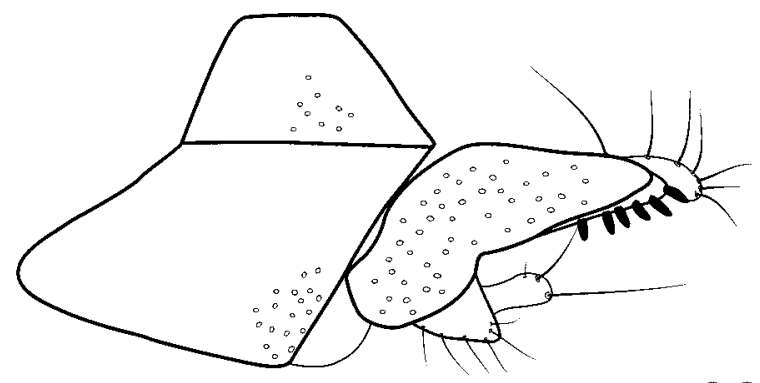

30A
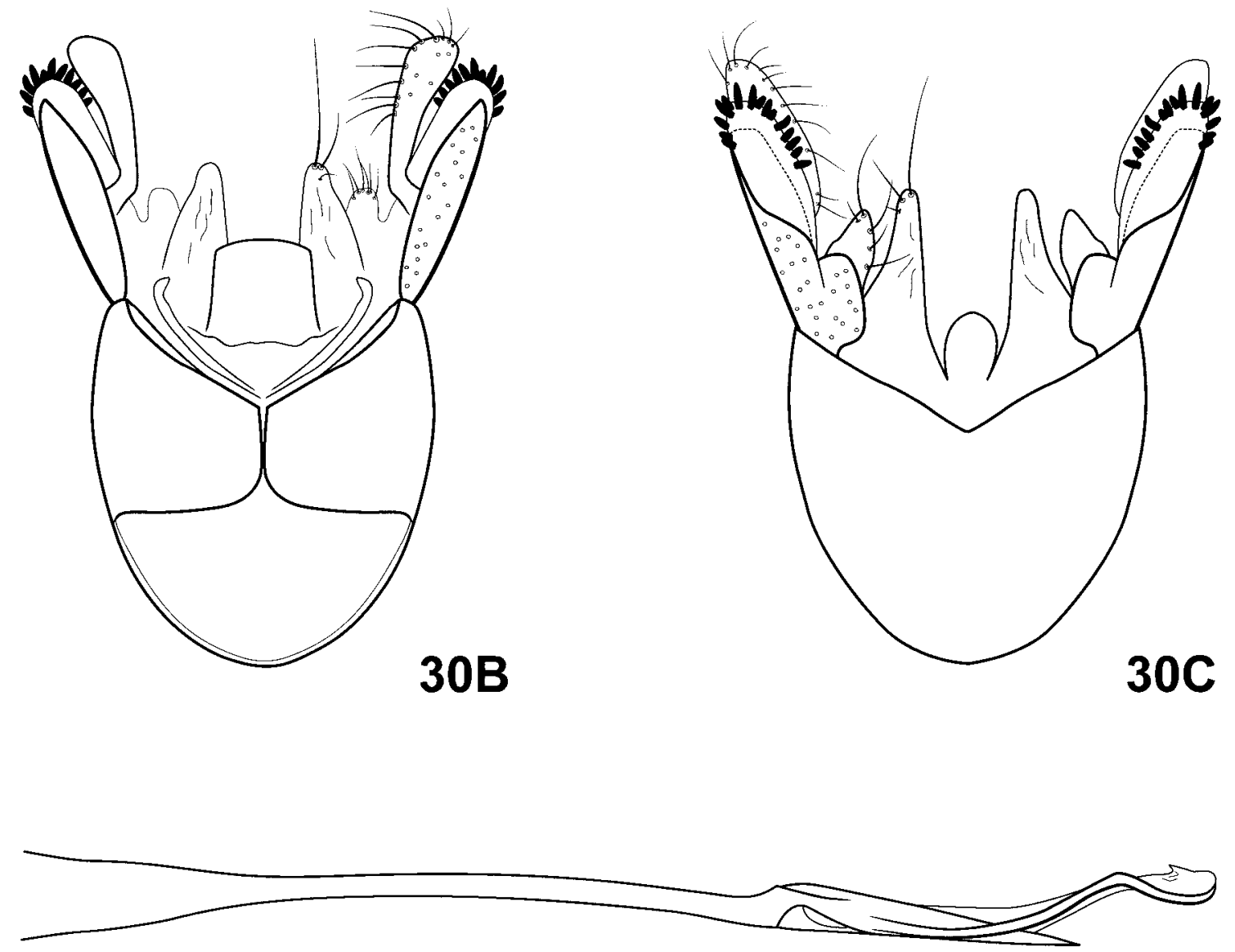

30D

FIGURE 30. Rhyacopsyche yatay Angrisano. Male genitalia: A-lateral; B-dorsal; C-ventral; D—phallus, ventral. Illustration after Angrisano 1989. 


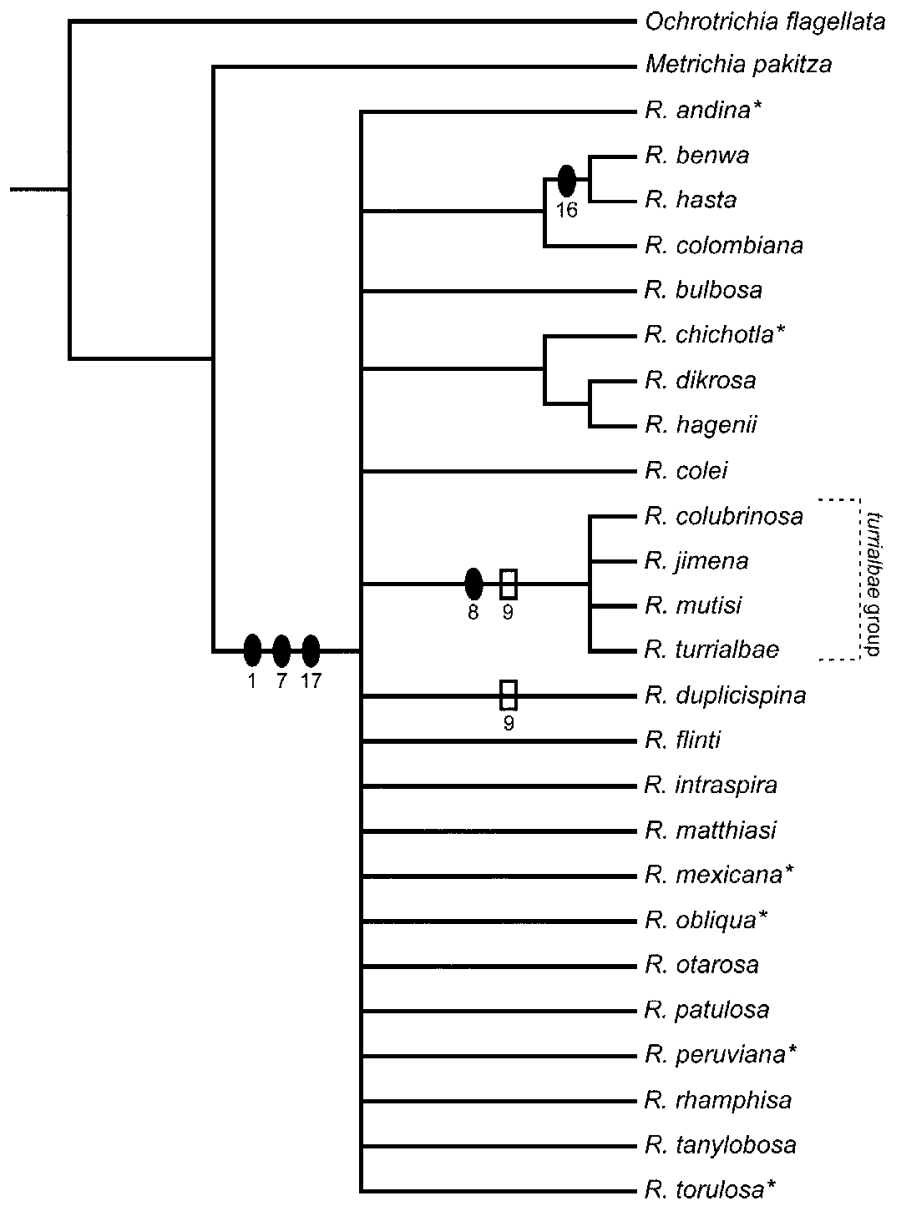

FIGURE 31. Strict consensus of 23 equally parsimonious trees, resulting from analysis of 20 morphological characters. *Flint's mexicana group. Characters with a consistency index of 1.00 (black oval) are shown; character 9, as an exception, has a CI of 0.50 (open rectangle) see discussion. Numbers refer to characters discussed in the text. 
